Summer 6-29-2021

\title{
An Investigation of Occupational Therapy Utilizing Sensory Modulation to Manage Co-Morbid Chronic Pain and Substance Use in Order to Promote Occupational Performance and Recovery
}

Claire Ruth

University of St. Augustine for Health Sciences

DOI: https://doi.org/10.46409/sr.UIEY5900

Follow this and additional works at: https://soar.usa.edu/capstones

Part of the Occupational Therapy Commons, Pain Management Commons, and the Substance Abuse and Addiction Commons

\section{Recommended Citation}

Ruth, C. (2021). An Investigation of Occupational Therapy Utilizing Sensory Modulation to Manage CoMorbid Chronic Pain and Substance Use in Order to Promote Occupational Performance and Recovery. [Doctoral project, University of St Augustine for Health Sciences]. SOAR @ USA: Student Capstone Projects Collection. https://doi.org/10.46409/sr.UIEY5900

This Capstone is brought to you for free and open access by the Student Research at SOAR @ USA. It has been accepted for inclusion in Student Capstone Projects by an authorized administrator of SOAR @ USA. For more information, please contact soar@usa.edu, erobinson@usa.edu. 
An Investigation of Occupational Therapy Utilizing Sensory Modulation to Manage Co-Morbid Chronic Pain and Substance Use in Order to Promote Occupational Performance and Recovery

Claire K. Ruth, OTD

Department of Occupational Therapy, University of St. Augustine for Health Sciences

A Capstone Presented in Partial Fulfillment of the Requirement for the Degree of DOCTOR OF OCCUPATIONAL THERAPY

University of St. Augustine for Health Sciences

June 2021 


\title{
An Investigation of Occupational Therapy Utilizing Sensory Modulation to Manage \\ Co-Morbid Chronic Pain and Substance Use in Order to Promote Occupational Performance and Recovery
}

\author{
Claire K. Ruth
}

Department of Occupational Therapy, University of St. Augustine for Health Sciences has been approved

June, 2021

APPROVED:

Susan MacDermott, OTD, OTR/L, Doctoral Coordinator

Erin Schwier, EdD, OTD, OTR/L, Program Director

ACCEPTED AND SIGNED:

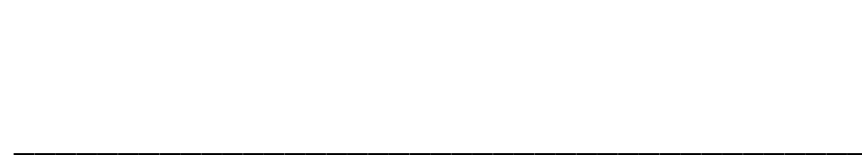

Susan MacDermott, OTD, OTR/L, Doctoral Coordinator

Erin Schwier

Erin Schwier, EdD, OTD, OTR/L, Program Director 
Copyright (C) Claire Ruth, 2021 all rights reserved 


\section{Table of Contents}

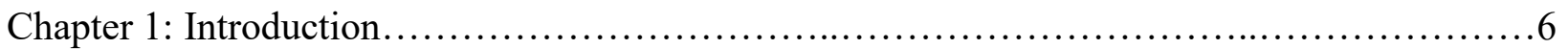

Background................................................................

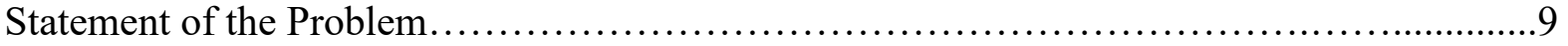

Purpose Statement............................................................ 10

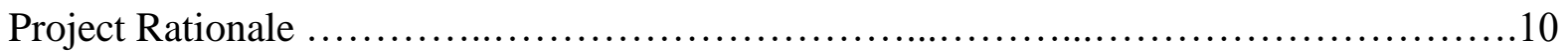

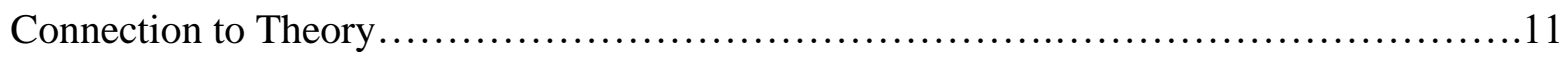

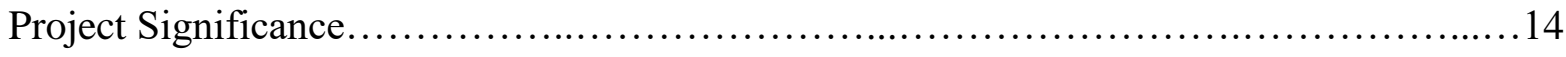

Objectives................................................................ 15

Definitions of Terms........................................................ 16

Assumptions, Limitations, and Delimitations.................................. 17

Chapter 2: Literature Review..................................................... 18

Effectiveness of OT in Chronic Pain............................................. 18

Emerging Role of Occupational Therapy and Substance Use Recovery..................21

Opioid Use and Chronic Pain..................................................22

Sensory Modulation with Substance Use and Chronic Pain..............................23

Complex Barriers to Treating Substance Use and Chronic Pain..........................25

Chapter 3: Project Description....................................................29

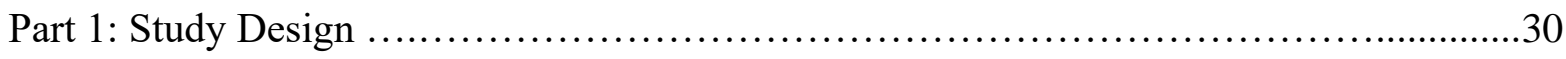

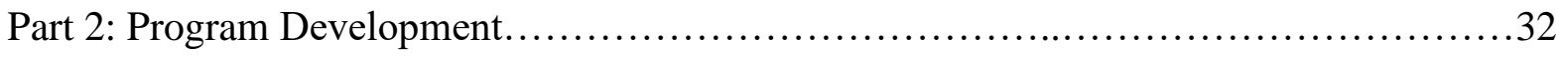

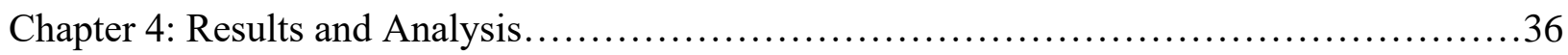

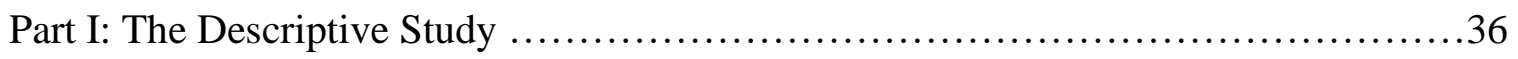

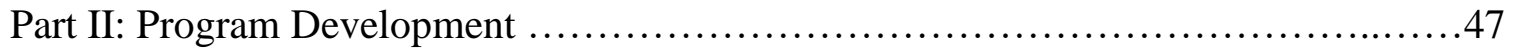


SENSORY MODULATION TO MANAGE CHRONIC PAIN AND SUBSTANCE USE

Limitations .49

Chapter 5: Discussion and Implications for OT Practice ..................................50

Discussion............................................................ 50

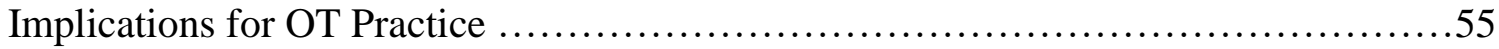

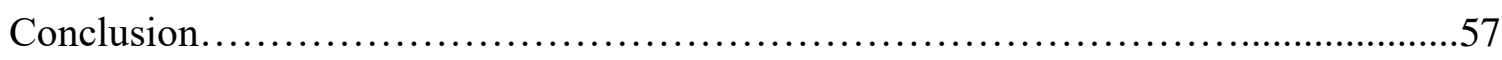

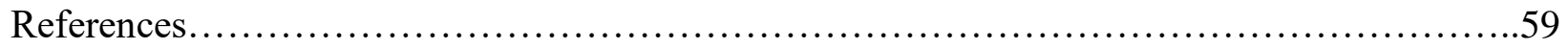

Appendix A - Verbal and Alumni Page Post Recruitment Letter.......................... 74

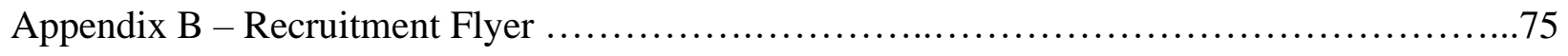

Appendix C - Assessments for Descriptive Study- Adult and Adolescent Sensory Profile......76

Appendix D - Assessments for Descriptive Study- The Brief Pain Inventory (Short Form) ......77

Appendix E - Assessments for Descriptive Study-The Personal Recovery Outcome Measure...79

Appendix F - Sensory Group Manual.............................................. 81

Appendix G- Project Dissemination Plan.......................................... 148 


\section{An Investigation of Occupational Therapy Utilizing Sensory Modulation to Manage \\ Co-Morbid Chronic Pain and Substance Use in Order to Promote Occupational \\ Performance and Recovery}

\section{Chapter 1: Introduction}

The intention of this capstone project is to develop a chronic pain program within a substance use recovery setting to highlight the role of occupational therapy in treating this complex comorbidity of chronic pain and substance use.

\section{Background}

Chronic non-cancerous pain is one of the most common reasons adults seek medical care (Dahlhamer et al., 2018). According to the Centers for Disease Control (CDC), it is estimated that 69.9 million of U.S. adults have some form of chronic pain, which totals more than the number of individuals with diabetes, heart disease, and cancer combined (CDC, 2016; Institute of Medicine, 2011). Higher prevalence is reported among women, older adults, previously but not currently employed adults, adults living in poverty, adults with public health insurance, and rural residents (Dahlhamer et al., 2018). These individuals are at a higher risk for limitations with mobility and daily activities, anxiety and depression, poor perceived health or reduced quality of life, and dependence on substances (Dahlhamer et al., 2018). One in four adults in residential substance use disorder (SUD) treatment settings have chronic pain (Ilgen et al., 2020). Those with persistent pain have worse drug and alcohol treatment outcomes and higher rates of relapse compared to those without pain or with reduced pain (Ilgen et al., 2020).

\section{Pharmacological Interventions for Chronic Pain}

Long term prescription opioids are commonly used to treat chronic pain and support occupational engagement and quality of life in many patients (Ilgen et al., 2020). However, the 


\section{SENSORY MODULATION TO MANAGE CHRONIC PAIN AND SUBSTANCE USE}

United States is facing an opioid epidemic: approximately 46 Americans die each day from opioid overdose (CDC, 2019). For example, in 2019, six out of ten deaths from drug overdoses involved opioids. Therefore, the Prescription Guidelines have made it increasingly hard to obtain opioids, even for patients who need them. (CDC, 2019; Cohen \& Hooten, 2019; Ilgen et al., 2020). Recent data shows that "most people who misuse illicit opioids do so for chronic pain after losing access to prescriptions" (Cohen \& Hooten, 2019, p.1).

Organizations like the Substance Abuse and Mental Health Services Administration, better known as SAMHSA, World Health Organization (WHO), and Healthy People 2020 have recognized substance abuse as a public health crisis and are working to educate the public about the risks of opioids. Opioids are undoubtedly dangerous when misused; therefore, risks and benefits should be weighed for each individual patient for comprehensive pain management within a substance use recovery setting (Cohen\& Hooten, 2019).

Other pharmacological interventions for chronic pain, such as Medication-Assisted Treatment (MAT), have been effective in the treatment of chronic pain and substance use (U.S. Food and Drug Administration [FDA], 2019). MAT includes the use of medication in combination with counseling and behavioral therapies (FDA, 2019). However, pharmacological treatment methods alone do not adequately meet the long-term needs of individuals with substantial substance use. Holistic treatment planning, including pharmacological, behavioral, cognitive, and functional therapies, are needed to achieve long term recovery.

\section{Occupational Therapy and Chronic Pain}

Nonpharmaceutical interventions for chronic pain have taken the forefront of emerging medicine in an attempt to decrease the number of opioids being prescribed for chronic pain and the supplement the use of MAT interventions. In 2018, former President Trump signed the 
SENSORY MODULATION TO MANAGE CHRONIC PAIN AND SUBSTANCE USE

Substance Use-Disorder Prevention that Promotes Opioid Recovery and Treatment (SUPPORT) for Patients and Communities Act (HR6) into effect (Majority and Minority Committees' Staffs, n.d.). This legislation lists occupational therapy as well as other allied health professions as suggested nonpharmacological interventions to chronic pain management and treatment, and it requires beneficiaries of Medicare Advantage plans and Part D prescriptions plans to provide coverage for these interventions (American Occupational Therapy Association [AOTA], 2018; Majority and Minority Committees' Staffs, n.d.).

Chronic pain affects all aspects of life. Roles, routines, rituals, psychological state, occupational performance, relationships with others, and life satisfaction are all impacted by an individual's pain (Fisher et al., 2007). Ongoing pain research has suggested that "engaging in occupation has the potential to mediate the pain experience and to alter biological, psychological, and social factors that are known to influence the pain experience" (Robinson et al., 2011, p.1). Occupational therapists combine their knowledge of the human system, activity analysis, and human occupation as both an end and a means to support engagement in occupations across the lifespan (Gray, 1998). As part of the interdisciplinary team, occupational therapists can use a variety of multi-modal interventions to improve patient quality of life, self-efficacy, and functional abilities (AOTA, 2020; Simon \& Collins, 2017).

\section{Occupational Therapy and Substance Use}

Occupational therapists have an emerging role in substance use services, as they assess habits, roles, and behaviors and help guide their clients to achieve their goal of a sober lifestyle (Rojo-Mota et al., 2017). Former AOTA President Ginny Stoffel stated that "occupational therapy can help people recognize how their substance use affects those roles that are most meaningful; it [occupational therapy] helps people explore and make those links, and move 
SENSORY MODULATION TO MANAGE CHRONIC PAIN AND SUBSTANCE USE

toward the occupational roles and patterns they want to achieve" (Opp, n.d., p. 1). Recently, there has been an investigation of addiction as an occupation itself and how sobriety then creates an occupational deficit (Wasmuth et al., 2014). The connection between addiction and occupation further supports occupational therapist involvement in substance use services, as occupation-guides their evaluations, assessments, interventions (Wasmuth et al., 2014).

\section{OT and the Comorbidity of Chronic Pain and Substance Use Disorder}

Occupational therapists have the unique skill set to address both the management and treatment of chronic pain and substance use, as they both have profound impacts on individual's functional independence and engagement in daily activities (AOTA, 2014). Research supports the role of occupational therapy in the comprehensive treatment of chronic pain and substance use individually but has not explored the role of OT in treating them as a comorbidity.

\section{Statement of Problem}

Given the high rate of individuals with co-morbid chronic pain and substance use which ultimately correlates with poor recovery outcomes, the demand for improved models of assessment and coordination of comprehensive healthcare services is on the rise (Hser et al., 2017; Ilgen et al., 2020). Current non-pharmacological strategies for pain relief in substance use recovery are limited to less than $50 \%$ of patients. The most used modalities include physical therapy, meditation or yoga, psychotherapy, and alternative medicine (Lin et al., 2017). Chronic pain management needs to be addressed throughout long-term substance use recovery in order to achieve and maintain recovery, while increasing occupational engagement, health management, and quality of life. Although occupational therapy has a distinct role in the evaluation, assessment, and treatment of this comorbidity, there is a significant gap in occupation-focused evidence. 
SENSORY MODULATION TO MANAGE CHRONIC PAIN AND SUBSTANCE USE

\section{Purpose Statement}

The purposes of this proposed capstone project are to: 1) determine current attitudes pertaining to chronic pain within a substance use recovery program; 2) to explore treatment modalities for chronic pain and substance use; and 3) to create an evidence-based program centered on occupational therapy's role to address the unique needs of a specific population: those with comorbid chronic pain and substance use. This project will promote the distinct value of occupational therapy as a provider of non-pharmacological treatment of chronic pain and the profession's role in substance use recovery.

\section{Project Rationale}

Given the magnitude of individuals experiencing chronic pain and the current public health concern of the opioid-abuse epidemic, occupational therapists and other allied healthcare professions need to have evidenced-based information to justify, advocate, and fulfill their role in the comprehensive treatment of individuals with comorbid chronic pain and substance use (CDC, 2016; IOM, 2011). Current programs face challenges because drug-seeking behaviors for active substance abuse can be very similar to the behaviors a patient with inadequately controlled chronic pain may experience (Prater et al., 2002; Volpe, 2019). Due to the complex interaction of conditions, occupational therapists need to understand clients' prior level of function, goals, and needs that pertain to the treatment of both chronic pain and recovery. A holistic and synergistic approach must be taken to view the individual as a whole and address individual occupational needs rather than diagnoses. This project will increase the body of knowledge for occupational therapists on the occupational deficits and needs of this population to better fill the current gap in treatment.

\section{Connection to Theory}


SENSORY MODULATION TO MANAGE CHRONIC PAIN AND SUBSTANCE USE

According to the American Occupational Therapy Association [AOTA] Occupational Therapy Practice Framework: Domain and Process Fourth Edition (2020) during the intervention process occupational therapists "integrate(s) information from the evaluation with theory, practice models, frames of reference, and research evidence" to guide the professional reasoning, intervention planning, implementation, and review (p.24). This capstone will be specifically guided by the Biopsychosocial Approach to managing chronic pain, the SAMHSA Recovery Model, and Dunn's model of Sensory Processing,

\section{Biopsychosocial Approach}

The Biopsychosocial Approach to pain is the most widely accepted, evidence-based model to conceptualize and treat pain. The Biopsychosocial Model for Pain and Disability "views pain and disability as a complex and dynamic interaction among physiologic, psychologic, and social factors that perpetuates - and may even worsen - the clinical presentation" of pain (Gatchel \& Okifuji, 2006, p. 781). This model is based off the assumption that prolonged pain causes changes in the parts of the brain that control cognition, mood, emotions, personality, and motor function (Breeden \& Rowe, 2017).

In addition to those biological changes from pain, an "individual's learned experiences with pain, expectation of how much pain should be present, personal beliefs regarding pain, current coping skills, self-efficacy, locus of control, fear of pain, involvement in the 'sick role', and tendency for catastrophizing may all influence pain perception" (Hansen \& Streltzer, 2005, p. 2). Social and cultural factors also impact one perception and experience of pain. Factors such as socioeconomic status, lack of social supports, unhealthy lifestyles, substance abuse, legal interactions, and family issues affect the pain experience (Hansen \& Streltzer, 2005). 
SENSORY MODULATION TO MANAGE CHRONIC PAIN AND SUBSTANCE USE

In order to effectively treat pain, the treatment team must understand the interactions and influence each of these factors has on the individual and develop a multimodal treatment intervention related to each area (Bracciano, 2008; Breeden \& Rowe, 2017). This project will apply foundational occupational therapy concepts to view chronic pain holistically. This holistic perspective will provide a better understanding of the factors that contribute to the pain and how they may impact the risk of developing addiction and recovery from addiction.

\section{SAMHSA Recovery Model}

The Biopsychosocial Theory will guide how this capstone views pain but is not applicable to substance use disorder and recovery. Occupational therapists can utilize Substance Abuse and Mental Health Services Administration's (SAMHSA) interdisciplinary Recovery Model to guide treatment planning and intervention decision-making (Brown et al., 2019). According to SAMHSA (2012), recovery is "a process of change through which individuals improve their health and wellness, live a self-directed life, and strive to reach their full potential" (para.1). The four dimensions of the recovery are home, health, purpose, and community (Brown et al., 2019). SAMHSA (2012) also identified ten guiding principles of recovery: hope, persondriven, many pathways, holistic, peer support, relational, culture, addresses trauma, strengths/responsibility, and respect.

These dimensions and guiding principles of recovery align with the philosophy of occupational therapy to be "client-centered collaborative, and focused on supporting resiliency, full participation, health promotion, and a wellness lifestyle" (AOTA, 2016). Occupational therapists adapt this model within their evaluations, assessments, treatment plans, goals, and therapeutic use of self. OT's goals in treating addiction and mental health are to "foster hope, motivation, and empowerment, as well as system change" (AOTA, 2016, para. 3). Using their 
SENSORY MODULATION TO MANAGE CHRONIC PAIN AND SUBSTANCE USE

knowledge in neurophysiology, psychosocial development, activity and environmental analysis, and group dynamics, OTs work collaboratively with their clients and their families "to fully participate and be successful and satisfied in his or her self-selected occupations" (AOTA, 2016, para. 3). The use of this model in conjunction with the OT philosophy is critical in understanding the recovery journey of individuals with addiction is multidimensional and not linear.

\section{Dunn's Model of Sensory Processing}

Both the Biopsychosocial Model and Recovery Model can be applied to occupational therapy practice but are not rooted in the profession of occupational therapy. Dunn's Model of Sensory Processing is a neuroscience-informed theoretical framework for understanding individuals' differences in processing sensory information (Brown \& Dunn, 2002). This model focuses on the "interaction between neurological thresholds for incoming sensory input and the behavioral response generated by them" (Brown \& Dunn, 2002; Cole \& Tufano, 2008, p.231). It describes four types of responses to sensory stimuli on two continua. One continuum is neurological threshold and the other is behavioral response.

The first neurological threshold describes how much sensory input is required for an individual to recognize sensation (Brown \& Dunn, 2002). A low neurological threshold is indicative of needing very little stimuli to elicit a response, while a high neurological threshold needs a great deal of sensory input to generate a response. The second continuum is behavioral response to sensory stimuli. This can either be an active or a passive behavioral response. People with high neurological thresholds tend to "score higher on scales measuring sensation seeking (active response) and low registration (passive response). People with low neurological thresholds score higher on sensation avoiding (active response) and sensory sensitivity” (Brown \& Dunn, 2002 as cited Meredith et al., 2015, p.2). 
SENSORY MODULATION TO MANAGE CHRONIC PAIN AND SUBSTANCE USE

The Adolescent and Adult Sensory Profile is an assessment tool commonly used in occupational therapy practice that measures sensory processing preferences based on Dunn's Model of Sensory Processing (1997) (Brown \& Dunn, 2002). This self-assessment asks questions pertaining to visual, auditory, tactile, taste, smell and movement (vestibular and proprioception), and activity level to determine an individual's sensory processing preferences (Brown \& Dunn, 2002; Meredith et al., 2015). This tool is important in developing sensory modulation strategies (Champagne, 2017). Sensory modulation is "the capacity to regulate and organize the degree, intensity and nature of responses to sensory input in a graded and adaptive manner. This allows the individual to achieve and maintain an optimal range of performance and to adapt to challenges in daily life" (Miller et al., 2001, p. 57). Occupational therapists use "therapeutic use of self...sensory-related assessment tools, sensorimotor activities, sensory modalities and environmental modifications" to help individuals modulate their own senses to improve occupational performance (Champagne, 2017, p.100).

This project uses sensory processing preferences as a basis for integrating the mind-bodyspirit connection into research and treatment of individuals with both chronic pain and substance use. Sensory modulation is an important tool in recovery, as "once an individual is aware of sensory processing preferences, that individual is better able to utilize strategies to create environments and situations that support those preferences" (Brown et al., 2002, p.123). Their self-knowledge helps to empower individuals, improve self-management, and decrease selfstigma (Brown et al., 2002, p.123, Champagne, 2017).

\section{Project Significance}

The economic burden of chronic pain is estimated to be $\$ 560$ billion each year in direct medical costs, lost productivity, and disability programs (Dahlhamer et al., 2018, p.1005). 
SENSORY MODULATION TO MANAGE CHRONIC PAIN AND SUBSTANCE USE

Prescription opioid misuse alone amounts to $\$ 78.5$ billion a year, including the costs of healthcare, lost productivity, addiction treatment, and criminal justice involvement (National Institute on Drug Abuse, 2020, para. 1). By investigating how these conditions interact and what the functional deficits are throughout the continuum of care, occupational therapists can begin to create more cost-effective care that limits spending and productivity loss.

Occupational therapists interact with individuals with chronic pain on a regular basis. While nonpharmacological interventions for chronic pain are becoming more popular, it is still imperative that these practitioners are comfortable with recognizing the early warning signs of addiction, screening clients for substance use and dependence, and providing referral/ information on addiction treatment and resources. These actions are within the occupational therapy scope of practice (Costa, 2017). There is also a significant stigma that surrounds addiction and MAT treatment that may be preventing individuals from receiving treatment for chronic pain (Yang et al., 2017). With a better understanding of the lived experience of these individuals, practitioners and advocates can work together to create helpful strategies and resources to deal with chronic pain and substance use recovery.

\section{Project Objectives}

\section{Learning Objectives}

- Identify the occupational needs of the chronic pain and substance use recovery population through interviews with professionals and clients at all levels of care.

- Synthesize these current models of care for chronic pain and substance use to better understand the current and potential future roles of occupational therapy.

- Identify the sensory processing preferences of those with co-morbid chronic pain and recovering from substance use and how it might be impacting their recovery. 
SENSORY MODULATION TO MANAGE CHRONIC PAIN AND SUBSTANCE USE

\section{Outcome Objectives}

- Disseminate findings to occupational therapists via an evidence-based article.

- Propose future areas of research, program development, and need for occupational therapists in the treatment of chronic pain and substance use.

- Develop a client-centered multimodal chronic pain program within a substance use. Treatment setting that incorporates the findings from the Adult and Adolescent Sensory Profile, Personal Recovery Outcomes Measure, and Brief Pain Inventory.

- Advocate for the role of occupational therapy within the interdisciplinary team managing chronic pain management programs within substance use recovery settings.

\section{Definition of Terms}

Chronic non-cancer pain Chronic non-cancer pain (CNCP) will be "described as moderate or severe pain that lasts for six or more months and is attributed to conditions such as neuropathic pain, rheumatoid arthritis, lower back pain, osteoarthritis, fibromyalgia and a range of several other conditions" (Genova et al., 2020). Recovery for the purpose of this paper will be defined by SAMHSA's working definition of recovery from mental disorders and/or substance use as "a process of change through which individuals improve their health and wellness, live a self-directed life, and strive to reach their full potential" (SAMHSA, 2020, para 1). In an effort to reflect the profession's holistic ideology and not reduce individuals to diagnoses (American Occupational Therapy Association, 2020; American Psychological Association, 2020), the term substance use will be defined as someone who has self-identified drug-related problems that are impacting individual's role fulfillment, occupational performance, and participation (Opp, n.d.). Sensory processing preferences are individuals' patterns of sensory processing that reflect the 
SENSORY MODULATION TO MANAGE CHRONIC PAIN AND SUBSTANCE USE

interaction between neurological threshold and self-regulation strategies and are based upon Dunn's Model of Sensory Processing (as cited in Alwawi \& Dean, 2018).

\section{Assumptions}

For the purpose of this capstone, it is assumed that clients in substance use recovery programs also have chronic pain management needs that are unmet. It is also assumed that chronic pain is limiting clients' success with occupational engagement and sobriety.

\section{Limitations}

Limitations of this capstone are COVID-19 may limit the amount of in-person and group treatment sessions, there is a lack of control over patient demographics, and there may be limited awareness of and access to all diagnoses.

\section{Delimitations}

One delimitation of this project is the investigation of only chronic pain. This project will not address cancer pain or acute pain because their mechanisms are different than that of chronic pain. In order to achieve an appropriate power and number of participants, patients can be in recovery for anything self-identified as substance use. The impact of other health problems not related to chronic pain is not being considered to limit health variables.

\section{Chapter II: Literature Review}

After exploring the current literature regarding occupational therapy's role in chronic pain and substance use, it can be concluded that there is value in expanding occupational practice knowledge and creating a multimodal program to treat pain within a recovery setting. Literature supports the effectiveness and value of occupational therapy for chronic pain management through a variety of modalities. In recent years, occupational therapy has advocated for the professions value in mental health and addiction (Amorelli, 2017). This area of emerging 
SENSORY MODULATION TO MANAGE CHRONIC PAIN AND SUBSTANCE USE

practice has occupation-based models to support OT's role, but little research to support its effectiveness. In order to improve long term recovery outcomes there needs to be more literature that investigates chronic pain and substance use comorbidities. Sensory processing has been shown to be a successful occupational therapy modality for chronic pain management and with mental health (Bar-Shalita et al., 2019; Meredith et al., 2015; Stols et al., 2013). These approaches have been found effective in improving self-management techniques in both chronic pain and mental health and should be further examined in recovery settings. When examining chronic pain and substance use, it is impossible to ignore that mental health and trauma histories play a role in the development and manifestation of these conditions (Hser et al., 2017; Stevenson \& Cole, 2015; Weiss \& Rao, 2017). Therefore, considering the complexity of each individual and their history, mental health, and physical health is essential in the treatment of this population.

\section{Effectiveness of OT in Chronic Pain}

The CDC (2016) recommended using nonopioid treatment methods for chronic pain whenever possible to include the use of interdisciplinary treatment. Occupational therapy has been recognized as part of the interdisciplinary treatment team for chronic pain because it addresses a broad range of self-care occupation and lifestyle-based interventions (Oslund et al., 2019). A major theme in a qualitative study about the lived experience of chronic pain was: "chronic pain and occupation are reciprocally related forces, which shows how, as meaningful and enjoyable occupational involvement increased, pain often decreased" (Fisher et al., 2007, p. 296). Simon and Collins (2017) assessed the effect an outpatient clinic-based Lifestyle Redesign® intervention for people living with chronic pain had on quality of life, function, selfefficacy, and pain levels. After an average of 18 weeks and 9 occupational therapy sessions, 
SENSORY MODULATION TO MANAGE CHRONIC PAIN AND SUBSTANCE USE

occupational satisfaction measured by the COPM increased. Participants reported an increase in quality of life physical and social functioning, energy and fatigue levels, and pain self-efficacy. They also experienced decreases in role limitation due to physical and emotional problems and general pain (Simon \& Collins, 2017).

In addition to Lifestyle Redesign $®$, the current evidence supports the use of pacing as a tailored intervention for adults with chronic pain to reduce the interference of fatigue, joint stiffness, and variability in physical activity (Guy et al., 2019). However, there is not enough evidence to determine if pacing strategies can improve a person's activity level, role satisfaction and participation, social functioning, or fatigue severity (Guy et al., 2019). Further research introducing pacing into activities and occupations needs to be done in order to determine the efficacy of this chronic pain management strategy (Guy et al., 2019, p. 7). When adding occupational therapy to a traditional pain management program, "participants were on average stable in observation-based measures of functional ability and patient-reported outcomes, except in overall mental well-being, favoring the enhanced intervention” (Amris et al., 2019, p. 1367). Perhaps the most notable contribution occupational therapists can make is to help clients return to work or education after or during chronic pain (Hill \& Macartney, 2019). Even after illness, disability, or injury, work remains central to the identity of many individuals. Vocational rehabilitation offered by occupational therapists can help patients "understand the meanings attached to work" and work with the patient to find a "new source of meaningful occupation" after disability, illness, or injury (Saunders et al., 2018, p. 2149). According to Lagueux et al. (2018), the major themes that support occupational therapy as a key player in chronic pain treatment are: 
SENSORY MODULATION TO MANAGE CHRONIC PAIN AND SUBSTANCE USE

(i) as an expert in enabling occupation, occupational therapists are particularly interested in how individuals living with CP can perform and engage in their daily occupations, (ii) the use of disciplinary models ensures a better emphasis on occupation as an end and as a mean throughout the entire OT treatment process, (iii) the top-down approach which is more in line with OT specific values and skills is complementary to 'the bottom-up approach' used by medical model focused practitioners. (p.16)

Humans are adaptable, and many patients with chronic pain have been living with it for many years. Occupational therapy can help build on the patient's already established coping mechanisms for pain to help them increase pain acceptance, social participation, role satisfaction, and occupational participation (Amorelli, 2016; Fisher et al., 2018; Jehl et al., 2017;

McCombie \& Sterling, 2018; Rojo-Mata et al., 2017; Rowe \& Breeden, 2018; S., 2014).

Additionally, using comprehensive and interdisciplinary nonpharmacological approaches to treating chronic pain have been shown to have an economic advantage compared to treatments using medications (Sletten et al., 2015). A Mayo Clinic study found that individuals who participated in a 3-week outpatient comprehensive pain program including daily PT, OT, and CBT therapies "with an emphasis on physical reconditioning, cognitive-behavioral interventions and weaning of opiate analgesic medications" had a significant decrease in medical costs: 86,68 , 64, and 90\% in the 3-, 6-, 12-, and 18-month post-treatment periods, respectively, when compared with the same pretreatment periods (Sletten et al., 2015, p. 900). At the 12- and 18month post-treatment marks, a significant decrease in healthcare utilization was found, including number of primary care visits, specialist visits, ER visits, DME claims, OT/PT/Chiropractic claims, and number of prescription drugs (Sletten et al., 2015, p. 902). A systematic literature review on the cost-effective non-invasion and non-pharmacological interventions for lower-back 
SENSORY MODULATION TO MANAGE CHRONIC PAIN AND SUBSTANCE USE

pain, which is one of the most common cause of chronic pain, found that "intervention that combined physical and psychological treatments, information and education interventions, and manual therapies appeared to be cost effective when compared with the study-specific comparators" (Andronis et al., 2017, para 4.). Improving models of care that are interdisciplinary and comprehensive chronic pain will not only improve patient outcomes but significantly decrease costs. This would be an important benefit to the U.S. healthcare system, because the cost of chronic plain is $\$ 635$ billion a year. This figure represents more than the yearly costs for cancer, heart disease and diabetes combined (Gaskin \& Richard, 2012, para. 1).

\section{Emerging Role of Occupational Therapy and Substance Use Recovery}

Occupational therapists are accustomed to and educated about treating chronic pain. Unfortunately, there is a need for increased education and training of OTs about substance use. McCombie and Sterling (2018) asked 182 occupational therapists about their experience and training with opioid use disorder. Fifty-two percent of the therapists reported that they currently had or had at some point over the past 12 months worked with a patient who "they knew for certain" were abusing opioids; 64\% "strongly suspected" abuse (para. 13). However, only 6\% of the therapists reported they had been formally trained on what to do in case of an overdose and how to treat these patients (McCombie \& Sterling, 2018, para. 11).

Although occupational therapists have been treating patients with substance use since the 1980s, there is a lack of research and training within this domain of occupational therapy (RojoMota et al., 2017). A systematic review found that "occupational therapy has models that are able to explain addiction from the occupational perspective, without requiring concepts and models from other disciplines;" however, these "theoretical models have not yet been translated into proposals for occupational intervention” (Rojo-Mota et al., 2017, p. 6). Occupational 
SENSORY MODULATION TO MANAGE CHRONIC PAIN AND SUBSTANCE USE

therapists are using the COPM, Quality of Life Rating Scale (QOLR), and OPHI-II as outcome measures for these patients, but there is little evidence to support their effectiveness or therapeutic value (Amorelli, 2016). The most common interventions OTs use with this population address life skills for relapse prevention, education for increasing client health literacy, medication management and vocational rehabilitation (Amorelli, 2016; Rowe \& Breeden, 2018, S., 2014). Since they focus on being client-centered and holistic in practice, occupational therapists present treatments through a variety of means and are trained in adapting environments and tailoring programs to the individual's needs (Rowe \& Breeden, 2018). Occupational therapists help patients fill their day, build self-esteem, and self-concept, using client directed, functional goals. This reflects the CDC recommendations for substance use treatment and recovery (Amorelli, 2016; Rowe \& Breeden, 2018; S., 2014). While the value of OT in substance use recovery is emerging, it is critical to build a body of research and evidencebased educational tools to support OT's work in this area (McCombie \& Sterling, 2018; RojoMota et al., 2017).

\section{Opioid Use and Chronic Pain}

Hser et al. (2017) conducted a study using electronic medical records (EMR) data of opioid use disorder and found that $64.4 \%$ of patients with chronic pain also had OUD (p. 4). This comorbidity of chronic pain and OUD needs to be addressed as one diagnosis and not reduced down to its component parts due to the complex interdependency of the two.

There is evidence that supports the use of occupational therapy in reducing the amount of morphine equivalents used to wean patients off opioids and increasing patient function (Breeden \& Rowe, 2017). Opioid weaning is a vital part of recovery from OUD and chronic pain because opioid use induces long lasting heightened sensitivity to pain (Eyler, 2013). Because of this 
SENSORY MODULATION TO MANAGE CHRONIC PAIN AND SUBSTANCE USE

sensory phenomenon, health care professionals, including occupational therapists, need to be aware that a cycle of pain and OUD is being created and that patients' pain may not be properly managed with medication. Debates about how to properly manage chronic pain and balance the risk of addiction are well discussed in the literature. There is a need for more research that examines chronic pain and any form of drug-related disfunction as a comorbidity and the outcomes non-pharmacological treatments have on pain levels, role attainment, occupational performance, and quality of life.

\section{Sensory Modulation with Substance Use and Chronic Pain}

Evidence suggests that sensory modulation disorder (SMD) and pain sensitivity co-exists in those with substance use (Meredith et al., 2015). It is well established that "adults with mental illness experience atypical neural responses in sensory gating and mismatch negativity (MMN), as well as abnormal physiological densities in neural cortices associated with sensory processing" (Bailliard \& Whigham, 2017, p.2). These individuals are in prolonged states of sensory defensiveness, which can "cause issues with cognitive, social, and sensory motor functioning that impact occupational engagement and performance" (Kimball et al., 2007, p. 408). Kelly et al. (2021) found that $91 \%$ of participants in a study on youth with substance use disorder (SUD) had atypical scores in at least one or more sensory patterns. With items in low registration, sensory sensitivity, and sensation avoiding were significantly higher ("More Than Other People" and "Much More Than Other People") than the normative population, while sensation seeking was both lower and higher (p.5).

Since those who use drugs regularly have atypical sensory experiences and addiction is categorized as both a sensory experience and mental health domain, sensory approaches should be considered in evaluation and treatment programs (Bar-Shalita et al., 2019; Kelly et al., 2021; 
SENSORY MODULATION TO MANAGE CHRONIC PAIN AND SUBSTANCE USE

Stols et al., 2013). Occupational therapists teach sensory modulation techniques to enhance selfregulation as well as to adapt the environment to support "patients' occupational engagement and to mitigate the occurrence of negative mental states" (Bailliard \& Whigham, 2017, p.2; Kimball et al., 2007). For example, the use of a deep pressure sensory modulating protocol can modulate cortisol levels in the body of those with PTSD but has not been explored in those with chronic pain or substance use (Kimball et al., 2007). Integrating sensory modulation techniques into substance use recovery will help to modulate the nervous system of clients and therefore "improve their ability to participate more fully in their occupations" (Kimball et al., 2007, p. 411).

Self-report assessments like The Adult Sensory Profile based upon Dunn’s Model of Sensory Processing are used to measure sensory processing preferences (Brown \& Dunn, 2002; Stols et al., 2013). Occupational therapists can use the results from the profile to analyze individuals' sensory processing preferences and to incorporate sensory strategies into their treatment sessions. They can also teach patients to adapt tasks or environments in order to meet their sensory needs (Bailliard \& Whigham, 2017; Brown \& Dunn., 2002; Dunn, 1997; Kimball et al., 2007)

Individuals' sensory processing preferences affect both how they feel pain and how they cope with it (Meredith et al., 2015). Those who score high sensory sensitivity and sensation avoiding tended to have higher levels of pain catastrophizing. On the other hand, those with high levels of sensation seeking were linked to active coping strategies, such as coping selfstatements, ignoring pain, diverting attention, and increasing behavioral activities (Meredith et al., 2015). Therefore, during evaluation and treatment, patients should use sensory modulation 
SENSORY MODULATION TO MANAGE CHRONIC PAIN AND SUBSTANCE USE

tools that take their individual sensory processing preferences into account to ensure their recovery meets their unique needs.

\section{Complex Barriers to Treating Addiction and Chronic Pain}

Sensory-based interventions can be beneficial for individuals with complex medical conditions (Champagne, 2017). Humans are dynamic systems that are impacted by biological, psychological, psychosocial, environmental, and cultural factors (Champagne, 2017, p. 163).

\section{Mental Health and Trauma}

When examining drug-related disfunction, the impact of mental health and trauma must also be acknowledged, as these are also additional co-diagnoses in a large number of patients (Hser et al., 2017; Stevenson \& Cole, 2015; Weiss \& Rao, 2017). It has been estimated that up to $70.9 \%$ of those with OUD and chronic pain have some mental health condition (Hser et al., 2017, p. 7). The most common diagnoses are anxiety and major depressive disorder (Hser et al., 2017, p.5). Mental health challenges are correlated with negative MAT addiction treatment outcomes

(Stevenson \& Cole, 2015). The use of sensory-based treatment is a good match for the treatment of co-occurring conditions because of its focus on empowering individuals' recovery, build therapeutic alliances, and facilitate self-management, and improving occupational engagement and not specific diagnoses (Brown \& Dunn, 2002; Champagne, 2017).

In addition to mental health challenges, trauma histories are associated with higher levels of substance use and chronic non-cancer pain (López-Martínez et al., 2019). Those with childhood trauma, such as emotional, physical, and sexual abuse, as well as veterans with PTSD, have a significantly higher risk for developing disfunction related to substance use (Khoury et al., 2010). 
SENSORY MODULATION TO MANAGE CHRONIC PAIN AND SUBSTANCE USE

Individuals who experience a higher level of trauma (measured by the ETI and TEI) have a greater severity of substance use (Khoury et al., 2010, p. 1084). Trauma affects the body’s nervous system, causing an increase in anxiety, physiological arousal, and avoidance behaviors. The nervous system is persistently reactive even after the traumatic incident has passed and substances are often used as modulators.

\section{Central Sensitization}

The mechanism in which pain moves from acute to chronic is called central sensitization (Institute of Chronic Pain, 2019). The body no longer reacts to the pain in a normal way, but instead becomes hyperalgesic, or more sensitive to pain. This is why those with trauma or an hyperreactive systems are more likely to develop chronic pain (Institute of Chronic Pain, 2019). These overlapping risk factors of substance use, chronic pain, trauma, and mental health challenges are difficult to disentangle and treat as independent diagnoses. Therefore, they need to be treated holistically (Hser et al., 2017; Stevenson \& Cole, 2015).

\section{Tolerance and Withdrawal}

In addition to the complexity of the diagnoses, the physiological nature of pain and addiction add challenges to treatment and treatment outcomes. Patients are likely to have a high tolerance to the substance they are using, and this tolerance has the potential to interfere with the effectiveness of other MAT treatments by creating cross tolerance of substances (Eyler, 2013). There is also a withdrawal period when an individual stop taking substances, and can cause a variety of symptoms, including pain (Eyler, 2013; Prater et al., 2002). Tolerance and withdrawal are both neurological and physiological processes that are related to a change in occupational engagement over time (Gutman, 2006; Schmitz, 2005).

\section{Opioid-Induced Hyperalgesia}


SENSORY MODULATION TO MANAGE CHRONIC PAIN AND SUBSTANCE USE

Individuals formerly addicted to opioids also experience higher rates of pain and a heightened pain sensitivity called opioid-induced hyperalgesia (Eyler, 2013). This paradoxical phenomenon "is generally thought to result from neuroplastic changes in the peripheral and central nervous system (CNS) that lead to sensitization of pro-nociceptive (pain) pathways" and can be long lasting (Eyler, 2013; Lee et al., 2011, p. 145).

\section{Pain Catastrophizing}

High rates of pain catastrophizing in those with substance use and trauma are another barrier to treatment. Pain catastrophizing is "a response associated with adverse pain-related clinical outcomes and characterized by magnification of the threat or negativity of painful experiences, feelings of helplessness, and preoccupation with pain-related thoughts" (Eyler, 2013, p. 77, Institute of Chronic Pain, 2019). Pain catastrophizing can interfere with work, relationships, and daily activities and should be addressed to improve coping skills (Eyler, 2013).

\section{Stigma}

Another challenge associated with substance use and chronic pain is facing societal stigma. According to a review conducted by Yang et al. (2017), the main stereotypes endorsed towards those with substance use were dangerous, unpredictable, immoral, had poor decisionmaking ability, were to blame for their decisions, and could "pull themselves together" without treatment (p.4). The general emotional reactions of the public towards those with substance use were pity, anger, fear, and desire to social distance (Yang et al., 2017). The stereotyping and negative emotions towards those with substance use challenges led to discrimination, a desire to restrict them from responsible societal roles, and reduction of policy-makers' willingness to "allocate financial resources to alleviate a problem, such as insurance reimbursement for substance abuse treatment" (Yang et al., 2017, p.7). 
SENSORY MODULATION TO MANAGE CHRONIC PAIN AND SUBSTANCE USE

Those with chronic pain also face stigma and resulting stereotypes. At times being labeled as lazy or sensitive, those with chronic pain face the frustration of not feeling believed by romantic partners, relatives, and health care practitioners (De Ruddere \& Craig, 2016; Saunder et al., 2018). This can cause disruptions in relationships and the ability to maintain a job (Fisher et al., 2007; Saunder et al., 2018). Additionally, because chronic pain is not always clearly medically understood, those in the general community and health care "are less inclined to help, feel less sympathy, dislike patients more, and suspect deception" (De Ruddere \& Craig, 2016, p. 1607). This results in poorer patient outcomes, both physically and psychologically speaking (De Ruddere \& Craig, 2016).

These stereotypes and attitudes may impact individuals' desire and ability to seek help for their chronic pain and substance use and further complicate treatment and treatment outcomes (Yang et al., 2017). All aspects of the client must be carefully considered when assessing individuals and developing programs to meet their needs.

\section{Literature Review Conclusion}

Literature supporting OT's role in chronic pain is well established within the traditional medical model. Nonpharmacological interventions, such as pacing, energy conservation, adaptative techniques, vocational rehabilitation, mindfulness, and pain acceptance, have proven to increase occupational participation and quality of life in those with chronic pain (Lagueux et al., 2018). However, mental health challenges, the lasting impacts of trauma, central sensitization, tolerance and withdrawal, opioid-induced hyperalgesia, pain catastrophizing, and stigma add complexity to client care. These challenges to treatment are biological, psychological, sociological, and difficult to manage. Therefore, an individualized and well monitored, treatment 
SENSORY MODULATION TO MANAGE CHRONIC PAIN AND SUBSTANCE USE

program must be implemented for each patient to achieve optimal outcomes (Eyler, 2013; Prater et al., 2003).

This capstone advocates for the unique role OTs can serve working with patients with comorbidities within a substance use recovery setting. The literature supports further investigation of the sensory profiles of those with chronic pain and substance use and the use of sensory modulation techniques to enhance recovery, self- management, and occupational performance (Brown, 2002; Kelly et al., 2021; Meredith et al., 2015). By integrating a sensory component into chronic pain and recovery programs, occupational therapists will be able to evaluate and interpret each individual's unique nervous systems tendencies and preferences and address areas that are limiting occupational performance. This capstone will focus on using an individual's sensory profile to tailor a self-management program that addresses their lived experience. As well as building individuals' self-knowledge and self-regulation skills to reduce the impact of stigma and support their successful, long-term recovery.

\section{Chapter 3: Project Description}

Those receiving care at substance use recovery settings are at a higher risk for uncontrolled pain as well as pain impacting their long-term recovery (Ilgen et al., 2020; Prater et al., 2002). The complicating factors of trauma, mental health, physiological and psychological mechanism of addiction, and chronic pain require a holistic and client centered approach that focuses on the empowerment and self-awareness aspects of recovery (Wallis et al., 2018). Sensory processing techniques target the physiological symptoms and the psychological aspects of both pain and mental health challenges (Brown, 2002). Occupational therapists have the unique skill set and training to use these techniques to adapt environment and tasks to fit the sensory needs of individuals (AOTA, 2017). However, there is a gap in the literature supporting 
SENSORY MODULATION TO MANAGE CHRONIC PAIN AND SUBSTANCE USE

the need for sensory processing techniques as nonpharmacological pain interventions within the substance use recovery setting. The specific purposes of this capstone study were to determine the sensory processing preferences of those with chronic pain and substance use and use those findings to inform a comprehensive and multimodal chronic pain program within a substance recovery setting.

\section{Part 1: Study Design}

Strong findings from the literature about the potential use of sensory processing within a chronic pain and recovery setting and clinical experience from mentors Leslie Bardin MS, OTR/L and Judith Giencke Kimball, Ph.D., OTR/L, FAOTA guided the initial investigation of this capstone project. A descriptive study was conducted to determine what the sensory processing preferences of people with co-occurring chronic pain and in recovery from substance use are. This preliminary descriptive study increased the body of knowledge of pain, recovery, and sensory processing and will serve as foundational knowledge for future study and exploration.

\section{Participants and Recruitment}

Participants were recruited from a Partial Hospitalization Program (PHP) and Intensive Outpatient Program (IOP) substance use recovery center in Scottsdale, Arizona, where the student investigator was completing a capstone experience associated. An announcement (see Appendix A) was be made on the Monday February 8, 2021 morning "Co-occurring \& Wellness" group sessions where a brief description of the study was announced, and clients were instructed that if they wished to participate, they should reach out either through e-mail or in person to the student investigator. Another post was made to the alumni page by the administration, see Appendix A, that recruited participants who have already completed the 
SENSORY MODULATION TO MANAGE CHRONIC PAIN AND SUBSTANCE USE

recovery program. All participants self-identified as having comorbid chronic pain and substance use. Additionally, a flyer (see Appendix B) was posted in the recovery center lunchroom. The inclusion criteria for this study were adults ages $18-75$ that were currently in recovery from any form of substance use and self-identify as having chronic pain (pain that has lasted 3 months or more). Exclusion criteria was any persons that is not in recovery for any substance, does not have chronic pain, and is out of the age range. All participants were either actively receiving individualized treatment at this setting or alumni, peer support, or employees.

\section{Methods}

The materials needed were the Adult and Adolescent Sensory Profile, the Brief Pain Inventory (Short Form), and the Personal Recovery Outcome Measure. The Adult and Adolescent Sensory Profile was obtained via the Library Access at The University of St. Augustine for Health Sciences. The Brief Pain Inventory was obtained through submitting a signed letter, on institutional letterhead, from the chair of The University of St. Augustine for Health Science thesis/dissertation committee endorsing the use of the tool in the student's training program. Then was purchased using a grant from The University of St. Augustine for Health Science Entry-Level OTD grant. Personal Recovery Outcome Measure is free to use online (MD Anderson, n.d.).

The Adult and Adolescent Sensory Profile consists of 60 questions relate to each of the four sensory profiles, Sensory Sensitive, Sensation Avoidance, Low Registration, and Sensation Seeking (see Appendix C). The tool can be used for both an assessment and intervention on both children and adults with varying conditions. It has been widely studied on children with sensory processing disorder, autism spectrum disorders, and ADHD (Tomcheck \& Dunn, 2007; Ghanizadeh, 2011). The tool has also been used on those with mental health diagnoses such as 
SENSORY MODULATION TO MANAGE CHRONIC PAIN AND SUBSTANCE USE

schizophrenia, mood disorders, PTSD, and OCD, substance abuse and anger behavior (Bailliard and Whigham, 2017, Kelly et al., 2021). Further studies need to assess the use of the AASP and adults in recovery for substance use. The Brief Pain Inventory (see Appendix D) is a 15-item, self-report questionnaire that assesses the severity of pain and the impact of pain on daily function. It specifically measures the severity of pain, impact of pain on daily function, location of pain, pain medications and amount of pain relief in the past 24 hours or the past week. It is a well-established tool that is used for clinical pain assessment, epidemiological studies, and in studies of the effectiveness of pain treatment (Cleeland \& Ryan, 1994; MD Anderson, n.d.). The Personal Recovery Outcome Measure (see Appendix E) was created by Skye Barbic a mental health Canadian Occupational Therapist. It is a 30-item questionnaire on recovery that scores can be tracked over time on a ruler out of a total of thirty. This assessment tool contains items on wellness, environment, social supports, personal emotions, and feelings (Barbic et al., 2016). This tool is also used as a starting point for discussion, assessment, and goal setting with occupational therapy clients (Barbic et al., 2016).

The participants of the study were asked to fill out the three assessments and student researcher, Claire Ruth OTD/S, scored and recorded each of the assessments according to their respective manuals. Scores were used to describe the populations pain, recovery, and sensory processing preferences. Study recruitment began in February 2021 and continued until the study was closed on April 1, 2021.

\section{Part 2: Program Development}

The proposed plan was to create a chronic pain management program within a substance use recovery treatment center that was informed by the results of the descriptive study. Due to 
SENSORY MODULATION TO MANAGE CHRONIC PAIN AND SUBSTANCE USE

limited time and setting constraints a 6-week sensory based occupational therapy group was implemented in its place.

Clients in this group were identified by the settings clinical team as benefiting from a two hour long weekly occupational therapy group. The clients in this group did not all have chronic pain but do struggle with occupational participation. Still using the information gained from the descriptive study on sensory processing preferences and recovery and the supervision of the site Occupational Therapist Caitlin Belvin MOTR/L a six-week OT sensory based self-management group was developed. This OT group focused on educating clients about occupational therapy, sensory processing, coping skills, self-management, and stress management promoting the profession's role in substance use recovery. Group goals, worksheets, and ideas were taken from Tina Champagne OTD, OTR/L, CAAP “The Sensory Modulation Program” and Karen Moore OTR/L “Sensory Connection Program Curriculum for Self- Regulation” (Champagne, 2017, Moore, 2014). In lieu of the originally planned chronic pain management program a seventh group focuses on pain self-management was added to the protocol in Appendix F. Primarily informed sensory modulation techniques, Pain psychologists Dr. Rachel Zoffness "The Pain Management Workbook” and Christine Miserandinos’ Spoon Theory (Champagne, 2017; Miserandios, 2003; Zoffness 2020).

\section{Mission and Vision Statements}

The vision for the group was to develop a sensory based OT group within a substance use recovery treatment setting. The mission of the group was to educate clients about sensory modulation and their own sensory processing preferences and aid them in developing the skills and plan to implement sensory strategies in their daily lives to improve both self-management 
SENSORY MODULATION TO MANAGE CHRONIC PAIN AND SUBSTANCE USE

and occupational participation in order to promote life satisfaction and recovery outcomes for long term health and sobriety.

\section{Timeline}

While collection and analyses of the descriptive studies data was still being performed by the student researcher the first group took place on Monday March 15, 2021. The OT group continued for 6-weeks total on Monday mornings at 10:00 am in a group therapy room at the recovery center until April 19, 2021. Evaluation of the program's strengths, weakness, barriers, and supports through a focus group would have been conducted in late April/ early May but was not completed due to time constraints.

\section{Goals and Objectives}

Goals and objectives had to be adjusted for the changes from the proposed program. As mentioned above a chronic pain management program was not feasible due to time, COVID-19, and setting restrictions. New goals and objectives were created to fit the OT group and deliverables that were created.

Goal 1: Facilitate a research informed six-week long sensory based OT group within a substance use recovery treatment setting.

Note: Objectives 1-4 were adapted Sensory Modulation \& Environment: Essential Elements of Occupation, $3^{\text {rd }}$ Ed. (Champagne, 2017, pp.125-128).

- SMART Objective 1: Facilitate client's self-awareness of their "unique tendencies and [sensory] preferences, and how these patterns influence self-organization" by having clients fill out a sensory self-assessment, score, and discuss results in group by March 2021. 
SENSORY MODULATION TO MANAGE CHRONIC PAIN AND SUBSTANCE USE

- Smart Objective 2: Create a sensory lab group that facilitates "Self-shaping: Exploring, Planning and Practicing” sensory modulation strategies for therapeutic purposes March 2021 through April 2021.

- Smart Objective 3: Facilitate clients to apply sensory modulation strategies to improve "Self-regulation and Positive Change" within their lives through continued practice, scenarios, and planning.

- Smart Objective 4: Focus on furthering clients "Repertoire Expansion" through skill enhancement of crisis and relapse prevention to facilitate occupational performance and health, wellness and long-term recovery.

- Smart Objective 5: Create a group focused on stress-management as informed by the PROM results (see Chapter 5) facilitating clients to utilize strategies such as a daily planner, advocating for ones needs, barrier setting, asking for help, and prioritizing.

Goal 2: Create a sensory OT group manual that can be adapted for co-occurring chronic pain and substance use in a variety of recovery settings.

- Smart Objective 1: Compile weekly notes and handouts from sensory based OT groups at the recovery center and edit them to grade up or down depending on client's needs and acuity by April 2021.

- Smart Objective 2: Add in a group for chronic pain management that is research informed and advocates for OTs role as a non-pharmacological treatment method for chronic pain that can be adapted according to practitioners setting and client needs by April 2021.

- Smart Objective 3: Disseminate the manual to the OT staff at the recovery center, USA staff, OT staff at NIH, and Interfaith staff via email by April 2021. 
Goal 3: Advocate for the role of Occupational Therapy in pain management and substance use within a recovery setting.

- SMART Objective 1: Submit to mental health OT podcast to be a guest speaker to discuss capstone experience and findings by May 2021.

- SMART Objective 2: Seek out opportunities to share findings and handout within the OT community at conferences, webinars, and other networking opportunities throughout the year 2021 .

While all of these goals and objectives were not completed within the time restraints of this OTD capstone they serve as direction for future projects, programs, and research to further expand occupational therapy practice in the area of recovery program development.

\section{Chapter 4: Results and Analysis}

A total of ten participants from the recovery center consented and participated in the study. This study employed a descriptive design. All assessments were scored according to their respective manuals by the student investigator, Claire Ruth OTD/S. Informed by the descriptive study results, a six-week long sensory based occupational therapy group was implemented at the capstone site.

\section{Part 1: The Descriptive Study}

A small descriptive study to determine the sensory processing patterns of those with comorbid chronic pain and recovery from substance use was conducted at a PHP/IOP recovery center in Scottsdale, AZ.

\section{Demographics}


SENSORY MODULATION TO MANAGE CHRONIC PAIN AND SUBSTANCE USE

A total of ten participants $(n=10)$ completed all three assessments. The average participant age was 30.7 years (range $21-44$ years), and the majority (60\%) were male.

\section{Adult and Adolescent Sensory Profile}

The first question that AASP asks is: "Are there aspects of daily life that are not satisfying to you? If yes, please explain.” Participants gave the following answers: the monotony of job/work life $(n=3)$, lack of mobility that interrupts hobbies/being active $(n=2)$, struggles with intimate relationships $(n=2)$, financial struggles $(n=1)$, school stress, struggling with self-care and ADLS ( $\mathrm{n}=1)$, and grief and sadness $(\mathrm{n}=1)$.

Table 1 identifies how many participants reported atypical AASP scores for at least one of the four sensory patterns. Atypical is defined scoring differently than "Similar To Most People" on any given sensory quadrant (Brown \& Dunn, 2002).

\section{Table 1}

Atypical Sensory Processing

\begin{tabular}{|l|l|l|}
\hline & Number of People $(\mathbf{n = 1 0})$ & Percentage of People (\%) \\
\hline 0 atypical quadrants & 1 & $10 \%$ \\
\hline 1 atypical quadrant & 3 & $30 \%$ \\
\hline 2 atypical quadrants & 2 & $20 \%$ \\
\hline & Number of Participants & Percentage of Participants \\
$(\mathrm{n}=10)$ & $(\%)$
\end{tabular}


SENSORY MODULATION TO MANAGE CHRONIC PAIN AND SUBSTANCE USE

\begin{tabular}{|l|l|l|}
\hline 3 atypical quadrants & 3 & $30 \%$ \\
\hline 4 atypical quadrants & 1 & $10 \%$ \\
\hline
\end{tabular}

Note. $90 \%$ of the sample reported atypical AASP scores for at least one of the four sensory patterns, $20 \%$ reported two atypical patterns, $30 \%$ three atypical patterns, and $10 \%$ reported atypical scores in all four sensory patterns.

Based on participants' self-report, results were categorized into each quadrant sensory pattern as "Much More Than Other People," "More Than Most People," "Similar to Most People," "Less That Most People," and "Much Less Than Most People” (Dunn \& Brown, 2002, p.19). These sensory patterns were totaled for the entire study sample $(n=10)$ and converted into percentages (see Column 2 in Table 3).

Table 3

Sensory Processing Preferences

\begin{tabular}{|c|l|l|l|}
\hline Sensory Variable & Study Sample (\%) & Normative Data (\%) & $\begin{array}{l}\text { Difference: Curve- } \\
\text { Sample }\end{array}$ \\
\hline Sensory Sensitivity & & & \\
\hline Much Less Than Most & 0 & 2 & 2 \\
\hline Less Than Most People & 0 & 14 & 14 \\
\hline Similar to Most People & 50 & 68 & 18 \\
\hline More Than Most People & 10 & 14 & 4 \\
\hline
\end{tabular}




\begin{tabular}{|c|c|c|c|}
\hline $\begin{array}{r}\text { Much More than Most } \\
\text { People }\end{array}$ & 40 & 2 & -38 \\
\hline Sensation Avoiding & & & \\
\hline $\begin{array}{r}\text { Much Less Than Most } \\
\text { People }\end{array}$ & 0 & 2 & 2 \\
\hline Less Than Most People & 0 & 14 & 14 \\
\hline Similar to Most People & 30 & 68 & 38 \\
\hline More Than Most People & 40 & 14 & -26 \\
\hline $\begin{array}{r}\text { Much More Than Most } \\
\text { People }\end{array}$ & 30 & 2 & -28 \\
\hline Sensory Variable & Study Sample (\%) & Normative Data (\%) & $\begin{array}{l}\text { Difference: Curve- } \\
\text { Sample }\end{array}$ \\
\hline Low Registration & & & \\
\hline $\begin{array}{r}\text { Much Less Than Most } \\
\text { People }\end{array}$ & 0 & 2 & 2 \\
\hline Less Than Most People & 10 & 14 & 4 \\
\hline Similar to Most People & 40 & 68 & 28 \\
\hline More Than Most People & 30 & 14 & -16 \\
\hline $\begin{array}{r}\text { Much More Than Most } \\
\text { People }\end{array}$ & 10 & 2 & -8 \\
\hline
\end{tabular}


SENSORY MODULATION TO MANAGE CHRONIC PAIN AND SUBSTANCE USE

\begin{tabular}{|r|l|l|l|}
\hline Sensation Seeking & & & \\
\hline Much Less Than Most & 0 & 2 & 2 \\
\hline Less Than Most People & 10 & 14 & 4 \\
\hline Similar to Most People & 80 & 68 & -12 \\
\hline More Than Most People & 10 & 14 & 4 \\
\hline Much More Than Most & 0 & 2 & 2 \\
\hline People & & & \\
\hline
\end{tabular}

Note. Layout of the above table was adapted from Kelly et al., 2021

The Kelly et al. (2021) study stated:

This descriptive data can also be compared with the normal distribution, in which $68 \%$ have "typical" sensory processing (similar to most; $<1$ standard deviation from the mean), $28 \%$ have a probable difference in sensory processing (1-2 standard deviations above or below the mean), and $4 \%$ have a definite difference in sensory processing (>2 standard deviations above or below the mean). Acceptable internal consistency was found with Cronbach's alpha of 0.78 for sensation seeking, 0.87 for sensation avoiding, 0.76 for sensory sensitivity and 0.77 for low registration. (Brown \& Dunn, 2002, pp.18-19 as cited in Kelly et al., 2021, p. 3).

The difference between the normative data and the study sample can be seen in column 4 of Table 3. Descriptive details for the categorical sensory variables, along with expected rates based on the normal curve, are presented in Table 3. Comparison revealed that the study sample 
reported higher levels ("Much More Than Other People" and "More than Other People") of low registration, sensory sensitivity, and sensation avoiding, and similar level sensation seeking.

This data can be seen in Figure 1 with the dashed line being the normal distribution of the sensory variables and the solid blue line being the study sample.

\section{Figure 1}

Sensory Processing Preferences Compared to Normative Values

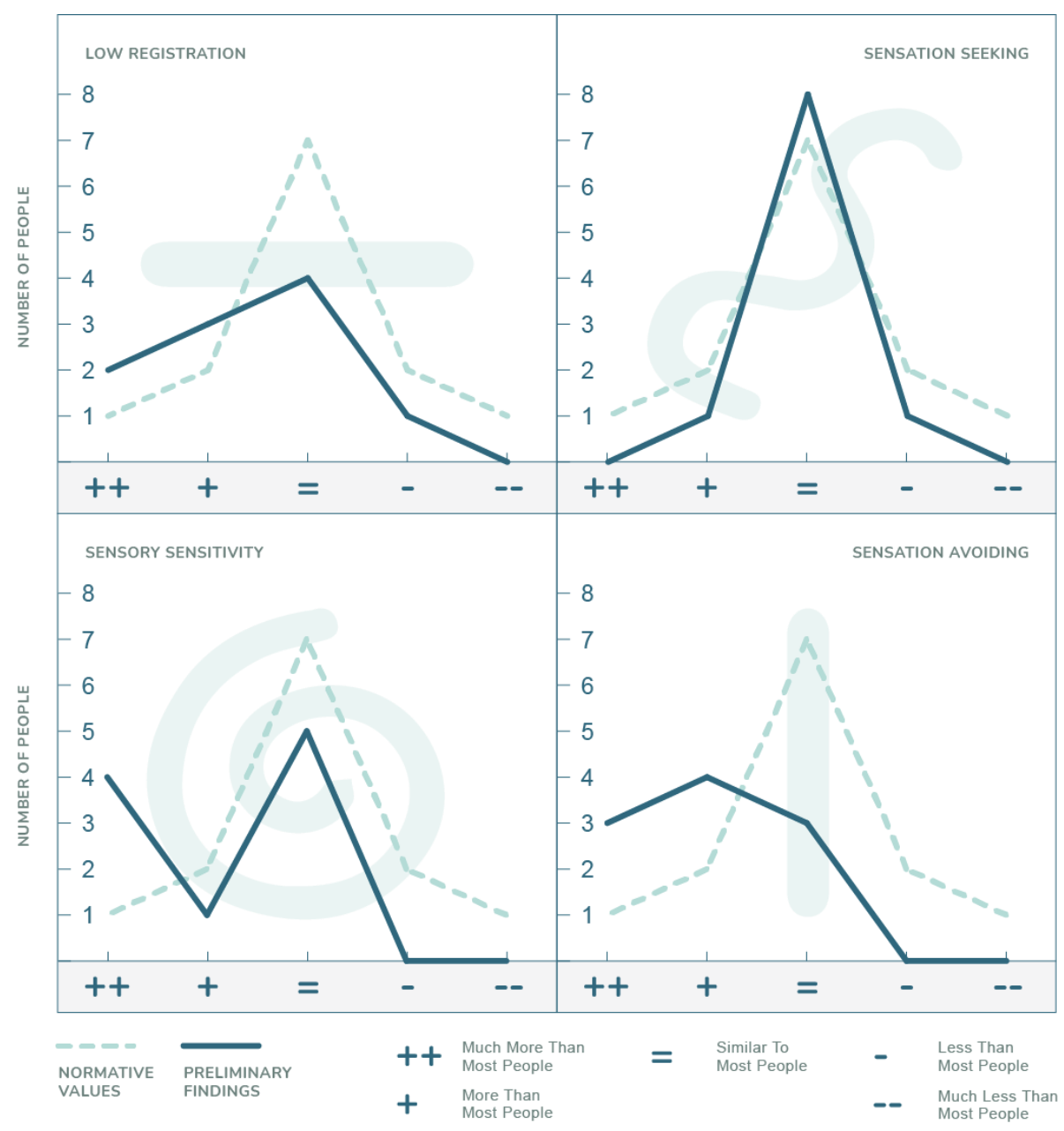

The figure above allows for a visual for how the sensory patterns of the study sample differ from the normative sample (Brown \& Dunn, 2002, pp. 18-19). Sensory sensitivity had the highest rate 
SENSORY MODULATION TO MANAGE CHRONIC PAIN AND SUBSTANCE USE

of "Much More Than Most People" (40\%) followed by Sensation avoiding (30\%) for "Much More Than Most People" and 40\% "More Than Most People." Sensation seeking was the closest to the normative distribution.

These results aligned with recent research on the sensory processing preferences of individuals recovering from substance use and with chronic pain. Kelly et al. (2021) found that youth who were voluntarily seeking treatment at a government funded alcohol and other drug (AOD) treatment service had sensory processing patters for low registration, sensory sensitivity, and sensation avoiding significantly higher than the normative population (p.4). Brown \& Knowles (2021) reported that individuals in recovery from substance use had higher rates of sensory sensitivity and sensory avoiding compared to the normative sample with moderate effect size $(\mathrm{p}<0.0001)$. When examining gender specific sensory patterns, women had higher rates of sensory sensitivity, low registration, and sensation avoiding compared to the normative sample with strong effect size (Brown \& Knowles, 2021). Findings from the Meredith et al. (2015) study supported this study's results that high scores on sensation avoiding and sensory sensitivity may lead to worse pain outcomes in terms of catastrophizing and the use of maladaptive coping strategies.

The AASP Pattern Grids can be used to further examine individuals' sensory processing preferences (Brown \& Dunn, 2002). Determining if an individual has a high neurological threshold or low neurological threshold can be useful in determining how much sensory stimulus that individual's nervous system can handle. Active and passive responses determine how an individual may respond to sensory stimulus. Pattern grids provide further detail and insight into what individual sensory systems belong in each quadrant classification (Brown \& Dunn, 2002). 
Table 4 shows the entire study sample's Pattern Grids. The highlighted boxes identify patterns a majority of the study participants reported.

Table 4

Pattern Grids

\begin{tabular}{|l|l|l|l|l|l|l|l|l|}
\hline Sensation & $\begin{array}{l}\text { Low } \\
\text { Neurological } \\
\text { Threshold }\end{array}$ & $\begin{array}{l}\text { High } \\
\text { Neurological } \\
\text { Threshold }\end{array}$ & $\begin{array}{l}\text { Active } \\
\text { Response }\end{array}$ & $\begin{array}{l}\text { Passive } \\
\text { Response }\end{array}$ & $\begin{array}{l}\text { Low } \\
\text { Registration }\end{array}$ & $\begin{array}{l}\text { Sensation } \\
\text { Seeking }\end{array}$ & $\begin{array}{l}\text { Sensory } \\
\text { Sensitivity }\end{array}$ & $\begin{array}{l}\text { Sensation } \\
\text { Avoiding }\end{array}$ \\
\hline Taste/Smell & 2 & 8 & 9 & 0 & 1 & 7 & 1 & 1 \\
\hline Movement & 1 & 9 & 6 & 4 & 2 & 6 & 2 & 0 \\
\hline Visual & 8 & 2 & 7 & 2 & 1 & 3 & 4 & 5 \\
\hline Touch & 7 & 3 & 7 & 3 & 1 & 6 & 1 & 3 \\
\hline Activity & 7 & 3 & 6 & 5 & 1 & 0 & 7 & 5 \\
\hline Auditory & 6 & 4 & 7 & 4 & 2 & 3 & 3 & 3 \\
\hline
\end{tabular}

Note. Some individuals scored the same for either both active or passive response or more than one quadrant for any given sensation. When that occurred, both were marked on the above table. Therefore, the total of every section will not be equal to the total number of participants $(n=10)$. This was done to show that some individuals did not score within one parameter of this assessment and therefore caution should be taken when classifying dynamic individuals into static categories.

A majority of the study sample reported a high neurological threshold for taste/smell and movement and a low neurological threshold for visual, touch, activity, and auditory stimulus. All participants self-reported having an "active response" to sensory stimuli. This is defined as taking direct action as a result of over or under stimulation, such as moving away from a certain stimulus (Brown \& Dunn, 2002, p.16). When totaling the individual sensations, the study sample 
had higher rates of sensation seeking for taste/smell, movement, and touch, sensory sensitivity for activity, sensation avoiding for visual stimulus, and mixed results for auditory.

\section{Brief Pain Inventory (Short Form)}

All participants completed and answered "Yes" to the question "Throughout our lives most of us have had pain from time to time (such as minor headaches, sprains, and toothaches). Have you had pain other than these everyday kinds of pain today?" (Cleeland, 1991, p.1). The primary causes of pain were lower back pain, neuromuscular pain in arms and legs, headaches/migraines, neck pain, and autoimmune pain. Table 5 shows the study sample average pain at its worst, best, on average, current, severity and interference on a Likert scale 0 to 10 (Cleeland, 1991).

\section{Table 5}

Brief Pain Inventory Results

\begin{tabular}{|l|l|}
\hline $\begin{array}{l}\text { Average pain at its worst in } \\
\text { past 24 hours }\end{array}$ & $6 / 10$ \\
\hline $\begin{array}{l}\text { Average pain at its best in the } \\
\text { past 24 hours }\end{array}$ & $2.2 / 10$ \\
\hline Average of average pain & $4 / 10$ \\
\hline Average of current pain & $4.6 / 10$ \\
\hline Total Average Pain Severity & $4.25 / 10$ \\
\hline Average Pain Interference & $4.44 / 10$ \\
\hline
\end{tabular}

The total average pain severity was $4.25 / 10$ and average pain interference with enjoyment of life, mood, and relations with others, walking, general activity, work, and sleep was 4.44/10. This 
was indicative of a moderate severity and moderate interference in one's occupational participation.

Figure 2 is a visual representation of the study sample's pain severity on a 0 to 10 Likert pain scale.

\section{Figure 2}

Average Pain Levels

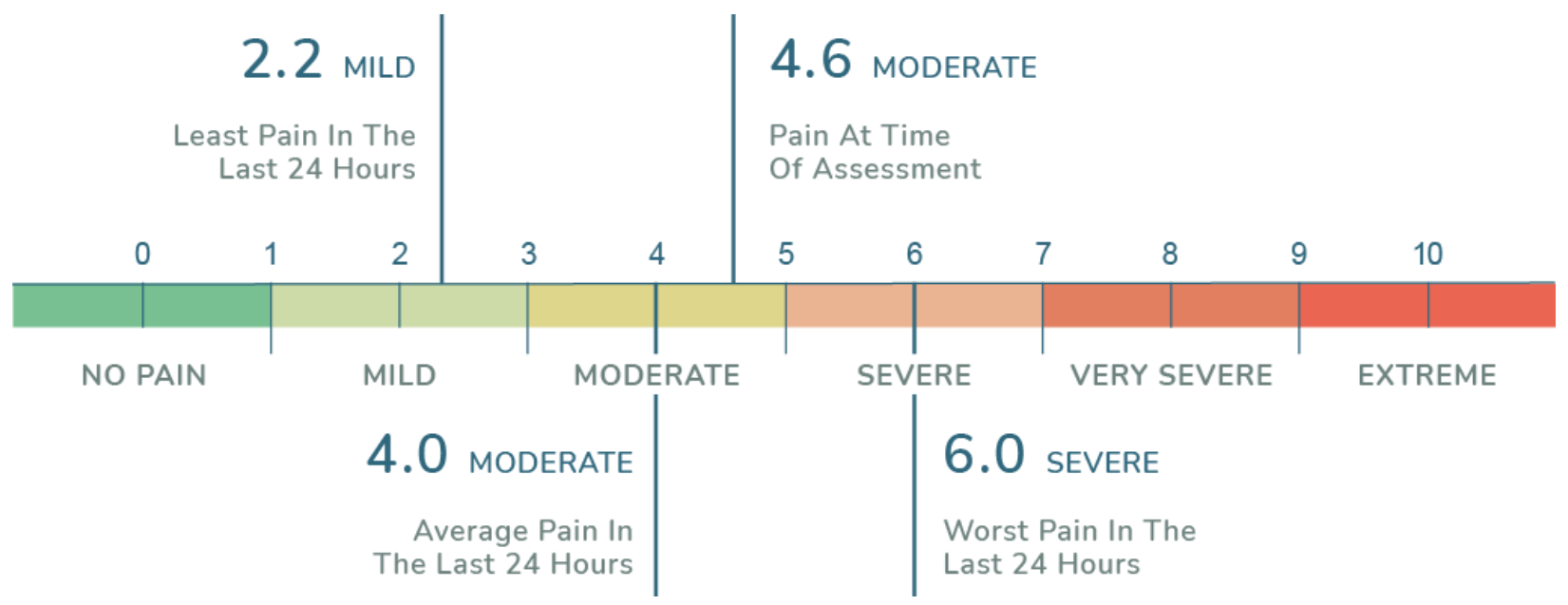

In order to gain a more comprehensive understanding of the participants' pain, the average of each pain severity score was taken. The average rating of pain at its worst in the past 24 hours was $6 / 10$, indicating severe pain; the average rating of pain at its best is the past 24 hours was 2.2/10, indicating mild pain; the mean of participants average pain was $4 / 10$, and the average of participants' current pain (while filling out the assessment) was 4.6/10; therefore, both indicated moderate pain (see Table 5 and Figure 2).

The Brief Pain Inventory (Short Form) asked about what treatment or medication the client was currently receiving for pain. Figure 3 shows the study participants' answers in percentages on a pie graph. 


\section{Figure 3}

\section{Current Pain Treatments}

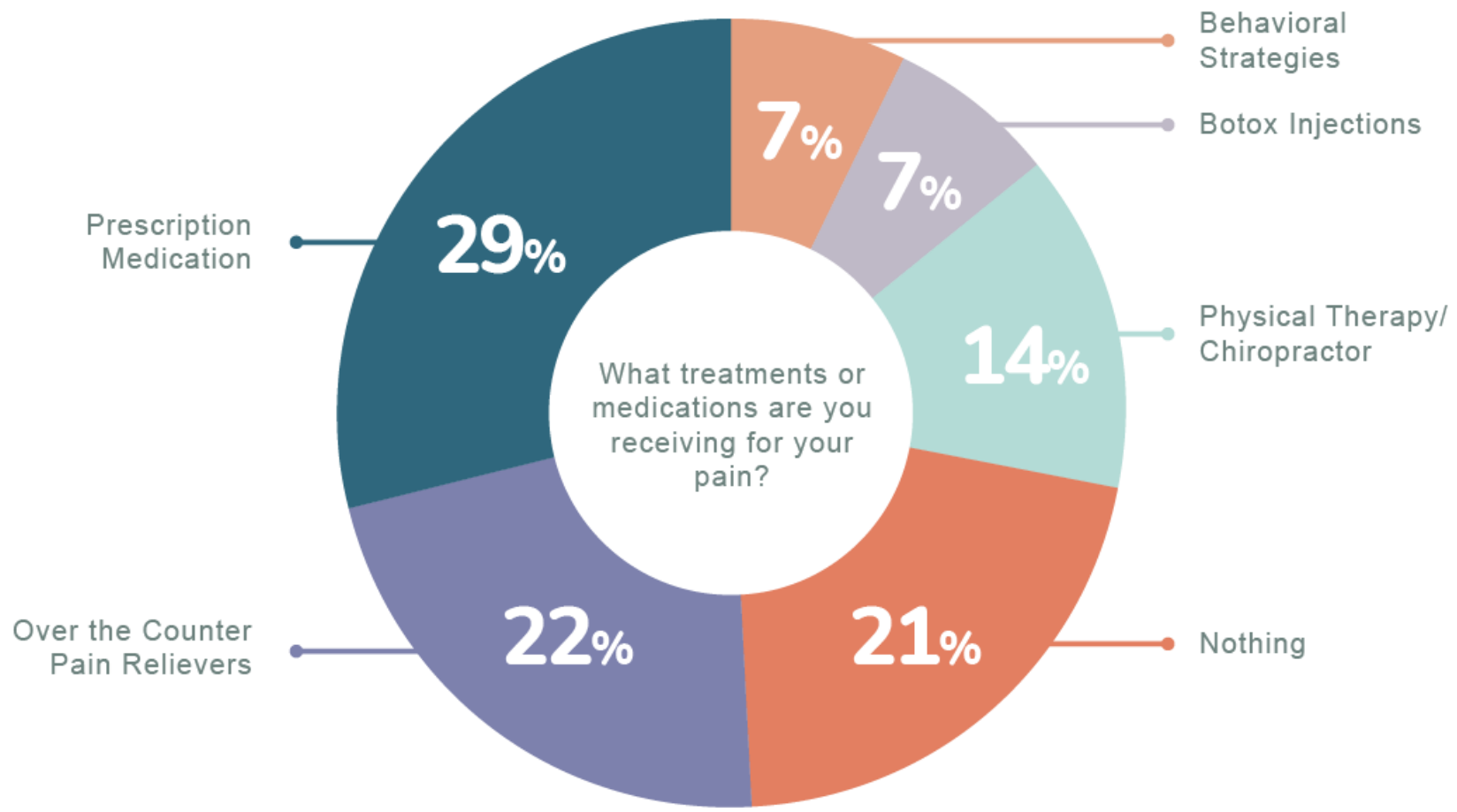

The most common treatments for pain were reported to be prescription medication (4), over-thecounter pain relievers, such as Ibuprofen/Tylenol (3), currently nothing (3), Botox (1), Physical Therapy (1), Chiropractor (1), and behavioral strategies, such as avoidance and distractions (1). The average percent pain relief these treatments or medications were providing clients was $33 \%$.

Clients at the research site had access to occupational therapy services but were not seeking them out to aid with pain management.

\section{Personal Recovery Outcome Measure}

Figure 3 is a visual representation of the average adjusted recovery score on the Personal Recovery Outcome Measure, which was 21.175/30 (range 10.5-25.5). The corresponding question associated with item 21 was the statement: "I can manage stress." (Barbic et al., 2016). 


\section{Figure 3}

Personal Recovery Outcome Measure Ruler

\section{Can Manage Stress}

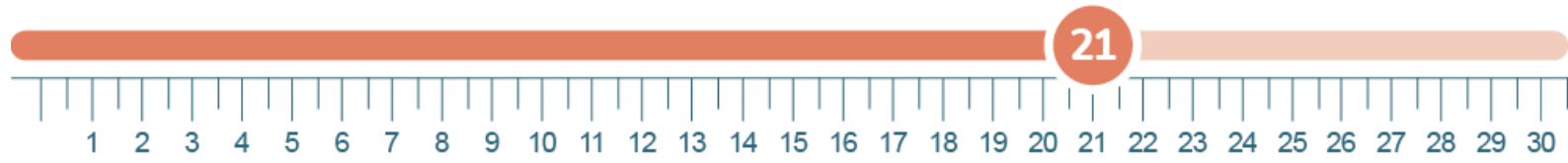

RECOVERY

Barbic et al., (2016) used the ruler to measure where an individual was in their recovery journey at a given point in time. The ruler is a familiar way of measuring. As scores get higher, so does

personal ability, item difficulty, and recovery (Barbic \& Rennie, 2016). Clients rated from 0-5 (0 being "None of the time" and 5 being "All the time") how often they felt the corresponding statement within the last week. The score of all 30 items was added together and divided by four. That number was then found on the recovery ruler.

The location where the person scores on the ruler can then be used to inform client care (Barbic \& Rennie, 2016). The practitioner should take the measurement on the ruler that the individual scored and refer back to that number's corresponding statement within the assessment. This can serve as a starting place for conversation, assessment, and goal setting with the client. Lower numbers are indicative of needing assistance with feeling hopeful and safe; middle numbers are indicative of needing assistance with self-esteem and stress management-related statements; and higher scores are indicative of needing assistance with contributing to the community, leisure, and peace of mind (Barbic \& Rennie, 2016).

\section{Part II: Program Development}


SENSORY MODULATION TO MANAGE CHRONIC PAIN AND SUBSTANCE USE

Due to limited time, the total implementation and evaluation of the research-informed sensory-based OT group were not completed. A total of five OT group sessions were implemented at the capstone setting with a focus on sensory modulation, crisis planning and intervention, and stress management. Future steps for the OT group would be to implement weekly group sessions, including sessions focused solely on chronic pain management and community mobility with pacing. Appendix F includes the five-week manual that was implemented along with an introduction pain management group that was not implemented.

\section{Program Assessment and Future Implications}

Limited time prevented a formal program assessment from being performed. If the OT groups were to continue at the recovery center a focus group would be conducted after the final group session. This focus group would last for 30 minutes and would have all the group participants participate. The following questions would be posed to the group for discussion.

1.) What is the main take aways from this group? What did you learn?

2.) Have you implemented any of the discussed strategies into your own daily routine? If so, which ones?

3.) What are you still currently struggling with in regard to pain and utilizing sensory modulation in your daily routine?

4.) What suggestions do you have to be relayed to the clinical director in regard to your sensory needs while at the recovery center? 
SENSORY MODULATION TO MANAGE CHRONIC PAIN AND SUBSTANCE USE

Answers would be recorded, coded, themes identified and then presented at the clinical meeting. Results would inform future OT groups, the need for OT groups, topics that clients want assistance with, and how the clinical team and adapt the environment to be sensory informed.

In conclusion, this descriptive study examined individuals sensory processing preferences, pain, and recovery. The key take aways for the initial results were $90 \%$ of study participants self-reported atypical sensory processing patterns in at least one quadrant, with the largest majority of participants having high scores of sensory sensitivity, sensory avoiding, and low registration. Participants were on average experiencing mild to severe pain (2.2-6.0/10) within the past 24 hours. Current treatment for pain was primarily medication, which was either prescribed $(29 \%)$ or over the counter $(22 \%)$ or nothing $(21 \%)$. Study participants on average scored 21/30 on the PROM, which may be indicative of needing assistance with managing stress.

\section{Limitations}

There were various limitations to this study that should be taken into consideration. The first was a small sample size $(n=10)$ taken from just one recovery center in a single geographical location. The restrictions related to the COVID-19 pandemic limited the researcher's access to potential participants and may have limited the number of individuals with chronic pain or other health concerns who chose to enter an in-person substance use treatment center. Therefore, these results are not generalizable to a larger population but could be used to inform future larger study designs.

Second, all assessments were self-reported and individuals self-identified as having chronic pain and being in recovery from substance use. No formal diagnostic criteria were used, and the type of chronic pain and substance use were not specified. This information would be 
SENSORY MODULATION TO MANAGE CHRONIC PAIN AND SUBSTANCE USE

valuable in future studies to determine if type of chronic pain or substance used correlated with certain sensory processing patterns, pain severity, pain interferences, and PROM outcomes.

The third limitation to this study was it did not include any assessment of mental health, trauma, quality of life, occupational participation, or other health concerns. Chronic pain is not the only co-morbidity within this population and may individuals have multiple co-morbidities that are impacting function. Future studies determining the differences in sensory processing preferences among various comorbid diagnoses would be useful creating treatment models and interventions to better meet the client's needs and support their long-term recovery.

The final limitation of this study was that gender differences in sensory processing preferences were not explored. Brown and Knowles (2021) determined that the sensory processing preferences of women in recovery for substance use were higher with a strong effect size in sensation avoiding, sensation sensitivity, and lower registration compared to the normative sample. Women may have different physiological, neurological, and hormonal reasons for using substances, and further investigation is needed (Brown \& Knowles, 2021).

\section{Chapter 5: Discussion and Implications for OT Practice}

While the COVID-19 pandemic caused limitations to the descriptive research and the capstone experience, resulting knowledge can inform future OT practice so therapists will better understand and meet the needs of individuals with chronic pain in recovery for substance use. This chapter will include a discussion on chronic pain and substance use, the Personal Recovery Outcome Measure, Sensory Assessments, and trauma-informed practice as well as implications for occupational therapy practice.

\section{Discussion}


SENSORY MODULATION TO MANAGE CHRONIC PAIN AND SUBSTANCE USE

\section{Chronic Pain and Substance Use}

The literature led the student researcher to believe there was a large number of individuals in recovery for substance use who have unmanaged chronic pain (American Occupational Therapy Association [AOTA], 2018; CDC, 2019; Cohen \& Hooten, 2019; Dahlhamer et al., 2018; Majority and Minority Committees' Staffs, n.d.; Ilgen et al., 2020). The initiative to better assess chronic pain within substance use recovery settings is an effort to decrease the number of opioids prescribed to individuals with chronic pain to hopefully decrease the impacts of the opioid epidemic (American Occupational Therapy Association [AOTA], 2018; CDC, 2019; Cohen \& Hooten, 2019; Majority and Minority Committees' Staffs, n.d.). In the researchers experience there were few clients who identified as having chronic pain and were in recovery for substance use. Those who did have chronic pain did not report their pain to have a profound impact on their functioning. These identified current attitudes pertaining chronic pain and its impact on recovery may inform further future qualitative research on the impact of health concerns, outside of sobriety, in individuals in recovery for substance use.

The particular substance use recovery center the study was conducted offers CBT, DBT, biofeedback, EMDR, individual counseling, and pharmacological services. The services offered may have impacted the number of patients with chronic pain as it is not a service they offer. Therefore, sensory informed pain management OT group may not be the best fit for this setting. Those with chronic pain were either receiving pharmacological interventions for their pain or nothings at all. This could be indicative of a potential gap in patient care and an opportunity for occupational therapy to be a non-pharmacological treatment for chronic pain within this setting (AOTA, 2018; Ilgen et al., 2020). Future studies including participants utilizing chronic pain 
SENSORY MODULATION TO MANAGE CHRONIC PAIN AND SUBSTANCE USE

services should be done to gain a deeper understanding of the populations needs and how treatment can support those needs.

\section{The Personal Recovery Outcome Measure}

The Personal Recovery Outcome Measure was the occupational therapy informed assessment too used to inform participants recovery journey in the descriptive study. The average score in the descriptive study was 21 , and the corresponding question stated: "I can manage stress" (Barbic et 1., 2016). These results may enlighten the need for stress management programs that promote health and wellbeing within this population. Occupational therapy can assist clients in utilizing stress reduction techniques, building routines, improving boundary setting and interpersonal skills to promote better occupational balance (Affleck et al., 1984; AOTA, 2020). This assessment shows promising potential as a standardized tool to assess the clients progress throughout treatment. It has relative ease to administer and does not take a significant amount of time for the client to complete. It also serves as a starting point for intervention with the scores corresponding questions to guide conversation and goal setting. The results of the descriptive study aligned with the consensus of the OT group members as stress management being an area, they wanted to improve their skills in. In addition to being used as a tool to guide practice it also can be used to demonstrate the recovery is not linear and ones PROM score is likely to move both up and down on the ruler throughout recovery. A place for future research could be to assess how a client's readiness to change correlates with their PROM scores throughout treatment and at different levels of care (Barbic \& Rennie, 2016).

\section{Sensory Assessments}


SENSORY MODULATION TO MANAGE CHRONIC PAIN AND SUBSTANCE USE

The study sample was small $(n=10)$, and none of the data can be generalized to a larger population but can serve as initial findings on sensation-specific threshold, response, and sensory patterns. Future studies should investigate any potential trends in responses to specific sensations in order to inform occupational therapy practice. In contrast to Dunn \& Browns (2002) Adolescent and Adult Sensory Profile used to determine individuals' sensory profiles the OT group members completed Tina Champagnes (2017) "Sensory Modulation Screening Tool”. This tool was used because of its ease to complete and score as well as asking open ended questions pertaining to individual sensory stimuli, seasonal and sleep patterns, caffeine pain, mind-body connectedness, learning styles and handedness, participation in roles and daily activities, and trauma and self-injury history (Champagne, 2017). This provides the therapist with subjective, client specific information, that helps gain a better picture of the client and their functioning.

While no formal evaluation of the sensory based OT group was done observations can still serve as insight into the value of the group. Group members were able to verbally explain constructs of sensory modulation to their peers, show insight into their own sensory processing preferences from the "Sensory Modulation Screening Tool" and how it related to their routines and habits. The group routinely identified and initiated the use of effective sensory based coping strategies to self-regulate. One group member was able to communicate his sensory needs to a sober living staff member and advocate for changes to his living environment to help him with self-regulation after being in a clinical setting all day. Discussing the individualized sensory processing preferences not only empowers clients it also builds rapport between the client and therapist.

\section{Trauma Informed Care}


SENSORY MODULATION TO MANAGE CHRONIC PAIN AND SUBSTANCE USE

There are many studies linking adverse childhood experiences (ACEs) with both substance use and chronic pain (Choi et al., 2017; Dube et al, 2003; Felitti et al., 1998; Schrepf et al., 2018; Stickley et al., 2015). It is therefore critical to consider the effects of these traumatic experiences on clients and how they may be impacting their occupational performance. The Power Threat Meaning Framework (PTMF) is an alternative to the more traditional medical models for psychiatric care that may be useful when providing OT services to clients with trauma histories. This model reframes the "symptoms" of mental health diagnoses as threat responses or learned survival responses. The PTMF is summarized in the following four questions, "What has happened to you? (How is power operating in your life?), how did it affect you? (What kind of threats does this pose?), what sense did you make of it? (What is the meaning of these situations and experiences to you?), and what did you have to do to survive? (What kinds of threat response are you using?)" (The British Psychological Society, n.d.' para. 11). This takes any blame off the client and attempts to understand client's behavior instead of extinguishing it. There is also extensive research done on the neurophysiology and neurobiology of trauma and how that impacts the brains functioning and reaction to sensory stimulus (van der Kolk, 2015). These trauma informed frameworks should guide OTs in understanding some of their clients' barriers to occupational engagement and encourage them to utilize sensory strategies to help modulate their nervous system as well as guiding documentation and clinical meeting language to be trauma informed.

Individuals with trauma histories have been found to have "atypical SP patterns, mainly expressed in sensory sensitivity, sensory avoidance and low registration as compared to the AASP normal range values" (Engel-Yeger et al., 2013; Engel-Yeger et al., 2015; Champagne, 2011; Serafini et al., 2016 as cited in McGreevy \& Boland, 2020, p.44). These sensory 
SENSORY MODULATION TO MANAGE CHRONIC PAIN AND SUBSTANCE USE

processing patterns match the ones found in the descriptive study of individuals with chronic pain and substance use. Therefore, sensory-based interventions such as utilizing a sensory room, creating a sensory kit, or incorporating sensory tools such as weighted blankets, tactical equipment, or aromatherapy into everyday occupations should be incorporated to into the treatment plans and mental health clinical spaces (McGreevy \& Boland, 2020). The implementation of sensory modulation techniques in individuals with co-occurring chronic pain and substance is a trauma-informed, recovery-oriented, individualized approach to care that can empower clients and enhance overall wellbeing and long-term sobriety (Brown 2002; Kelly et al., 2020).

\section{Implications for OT Practice}

Research surrounding the unique sensory processing profiles of those with mental health diagnoses and behavioral patterns is rapidly emerging. Researchers and clinicians are finding commonalities in these patterns amongst various commonly co-occurring diagnoses. Sensory sensitivity, sensation avoiding, and low registration are increasingly common sensory processing patterns found in individuals with substance use, trauma, and mental health diagnoses (Brown et al., 2020; Brown \& Knowles 2021; Kelly et al., 2021; McGreevy \& Boland, 2020). Defining these sensory processing patterns may encourage occupational therapy practitioners to consider the interventions and environmental adaptations that fits these patterns in settings that serve these populations. OTs also can educate housing and clinical staff about sensory modulation techniques and the potential sensory specific needs of some of the clients under their care.

However, it is important to keep in mind as occupational therapy practitioners that there is no "one size fits all" approach to therapy, especially when it comes to sensory modulation. Each individual is going to have a unique set of sensory preferences, thresholds, and responses. 
SENSORY MODULATION TO MANAGE CHRONIC PAIN AND SUBSTANCE USE

Therefore, clinicians should be proceeded with caution when recommending sensory strategies to large groups. An example of this is the emerging popularity of Mindfulness and its recommendation as a tool for managing chronic pain (Goodman et al., 2019; Hardision \& Roll, 2016; Merkes, 2010). This intervention modality may not fit individuals who seek out proprioceptive or vestibular input as a calming strategy (Hebert, 2015). The same can be said about environmental adaptations. OTs should educate clients and staff and advocate for the individualization of sensory based adaptations. This way both staff and clients will understand what sensory modifications they may need and why. Additionally, OTs should be looking for opportunities to support clients' sensory needs during occupation instead as primarily as a preparatory activity for occupation. This means integrating sensory modulation strategies into ADLS and IADLS to support client engagement. Building rapport with clients is essential when utilizing sensory modulation. According to Champagne (2017) "the most important sensory modulation tool any practitioner has is the therapeutic use of self' (p.102). Being responsive, using empathic listening, and establishing trust are fundamental sensory modulation approaches help to establish client feelings of safety and security which is particularly important when working with populations that may have high rates of trauma histories (Champagne, 2017, p. 102).

Finally, occupational therapists need to assess all aspects of a person's life that may be interfering with occupational participation. Which includes areas surrounding pain and sensory processing. By integrating a chronic pain screening and sensory profile into common substance use rehabilitation practice interdisciplinary teams can work together to establish treatment protocol for those with chronic pain and substance use occurring comorbidly. 
SENSORY MODULATION TO MANAGE CHRONIC PAIN AND SUBSTANCE USE

\section{Conclusion}

One of the main aims of this capstone project is to advocate for OT's role within a substance use recovery setting, specifically working with pain. A small descriptive study was conducted on the sensory processing preferences, pain, and recovery of those with chronic pain and substance use. A majority of the study's sample had atypical sensory processing preferences, mild to moderate pain, were not receiving nonpharmacological treatments for their pain, and had difficulty managing stress. These findings informed a six-week sensory based occupational therapy group was implemented. Clients learned about their own sensory processing preferences, participated in a sensory lab, created their own sensory diets, identified and implemented sensory modulation techniques into their daily lives, created crisis intervention plans, and applied strategies learned to aid in stress management. While chronic pain was not specifically addressed in the OT group, the sensory strategies, crisis prevention, and stress management skills are essential components to behavioral pain management and could be addressed in group or individual OT sessions.

By advocating to implement routine OT assessments for every individual who enters into a substance use recovery setting will hopefully decrease the number of clients with unmanaged and untreated pain, improve self-management and coping skills that will improve long term recovery and sobriety outcomes. By involving occupational therapy and sensory techniques from the start clients will learn how their body is processing sensory information and be an empowering first step in the recovery process (Brown, 2002). Sensory modulation has the potential to serve as the ultimate tool in recovery. Informing individuals on how their nervous system interprets and responses the world around them around them will aid in transitioning clients from feeling dominated and hopeless in their environments to a position of mastery and 
SENSORY MODULATION TO MANAGE CHRONIC PAIN AND SUBSTANCE USE

self-management. These client-centered, trauma informed, recovery-oriented methods to selfmanagement can serve as valuable tools across disciplines, lifespans, and co-morbidities. 
SENSORY MODULATION TO MANAGE CHRONIC PAIN AND SUBSTANCE USE

\section{References}

Affleck, A., Bianchi, E., Cleckley, M., Donaldson, K., McCormack, G., \& Polon, J. (1984).

Stress management as a component of occupational therapy in acute care settings. Occupational therapy in health care, 1(3), 17-41.

https://doi.org/10.1080/J003v01n03_04

Alwawi, D. \& Dean, E. (2018). Exploring sensory processing patterns and their relationship with fatigue perception and motor changes in people after stroke. American Journal of Occupational Therapy, 72. https://doi.org/10.5014/ajot.2018.72S1-PO4008

American Occupational Therapy Association [AOTA]. (2014). Occupational therapy and pain rehabilitation [FactSheet]. AOTA.

https://www.aota.org/ /media/Corporate/Files/AboutOT/Professionals/WhatIsOT/HW/Fa cts/Pain\%20Rehabilitation\%20fact\%20sheet.pdf

American Occupational Therapy Association [AOTA]. (2016). Occupational therapy's role in mental health recovery. https://www.aota.org/About-Occupational-

Therapy/Professionals/MH/mental-health-recovery.aspx

American Occupational Therapy Association [AOTA]. (2017). Occupational therapy using a sensory integration-based approach with adult populations [Fact Sheet]. AOTA. https://www.aota.org/About-Occupational-Therapy/Professionals/HW/Using-SensoryIntegration-Based-Approach-With-Adult-Populations.aspx

American Occupational Therapy Association [AOTA]. (2018). Occupational therapy included in new law to address opioid epidemic. https://www.aota.org/Advocacy$\underline{\text { Policy/Congressional-Affairs/Legislative-Issues-Update/2018/occupational-therapy- }}$ included-new-law-opioid-epidimic-pain-management.aspx 
SENSORY MODULATION TO MANAGE CHRONIC PAIN AND SUBSTANCE USE

American Occupational Therapy Association. (2020). Occupational therapy practice framework: Domain and process (4th ed.). American Journal of Occupational Therapy, 74(Suppl. 2), 7412410010. https://doi. org/10.5014/ajot.2020.74S2001

American Psychological Association. (2020). Publication manual of the American psychological association: The official guide to APA style (7th ed). American Psychological Association.

Amorelli, C. R. (2016). Psychosocial occupational therapy interventions for substance-use disorders: A narrative review. Occupational Therapy in Mental Health, 32(2), 167-184. https://doi.org/10.1080/0164212X.2015.1134293

Amris, K., Bülow, C. von, Christensen, R., Bandak, E., Rasmussen, M. U., Danneskiold-Samsøe, B., \& Wæhrens, E. E. (2019). The benefit of adding a physiotherapy or occupational therapy intervention programme to a standardized group-based interdisciplinary rehabilitation programme for patients with chronic widespread pain: A randomized active-controlled non-blinded trial. Clinical Rehabilitation, 33(8), 1367-1381. https://doi.org/10.1177/0269215519843986

Andronis, L., Kinghorn, P., Qiao, S., Whitehurst, D. G. T., Durrell, S., \& McLeod, H. (2017). Cost-effectiveness of non-invasive and non-pharmacological interventions for low back pain: a systematic literature review. Applied Health Economics and Health Policy, 15(2), 173. DOI:10.1007/s40258-016-0268-8

Bailliard, A. L., \& Whigham, S. C. (2017). Centennial topics-Linking neuroscience, function, and intervention: A scoping review of sensory processing and mental illness. American Journal of Occupational Therapy, 71, 7105100040.

https://doi.org/10.5014/ajot.2017.024497 
SENSORY MODULATION TO MANAGE CHRONIC PAIN AND SUBSTANCE USE

Bar-Shalita, T. Asayag, N., Bonneh, Y., \& Parush, S. (2019). Sensory modulation disorder (SMD) and pain in substance-use disorder (SUD). American Journal of Occupational Therapy, 73(4). https://doi.org/10.5014/ajot.2019.73S1-RP103B

Barbic, S. \& Rennie, M. (2016). A new way of measuring recovery: Personal recovery outcome measure [PowerPoint slides]. Mental Health Commission of Canada. https://www.mentalhealthcommission.ca/sites/default/files/201612/recovery_webinar_nov_2016.pdf

Barbic, S., Kidd, S. A., Backman, C., Honer, W., Irving, S., \& McKenzie, K. (2016). Development and testing of the Personal Recovery Outcome Measure (PROM) for people with mental illness. Paper presented at the Canadian Association of Occupational Therapists, Banff, Canada.

Braccinao, A. (2008). Physical agent modalities: Theory and application for the occupational therapist. SLACK Incorporated.

Breeden, K., \& Rowe, N. (2017). A Biopsychosocial approach for addressing chronic pain in everyday occupational therapy practice. OT Practice, CE-1-CE-8. https://www.proquest.com/trade-journals/biopsychosocial-approach-addressing-chronicpain/docview/1923231667/se-2?accountid=158603

Brown, C. (2002) What is the best environment for me? A Sensory processing perspective. Occupational Therapy in Mental Health, 17(4), 115-125, DOI: 10.1300/J004v17n03_0

Brown, C. \& Knowles, R. (2021). Sensory processing preferences for people recovering from substance use. Presented at AOTA Inspire Conference.

Brown, C., \& Dunn, W. (2002). Sensory profile user's manual. Psychological Corporation. 
SENSORY MODULATION TO MANAGE CHRONIC PAIN AND SUBSTANCE USE

Brown, C., Cromwell, R. L., Filion, D., Dunn, W., \& Tollefson, N. (2002). Sensory processing in schizophrenia: Missing and avoiding information. Schizophrenia Research, 55(1-2), 187195. https://doi.org/10.1016/S0920-9964(01)00255-9

Brown, C., Karim, R., \& Steuter, M. (2020). Retrospective analysis of studies examining sensory processing preferences in people with a psychiatric condition. The American Journal of Occupational Therapy, 74(4), 7404205130p1-7404205130p11. https://doi.org/10.5014/ajot.2020.038463

Brown, C., Stoffel, V., Muñoz, J. (2019). Occupational therapy in mental health: A vision for participation. Chapter 1 (2nd ed.). F.A. Davis Company.

Centers for Disease Control and Prevention. (2016). Nonopioid treatment for chronic pain. U.S. Department of Health and Human Services. https://www.cdc.gov/drugoverdose/pdf/nonopioid_treatments-a.pdf

Centers for Disease Control and Prevention. (2019). Overdose death maps. https://www.cdc.gov/drugoverdose/data/prescribing/overdose-death-maps.html

Champagne, T. (2017). Sensory modulation \& environment: Essential elements of occupation ( $3^{\text {rd }}$ ed.) Pearson Australia Group.

Choi, N. G., DiNitto, D. M., Marti, C. N., \& Choi, B. Y. (2017). Association of adverse childhood experiences with lifetime mental and substance use disorders among men and women aged 50+ years. International Psychogeriatrics, 29(3), 359-372.

doi:10.1017/S1041610216001800

Cleeland, C. (1991). The brief pain inventory user guide. M.D. Anderson Cancer Center. 
SENSORY MODULATION TO MANAGE CHRONIC PAIN AND SUBSTANCE USE

Cleeland, C. S., \& Ryan, K. M. (1994). Pain assessment: Global use of the Brief Pain Inventory. Annals, Academy of Medicine, Singapore, 23(2), 129-138. https://pubmed.ncbi.nlm.nih.gov/8080219/

Cohen, S. P., \& Hooten, W. M. (2019). Balancing the risks and benefits of opioid therapy: The pill and the pendulum. Mayo Clinic Proceedings, 94(12), 2385-2389. https://doi.org/10.1016/j.mayocp.2019.10.006

Cole, M. B., \& Tufano, R. (2008). Applied theories in occupational therapy: A practical approach. Thorofare, NJ: SLACK.

Costa, D. (2017, January 23). Occupational therapy's role in countering opioid addiction. OT Practice, 22,(1), 13-16. https://www.proquest.com/trade-journals/occupational-therapysrole-countering-opioid/docview/1892742515/se-2 ?accountid=158603

Dahlhamer, J. (2018). Prevalence of Chronic Pain and High-Impact Chronic Pain Among Adults-United States, 2016. Morbidity and Mortality Weekly Report, 67. https://doi.org/10.15585/mmwr.mm6736a2

De Ruddere, L., \& Craig, K. D. (2016). Understanding stigma and chronic pain: A-state-of-theart review. Pain, 157(8), 1607-1610. https://doi.org/10.1097/j.pain.0000000000000512

Dube, S. R., Felitti, V. J., Dong, M., Chapman, D. P., Giles, W. H., Anda, R. F. (2003). Childhood abuse, neglect, and household dysfunction and the risk of illicit drug use: the adverse childhood experiences study. Pediatrics 111(3), 564-572. https://www.proquest.com/trade-journals/occupational-therapys-role-counteringopioid/docview/1892742515/se-2?accountid=158603 
SENSORY MODULATION TO MANAGE CHRONIC PAIN AND SUBSTANCE USE

Dunn, W. (1997). The impact of sensory processing abilities on the daily lives of young children and their families: A conceptual model. Infants and Young Children, 9(4), 2325. https://doi.org/10.1097/00001163-199704000-00005

Dunn, W. (2001). The sensations of everyday life: Theoretical, conceptual and pragmatic considerations. American Journal of Occupational Therapy, 55, 608-620.

Engel-Yeger, B., Palgy-Levin, D. and Lev-Wiesel, R. (2013). The sensory profile of people with post- traumatic stress symptoms. Occupational Therapy in Mental Health, 29(3), 266278. DOI: $\underline{10.1080 / 0164212 X .2013 .819466}$

Engel-Yeger, B., Palgy-Levin, D. and Lev-Wiesel, R. (2015). Predicting fears of intimacy among individuals with post-traumatic stress symptoms by their sensory profile. British Journal of Occupational Therapy, 78(1), 51-57. DOI: 10.1177/0308022614557628

Eyler, E. C. H. (2013). Chronic and acute pain and pain management for patients in methadone maintenance treatment. American Journal on Addictions, 22(1), 75-83. DOI: 10.1111/j.1521-0391.2013.00308.x

Felitti, V. J., Anda, R. F., Nordenberg, D., Williamson, D. F., Spitz, A. M., Edwards, V., ... \& Marks, J. S. (1998). Relationship of childhood abuse and household dysfunction to many of the leading causes of death in adults: The Adverse Childhood Experiences (ACE) Study. American Journal of Preventive Medicine, 14(4), 245-258. doi:10.1016/S07493797(98)00017-8

Fisher, G. S., Emerson, L., Firpo, C., Ptak, J., Wonn, J., \& Bartolacci, G. (2007). Chronic pain and occupation: An exploration of the lived experience. American Journal of Occupational Therapy, 61(3), 290-302. https://doi.org/10.5014/ajot.61.3.290 
SENSORY MODULATION TO MANAGE CHRONIC PAIN AND SUBSTANCE USE

Gaskin, D. \& Richard, P. (2012). The economic costs of pain in the united states. The Journal of Pain, 13(8), 715 DOI: 10.1016/j.jpain.2012.03.009

Gaskin, D., \& Richard, P. (2012). The economic costs of pain in the United States. The Journal of Pain: Official Journal of the American Pain Society, 13(8), 715-24. https://doi.org/10.1016/j.jpain.2012.03.009

Genova, A., Dix, O., Thakur, M., \& Sangha, P. S. (2020). Chronic non-cancer pain management and addiction: A review. Cureus, 12(2), e6963. https://doi.org/10.7759/cureus.6963

Ghanizadeh A. (2011). Sensory processing problems in children with ADHD, a systematic review. Psychiatry investigation, 8(2), 89-94. https://doi.org/10.4306/pi.2011.8.2.89

Goodman, V., Wardrope, B., Myers, S., Cohen, S., McCorquodale, L., \& Kinsella, E. A. (2019). Mindfulness and human occupation: A scoping review. Scandinavian Journal of Occupational Therapy, 26(3), 157-170. https://doi.org/10.1080/11038128.2018.1483422

Gray J. M. (1998). Putting occupation into practice: occupation as ends, occupation as means. The American Journal of Occupational Therapy, 52(5), 354-364. https://doi.org/10.5014/ajot.52.5.354

Gutman, S. (2006) Why addiction has a chronic, relapsing course. The neurobiology of addiction. Occupational Therapy in Mental Health, 22(2), 1-29.

DOI: $\underline{10.1300 / J 004 v 22 n 02 \_01}$

Guy, L., Mckinstry, C., \& Bruce, C. (2019). Effectiveness of pacing as a learned strategy for people with chronic pain: A systematic review. The American Journal of Occupational Therapy, 73(3). DOI: 10.5014/ajot.2019.028555

Hansen, G. R., \& Streltzer, J. (2005). The psychology of pain. Emergency Medicine Clinics of North America, 23, 339-348. https://doi.org/10.1016/j. emc.2004.12.005 
SENSORY MODULATION TO MANAGE CHRONIC PAIN AND SUBSTANCE USE

Hardison, M. E., \& Roll, S. C. (2016). Mindfulness Interventions in Physical Rehabilitation: A scoping review. The American Journal of Occupational Therapy, 70(3), 7003290030p17003290030p9. https://doi.org/10.5014/ajot.2016.018069

Hebert, K. (2015). The feeling of mindfulness: How sensory processing styles influence mindful awareness of daily experiences. American Journal of Occupational Therapy, 69(1):6911505208. https://doi.org/10.5014/ajot.2015.69S1-PO7095

Hill, W., \& Macartney, M. (2019). The role of occupational therapy in enabling people with chronic pain to return to work or education. Anesthesia \& Intensive Care Medicine. https://doi.org/10.1016/j.mpaic.2019.05.007

Hser, Y.-I., Mooney, L. J., Saxon, A. J., Miotto, K., Bell, D. S., \& Huang, D. (2017). Chronic pain among patients with opioid use disorder: Results from electronic health records data. Journal of Substance Abuse Treatment, 77, 26-30. https://doi.org/10.1016/j.jsat.2017.03.006

Ilgen, M. A., Coughlin, L. N., Bohnert, A., Chermack, S., Price, A., Kim, H. M., Jannausch, M., \& Blow, F. C. (2020). Efficacy of a psychosocial pain management intervention for men and women with substance use disorders and chronic pain: A randomized clinical trial. JAMA Psychiatry. https://doi.org/10.1001/jamapsychiatry.2020.2369

Institute of Chronic Pain. (2019). Trauma. https://www.instituteforchronicpain.org/understanding-chronicpain/complications/trauma

Institute of Medicine. (2011). Relieving pain in America: A blueprint for transforming prevention, care, education, and research. http://dx.doi.org/ crossref.org/10.17226/13172 
SENSORY MODULATION TO MANAGE CHRONIC PAIN AND SUBSTANCE USE

Jehl, E., Solger, E., Weaver, C., Oliveira, D., Kornblau, B., Mbiza, S., \& Alexander, A. (2017). Chronic pain patients' perceptions of treatments that decrease pain and increase function. American Journal of Occupational Therapy, 71, 33-33. https://doi.org/10.5014/ajot.2017.71S1-PO4160

Kelly, J., Meredith, P., Taylor, M., Morphett, A. \& Wilson, H. (2021): Substances and your senses: The sensory patterns of young people within an alcohol and drug treatment service. Substance Abuse, 42. https://doi.org/10.1080/08897077.2021.1901177

Khoury, L., Tang, Y. L., Bradley, B., Cubells, J. F., \& Ressler, K. J. (2010). Substance use, childhood traumatic experience, and posttraumatic stress disorder in an urban civilian population. Depression and Anxiety, 27(12), 1077-1086.

https://doi.org/10.1002/da.20751

Kimball, J. G., Lynch, K. M., Stewart, K. C., Williams, N. E., Thomas, M. A., \& Atwood, K. D. (2007). Using salivary cortisol to measure the effects of a Wilbarger protocol-based procedure on sympathetic arousal: A pilot study. American Journal of Occupational Therapy, 61, 406-413.

Lagueux, É., Dépelteau, A., \& Masse, J. (2018). Occupational therapy’s unique contribution to chronic pain management: A scoping review. Pain Research and Management, 1-19. https://doi.org/10.1155/2018/5378451

Lee, M., Silverman, S. M., Hansen, H., Patel, V. B., \& Manchikanti, L. (2011). A comprehensive review of opioid-induced hyperalgesia. Pain Physician, 14(2), 145-161. http://search.ebscohost.com/login.aspx?direct=true\&db=ccm\&AN=104848734\&site=eds -live. 
SENSORY MODULATION TO MANAGE CHRONIC PAIN AND SUBSTANCE USE

Lin, L. A., Bohnert, A. S. B., Jannausch, M., Goesling, J., \& Ilgen, M. A. (2017). Use of nonpharmacological strategies for pain relief in addiction treatment patients with chronic pain. American Journal on Addictions, 26(6), 564-567. DOI: 10.1111/ajad.12600

López-Martínez, A. E., Reyes-Pérez, Á., Serrano-Ibáñez, E. R., Esteve, R., \& Ramírez-Maestre, C. (2019). Chronic pain, posttraumatic stress disorder, and opioid intake: A systematic review. World Journal of Clinical Cases, 7(24), 4254-4269. https://doi.org/10.12998/wjcc.v7.i24.4254

Majority and Minority Committees'Staffs. (n.d.). H.R. 6 SUPPORT for patients and communities act. https://www.asam.org/docs/default-source/advocacy/hr6_09-28-18final-opioid-sec-by-sec_bipart-bicam.pdf?sfvrsn=49d048c2_2

McCombie, R. P., \& Stirling, J. L. (2018). Opioid substance abuse among occupational therapy clients. Occupational Therapy in Mental Health, 34(1), 49-60. https://doi.org/10.1080/0164212X.2017.1360827

McGreevy, S. and Boland, P. (2020). Sensory-based interventions with adult and adolescent trauma survivors: An integrative review of the occupational therapy literature. Irish Journal of Occupational Therapy, 48(1), 31-54. https://doi.org/10.1108/IJOT-10-2019$\underline{0014}$

MD Anderson. (n.d.). The brief pain inventory. The University of Texas MD Anderson Center. https://www.mdanderson.org/research/departments-labs-institutes/departmentsdivisions/symptom-research/symptom-assessment-tools/brief-pain-inventory.html Meredith, P. J., Rappel, G., Strong, J., \& Bailey, K. J. (2015). Sensory sensitivity and strategies for coping with pain. American Journal of Occupational Therapy, 69 (4). http://dx.doi.org/10.5014/ajot.2015.014621। 
SENSORY MODULATION TO MANAGE CHRONIC PAIN AND SUBSTANCE USE

Merkes M. (2010). Mindfulness-based stress reduction for people with chronic diseases. Australian journal of primary health, 16(3), 200-210. https://doi.org/10.1071/PY09063

Miller, L. J., Reisman, J. E., McIntosh, D.N., Simon, J. (2001). An ecological model of sensory modulation. In S. Smith Roley, E. I. Blanche, \& R. C. Schaaf(Eds.). Understanding the nature of sensory integration with diverse populations. Therapy Skill Builders.

Miserandion, C. (2003). The spoon theory [PDF]. You Don't Look Sick. https://cdn.totalcomputersusa.com/butyoudontlooksick.com/uploads/2010/02/BYDLSTheSpoonTheory.pdf

Moore, Karen. (2014). Sensory connection program curriculum for self-regulation. Therapro.

National Institute on Drug Abuse. (2020). Opioid overdose crisis. National Institute of Health. https://www.drugabuse.gov/drug-topics/opioids/opioid-overdose-crisis

Opp, R. (n.d.). Recovery with purpose: Occupational therapy and drug and alcohol abuse. AOTA. https://www.aota.org/About-OccupationalTherapy/Professionals/MH/Articles/RecoveryWithPurpose.aspx

Oslund, S., Robinson, R. C., Clark, T. C., Garofalo, J. P., Behnk, P., Walker, B., Walker, K. E., Gatchel, R. J., Mahaney, M., \& Noe, C. E. (2009). Long-term effectiveness of a comprehensive pain management program: strengthening the case for interdisciplinary care. Proceedings (Baylor University. Medical Center), 22(3), 211-214. https://doi.org/10.1080/08998280.2009.11928516

Prater, C. D., Zylstra, R. G., \& Miller, K. E. (2002). Successful pain management for the recovering addicted patient. Primary Care Companion to The Journal of Clinical Psychiatry, 4(4), 125-131. https://doi.org/10.4088/pcc.v04n0402 
SENSORY MODULATION TO MANAGE CHRONIC PAIN AND SUBSTANCE USE

Robinson, K., Kennedy, N., \& Harmon, D. (2011). Is occupational therapy adequately meeting the needs of people with chronic pain? American Journal of Occupational Therapy, 65(1), 106-113. https://doi.org/10.5014/ajot.2011.09160

Rojo-Mota, G., Pedrero-Pérez, E. J., \& Huertas-Hoyas, E. (2017). Systematic review of occupational therapy in the treatment of addiction: Models, practice, and qualitative and quantitative research. American Journal of Occupational Therapy, 71(5), 7105100030p17105100030p11. https://doi.org/10.5014/ajot.2017.022061

S., Lakshmanan. (2014). Occupational therapy structured activities for substance use recovery. WFOT Bulletin, 70(1), 30-31. DOI: 10.1179/otb.2014.70.1.008

Saunders, S., Nedelec, B., \& MacEachen, E. (2018). Work remains meaningful despite time out of the workplace and chronic pain. Disability and Rehabilitation: An International, Multidisciplinary Journal, 40(18), 2144-2151. https://doi.org/10.1080/09638288.2017.1327986

Schmitz, J. M. (2005). The interface between impulse-control disorders and addictions: Are pleasure pathway responses shared neurobiological substrates? Sexual Addiction \& Compulsivity, 12(2), 149-168. https://doi.org/10.1080/10720160500203641

Schrepf, A., Naliboff, B., Williams, D. A., Stephens-Shields, A. J., Landis, J. R., Gupta, A., Mayer, E., Rodriguez, L. V., Lai, H., Luo, Y., Bradley, C., Kreder, K., \& Lutgendorf, S. K. (2018). Adverse childhood experiences and symptoms of urologic chronic pelvic pain syndrome: A multidisciplinary approach to the study of chronic pelvic pain research network study. Annals of Behavioral Medicine, 52(10), 865-877. https://doi.org/10.1093/abm/kax060 
SENSORY MODULATION TO MANAGE CHRONIC PAIN AND SUBSTANCE USE

Serafini, G., Gonda, X., Pompili, M., Rihmer, Z., Amore, M. and Engel-Yeger, B. (2016). The relationship between sensory processing patterns, alexithymia, traumatic childhood experiences, and quality of life among patients with unipolar and bipolar disorders. Child Abuse and Neglect, 62, 9-50. https://doi.org/10.1016/j.chiabu.2016.09.013

Simon, A. U., \& Collins, C. E. R. (2017). Lifestyle Redesign® for chronic pain management: A retrospective clinical efficacy study. American Journal of Occupational Therapy, 71(4), 7104190040p1-7104190040p7. https://doi.org/10.5014/ajot.2017.025502

Sletten, C. D., Kurklinsky, S., Chinburapa, V., \& Ghazi, S. (2015). Economic analysis of a comprehensive pain rehabilitation program: A collaboration between Florida blue and Mayo clinic Florida. Pain Medicine, 16(5), 898-904.

http://search.ebscohost.com/login.aspx?direct=true \&db=s3h\&AN=102821151\&site=eds$\underline{\text { live }}$

Stevenson, E., \& Cole, J. (2015). Associations between chronic non-cancer pain and medication assisted treatment outcomes for opiate addiction. American Journal on Addictions, 24(2), 138-143. DOI: 10.1111/ajad.12151

Stickley A, Koyanagi A, Kawakami N. (2015). Childhood adversities and adult-onset chronic pain: results from the world mental health survey, Japan. European Journal of Pain,19(10), 1418-1427. https://doi.org/10.1002/ejp.672

Stols, D., van Heerden, R., van Jaarsveld, A., \& Nel, R. (2013). Substance abusers' anger behaviour and sensory processing patterns: An occupational therapy investigation. South African Journal of Occupational Therapy, 43, 25-34. 
SENSORY MODULATION TO MANAGE CHRONIC PAIN AND SUBSTANCE USE

Substance Abuse and Mental Health Services Administration. (2012). SAMHSA's working definition of recovery. http://store.samhsa.gov/shin/content//PEP12-RECDEF/PEP12$\underline{\text { RECDEF.pdf }}$

The British Psychological Society. (n.d.). Introduction to the PTMF. https://www.bps.org.uk/power-threat-meaning-framework/introduction-ptmf

The British Psychological Society. (n.d.). The power threat meaning framework: Summary [PDF]. https://www.bps.org.uk/sites/www.bps.org.uk/files/Policy/Policy\%20\%20Files/PTM\%20Summary.pdf

Tomchek, S. \& Dunn, W. (2007). Sensory processing in children with and without autism: A comparative study using the short sensory profile. The American Journal of Occupational Therapy, 61,190-200.

http://search.ebscohost.com/login.aspx?direct=true\&db=ccm\&AN=106115855\&site=eds -live.

U.S. Food and Drug Administration. (2019). Information about medication-assisted treatment (MAT). https://www.fda.gov/drugs/information-drug-class/information-about$\underline{\text { medication-assisted-treatment-mat }}$

van der Kolk, B. (2015), The Body keeps the score: Mind and body in the transformation of trauma. Allen Lane.

Volpe, K. (2020). Managing opioid use disorders and chronic pain. practical pain management. Practical Pain Management, 12(2). doi:https://www.practicalpainmanagement.com/treatments/addiction-medicine/opioiduse-disorder/managing-opioid-use-disorders-chronic-pain 
SENSORY MODULATION TO MANAGE CHRONIC PAIN AND SUBSTANCE USE

Wallis, K., Sutton, D. \& Bassett, S. (2018) Sensory modulation for people with anxiety in a community mental health setting. Occupational Therapy in Mental Health, (34)2, $122-$ 137, DOI: 10.1080/0164212X.2017.1363681

Wasmuth, S., Crabtree, J. L., \& Scott, P. J. (2014). Exploring addiction-as-occupation. British Journal of Occupational Therapy, 77(12), 605+. https://link.gale.com/apps/doc/A394685513/HRCA?u=mlin_m_hebrew\&sid=HRCA\&xi $d=54675 f 36$

Weiss, R. D., \& Rao, V. (2017). The prescription opioid addiction treatment study: What have we learned. Drug and Alcohol Dependence, 173(Supplement 1), S48-S54. https://doi.org/10.1016/j.drugalcdep.2016.12.001

Yang, L. H., Wong, L. Y., Grivel, M. M., \& Hasin, D. S. (2017). Stigma and substance use disorders: An international phenomenon. Current Opinion in Psychiatry, 30(5), 378-388. https://doi.org/10.1097/YCO.0000000000000351

Zoffness, R. (2020). The pain management workbook: Powerful CBT and Mindfulness skills to take control of pain and reclaim your life. New Harbinger Publications. 


\title{
Appendix A
}

\author{
Verbal and Alumni Page Post Recruitment Letter
}

Hello, my name is Claire Ruth, and I am a currently in school to get my Doctorate in Occupational Therapy at The University of St. Augustine for Health Sciences.

As a part of my education, I am seeking participants for a research study to look at people's response to sensory input (examples: taste, touch, sound, vision), their pain levels pain, and substance use recovery journey. Participants will need to have both chronic pain (pain lasting 3 months or more) and recovering from any type of substance use. Participants will be asked to fill out three surveys for a total of one hour of time. No personal information (Name, birthday, medical information) will be asked, and it is completely up to the you if you want to participate.

If you have both chronic pain and are at any stage of recovery from substance use disorder and have any potential interest, please contact me at

I am hoping to learn more about people with both chronic pain and substance use in order to improve occupational therapy's role in helping this population.

Sincerely,

Claire Ruth OTD/S

The University of St. Augustine for Health Sciences- San Marcos Campus Email:

Phone:

THIS PROJECT HAS BEEN REVIEWED BY THE UNIVERSITY OF ST. AUGUSTINE FOR HEALTH SCIENCES INSTITUTIONAL REVIEW BOARD FOR THE PROTECTION OF HUMAN SUBJECTS.

IF YOU HAVE QUESTIONS OR CONCERNS, PLEASE CONTACT THE INSTITUTIONAL IRB CHAIR, DR. ELIZABETH ARDOLINO, EMAIL: EARDOLINO@USA.EDU, PHONE: 737-202-3343. 


\section{Appendix B}

Recruitment Flyer

\section{RESEARCH STUDY \\ OPPORTUNITY}

IF YOU HAVECO-OCCURRING CHRONIC PAIN AND ARE IN RECOVERY FOR SUBSTANCE USE CONSIDER PARTICIPATING

AIM OF THE STUDY: IMPROVE UNDERSTANDING OF CHRONIC PAIN, RECOVERY, AND SENSORY PROCESSING PREFERENCES

PARTICIPANTS WILL BE ASKED TO FILL OUT THREE SURVEYS

ESTIMATED PARTICIPATION TIME: 1 HOUR

Please reach out to Claire Ruth OTD/S at for participation details 


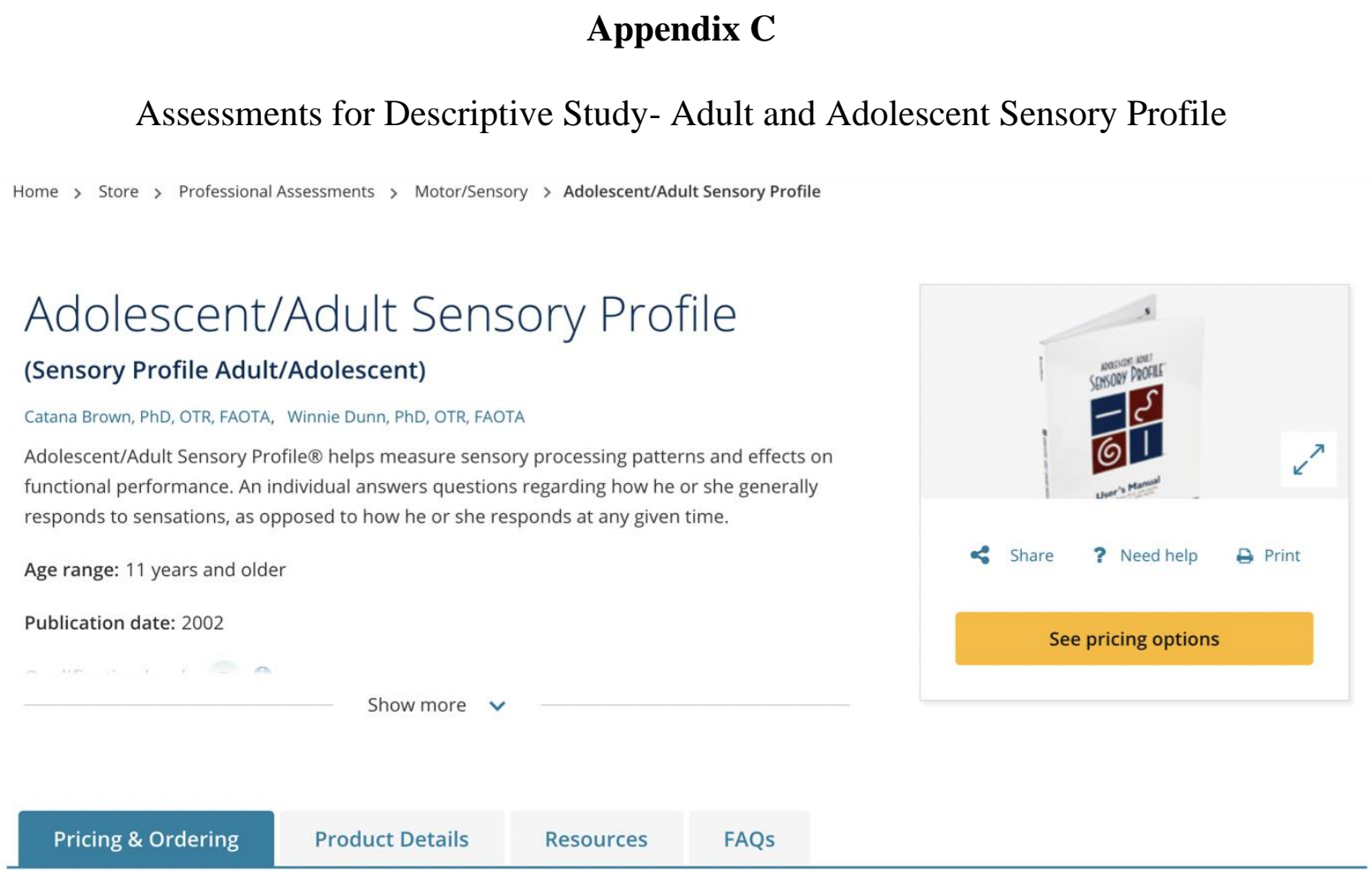

For Copyright reasons, a full copy of the Adult and Adolescent Sensory Profile Questionnaire cannot be included in this IRB Application. Above is a screenshot of the website where the questionnaire can be obtained.

Active Link:

https://www.pearsonassessments.com/store/usassessments/en/Store/ProfessionalAssessments/Motor-Sensory/Adolescent-Adult-Sensory-Profile/p/100000434.html?tab=productdetails 


\section{Appendix D}

Assessments for Descriptive Study- Brief Pain Inventory (Short Form)

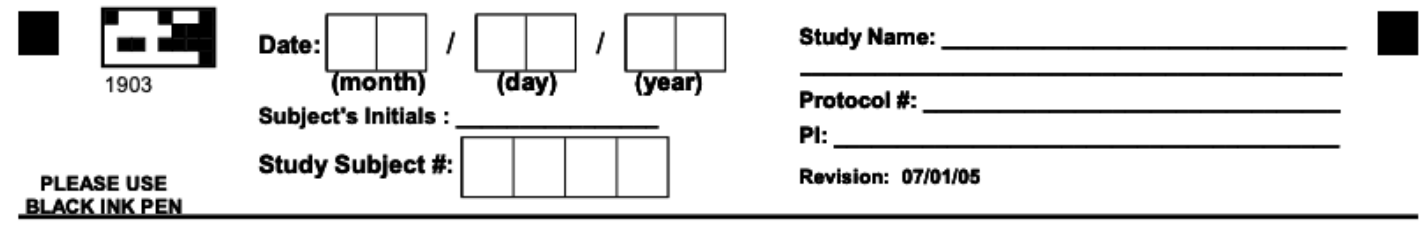

\section{Brief Pain Inventory (Short Form)}

1. Throughout our lives, most of us have had pain from time to time (such as minor headaches, sprains, and toothaches). Have you had pain other than these everyday kinds of pain today?

$\square$ Yes $\square$ No

2. On the diagram, shade in the areas where you feel pain. Put an $X$ on the area that hurts the most.

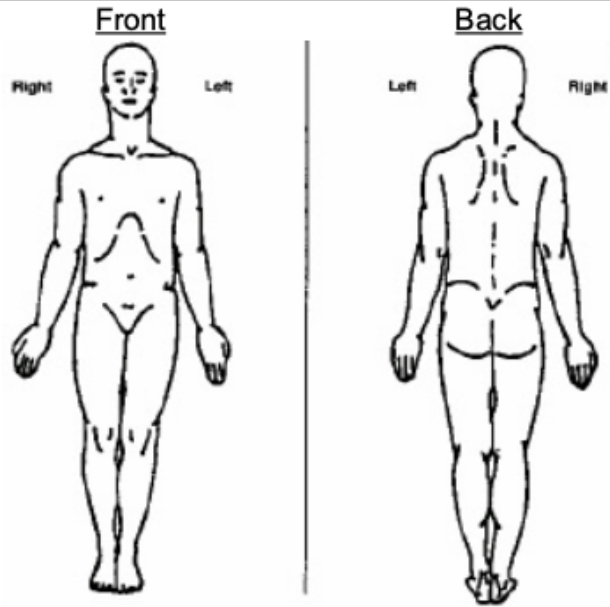

3. Please rate your pain by marking the box beside the number that best describes your pain at its worst in the last 24 hours.

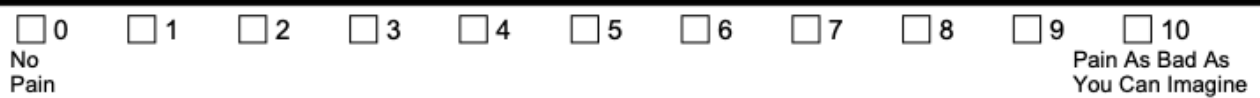

4. Please rate your pain by marking the box beside the number that best describes your pain at its least in the last 24 hours.

$\square 0$
$\begin{aligned} & \text { No } \\ & \text { Pain }\end{aligned}$ 1 $\quad \square 2 \quad \square 3 \quad \square 4 \quad \square 5 \quad \square 6 \quad \square 7 \quad \square 8 \quad \square 9 \quad \begin{aligned} & \square 10 \\ & \begin{array}{l}\text { Pain As Bad As } \\ \text { You Can Imagine }\end{array}\end{aligned}$

5. Please rate your pain by marking the box beside the number that best describes your pain on the average.

$\square 0 \quad \square 1 \quad \square 2 \quad \square 3 \quad \square 4 \quad \square 5 \quad \square 6 \quad \square 7 \quad \square 8 \quad \square 9 \underset{\text { Pain As Bad As }}{\square \text { (10 }}$

Pain You Can Imagine

6. Please rate your pain by marking the box beside the number that tells how much pain you have right now.

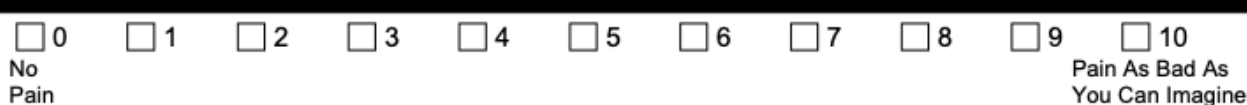

Page 1 of 2

Copyright 1991 Charles S. Cleeland, PhD

Pain Research Group

All rights reserved 


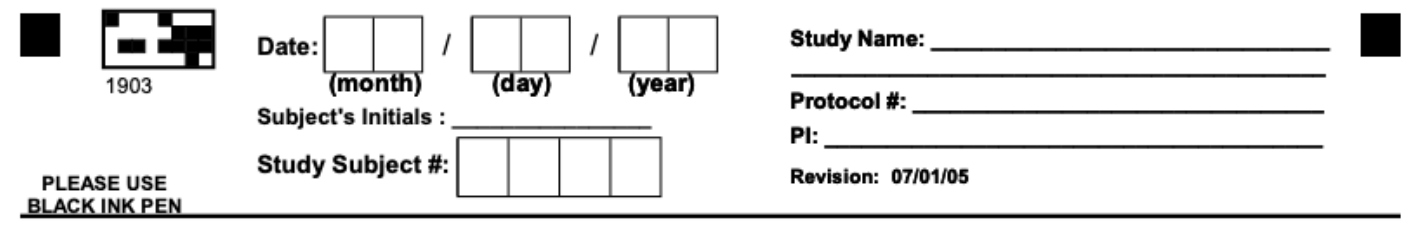

7. What treatments or medications are you receiving for your pain?

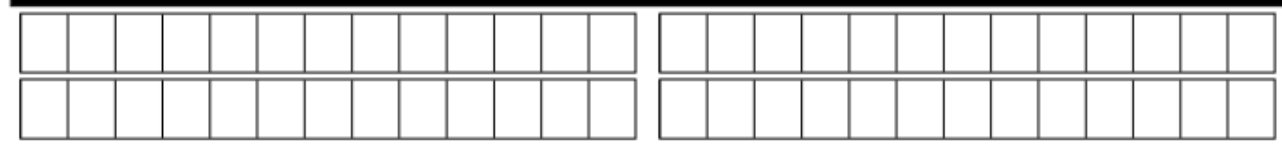

8. In the last 24 hours, how much relief have pain treatments or medications provided? Please mark the box below the percentage that most shows how much relief you have received.

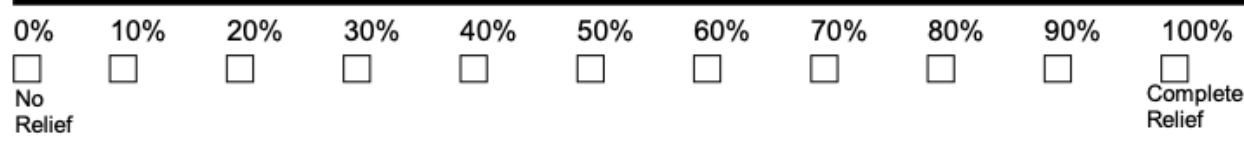

9. Mark the box beside the number that describes how, during the past 24 hours, pain has interfered with your:

\section{A. General Activity}

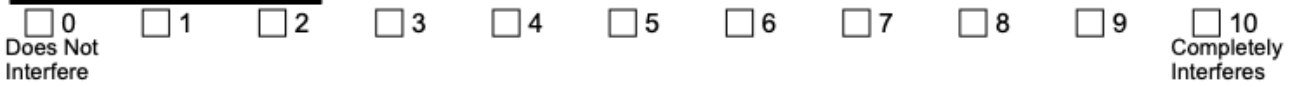

\section{B. Mood}

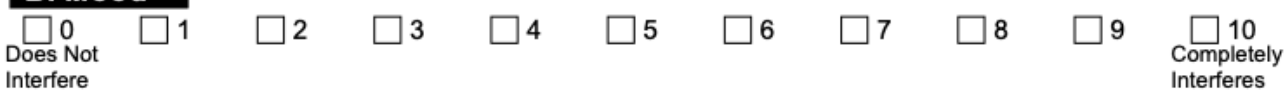

\section{Walking ability}

$\square 0$
Does Not $\quad \square 1 \quad \square 2 \quad \square 3 \quad \square 4 \quad \square 5 \quad \square 6 \quad \square 7 \quad \square 8 \quad \square 9 \quad \begin{aligned} & \square_{\text {Completely }} \\ & \text { (1) }\end{aligned}$

Interfere

Interferes

D. Normal Work (includes both work outside the home and housework)

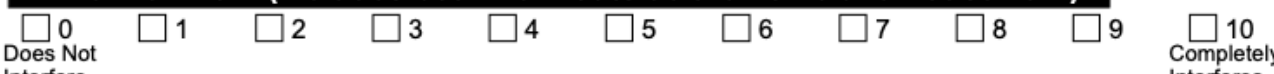
$\begin{array}{ll}\text { Does Not } & \text { Completely } \\ \text { Interfere } & \text { Interferes }\end{array}$

\section{E. Relations with other people}

${ }_{\text {Does Not }}^{0} \quad \square 1 \quad \square 2 \quad \square 3 \quad \square 4 \quad \square 5 \quad \square 6 \quad \square 7 \quad \square 8 \quad \square 9 \quad \square_{\text {Completely }}$ Interfere

\section{F. Sleep}

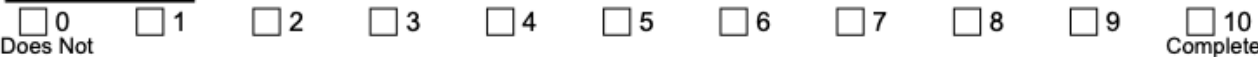

Interfere

\section{G. Enjoyment of life}

$\square 0$

Does Not

Interfere

Page 2 of 2

Copyright 1991 Charles S. Cleeland, PhD 


\section{Appendix E}

Assessments for Descriptive Study- Personal Recovery Outcome Measure

\section{Subject \\ Number \\ Interviewers \\ Initials \\ Personal Recovery Outcome Measure (PROM)}

Please take the time to fill in the following questionnaire.

There are 30 questions. The score for each question is as follows:

Based on your experiences in the last week, please indicate how often

you have felt this way by selecting the option you most agree with.

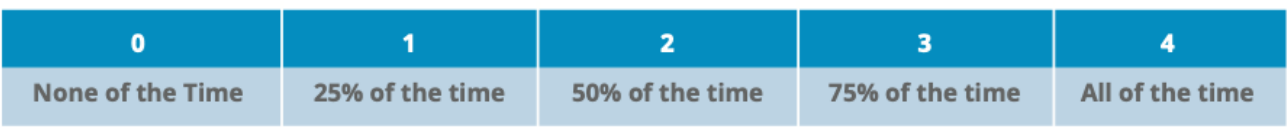

\begin{tabular}{|l|l|l|l|l|l|}
\hline \multicolumn{4}{|c|}{ QUESTIONS } & \multicolumn{5}{|c|}{ RESPONSE } \\
\hline 1. I am motivated to keep myself well & 0 & 1 & 2 & 3 & 4 \\
\hline 2. I can access the health and social services that I need & 0 & 1 & 2 & 3 & 4 \\
\hline 3. $\quad$ I am hopeful about my future & 0 & 1 & 2 & 3 & 4 \\
\hline 4. $\quad$ I feel safe & 0 & 1 & 2 & 3 & 4 \\
\hline 5. $\quad$ I sleep well & 0 & 1 & 2 & 3 & 4 \\
\hline 6. $\quad$ I like myself & 0 & 1 & 2 & 3 & 4 \\
\hline 7. $\quad$ I have enough money to meet my basic needs & 0 & 1 & 2 & 3 & 4 \\
\hline 8. $\quad$ I am happy & 0 & 1 & 2 & 3 & 4 \\
\hline 9. I am driven by meaningful goals & 0 & 1 & 2 & 3 & 4 \\
\hline 10. I can identify the early warning signs of becoming unwell & 0 & 1 & 2 & 3 & 4 \\
\hline 11. I am confident & 0 & 1 & 2 & 3 & 4 \\
\hline 12. I know what helps me stay well & 0 & 1 & 2 & 3 & 4 \\
\hline 13. I have energy & 0 & 1 & 2 & 3 & 4 \\
\hline 14. I have a purpose in life & 0 & 1 & 2 & 3 & 4 \\
\hline 15. I accomplish the goals I set out for myself & 0 & 1 & 2 & 3 & 4 \\
\hline
\end{tabular}



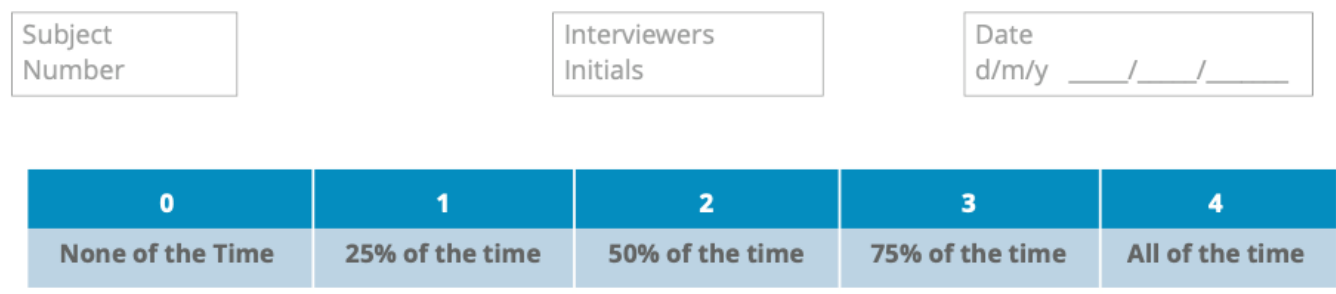

\begin{tabular}{|l|l|l|l|l|l|}
\hline \multicolumn{2}{|c|}{ QUESTIONS } & \multicolumn{4}{|c|}{ RESPONSE } \\
\hline 16. I have new interests & 0 & 1 & 2 & 3 & 4 \\
\hline 17. I have fun & 0 & 1 & 2 & 3 & 4 \\
\hline 18. I have an idea of who I want to become & 0 & 1 & 2 & 3 & 4 \\
\hline 19. I have good self-esteem & 0 & 1 & 2 & 3 & 4 \\
\hline 20. I am supported by my friends and family & 0 & 1 & 2 & 3 & 4 \\
\hline 21. I can manage stress & 0 & 1 & 2 & 3 & 4 \\
\hline 22. I can be an advocate for myself & 0 & 1 & 2 & 3 & 4 \\
\hline 23. I feel a part of my community & 0 & 1 & 2 & 3 & 4 \\
\hline 24. I like the place that I live in (house, apartment, etc...) & 0 & 1 & 2 & 3 & 4 \\
\hline 25. I am respected by others & 0 & 1 & 2 & 3 & 4 \\
\hline 26. I contribute to my community & 0 & 1 & 2 & 3 & 4 \\
\hline 27. I spend my day doing the things that I enjoy & 0 & 1 & 2 & 3 & 4 \\
\hline 28. I have control over my life & 0 & 1 & 2 & 3 & 4 \\
\hline 29. I am satisfied with my intimate relationships & 0 & 1 & 2 & 3 & 4 \\
\hline 30. I have peace of mind & 0 & 1 & 2 & 3 & 4 \\
\hline TOTAL SCORE & I120 & ADJUSTED SCORE = TOTAL SCORE /4 \\
\hline
\end{tabular}

\section{Scoring Instructions}

1. Add up total score and divide by 4 to give you the ADJUSTED SCORE.

2. Based on the ADJUSTED score, mark an $\mathrm{X}$ on the ruler below corresponding to this number.

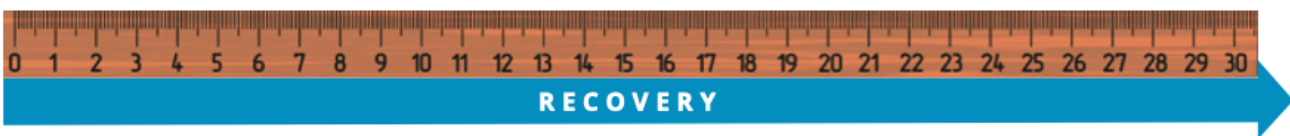

3. Return to the question on the scale that corresponds with the number on the ruler.

4. Begin conversation, assessment, and goal setting at this point. 


\section{Appendix F}

Sensory Group Manual

\section{6}

The experience of being human is embedded in the sensory events of our everyday lives. - Winnie Dunn
A SENSORY BASED OT GROUP FOR INDIVIDUALS IN RECOVERY FOR SUBSTANCE USE 
Acknowledgments:

This manual was created as partial requirements of the completion of The Doctor of Occupational Therapy program at The University of St. Augustine for Health Sciences.

I would like to say thank you to Caitlin Belvin MOTR/L for her support and assistance throughout this project. Your guidance and clinical experience helped facilitate my learning and gain a deeper understanding of what it means to be a client-centered healthcare practitioner.

Dedication: To my little sister-

Who nearly carried her weighted blanket around the world.

Copyright @ Claire Ruth, 2021 all rights reserved 
SENSORY MODULATION TO MANAGE CHRONIC PAIN AND SUBSTANCE USE

\section{Table of Contents}

Week One: Introduction to Sensory Modulation.........................................4

Week Two: Sensory Lab...................................................... 12

Week Three: Sensory Strategies Game.............................................23

Week Four: Crisis Prevention Planning and Intervention ................................ 34

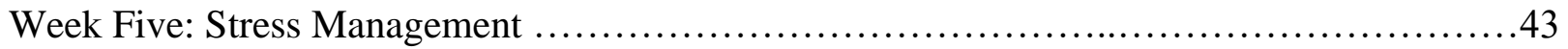

Week Six: Additional Specific Pain Management Group...............................51

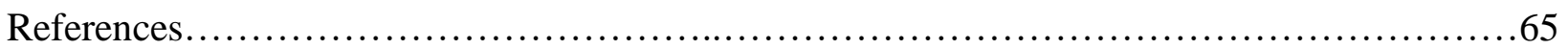


SENSORY MODULATION TO MANAGE CHRONIC PAIN AND SUBSTANCE USE

\section{Week One: Introduction to Sensory Modulation}

\section{Length of session: 2 hours}

Group Goal: "Facilitating Self-awareness (Self-awareness and Meaning-making). Facilitating the identification of one's unique tendencies and preferences, and how these patterns influence self-organization" (p.126).

\section{Two short-term goals:}

1. Group members will be able to identify at least one example for each of the body sensory systems with no more than two verbal cues/hints.

2. All group members will all complete Tina Champagnes (2017) "The Sensory Modulation Screening Tool" and turn it into the group facilitator for scoring to educate themselves on the impact their sensory processing has on overall function.

Introduction: Introduce self as therapist. Have group members introduce themselves in a circle. Warm up activity: Introduce what occupational therapy is. List all the areas of occupation outlined in the AOTA OTPF $4^{\text {th }}$ Ed. (2020). Answer any questions group members may have about occupational therapy and the group. Encourage group members to get comfortable and take out a pen, pencils, markers ect. to take notes with. Then a brief outline of the activity for the day will be presented including the purpose and timeline for the session. Group expectations will also be established.

Activity: Group members will spend the first portion of the group learning about sensory modulation. The group will discuss the "Introduction to Sensory Modulation" handout, each member of the group is encouraged to take notes and follow along. The white board will be used to write ideas on what sensory process is and examples of each senses. As many examples as possible should be given in order to increase group members knowledge of the topic and 
SENSORY MODULATION TO MANAGE CHRONIC PAIN AND SUBSTANCE USE

concept. Once the group has completed the worksheet and has a better understanding of sensory modulation each group member will individually complete "The Sensory Modulation Screening Tool” and hand it back into the group facilitator for scoring (Champagne, 2017).

Sharing: Ask for a volunteer to share one thing they learned in group today. This is done to increase group learning by having group members repeat what they learned in their own words. Each person will share at least one comment in a clockwise direction around the table.

Processing: Have group members process and talk about sensations they feel like their nervous system seeks and avoids. Individuals will share and others will listen and respond to other group members in a trusting, honest, and safe way. Group leader will mediate this to ensure that everyone is heard, and the group is respectful.

Generalization: Ask group members to share a time when they felt like their sensory preferences did not match another person's sensory preferences or the sensory preferences of a particular environment. For example, is the group room too bright? Loud? What about a certain environment do you like? Have you ever had to ask your roommate to turn down the TV when you are concentrating on something? Is there fabrics you will or will not wear? Address any conflict that arose in the groups and ask what a positive response might be instead. Application: Ask group members questions about ways they can incorporate sensory modulation strategies into their day to day lives. Are there any strategies the group members are already using? How could they future enhance these strategies?

Summary: Summarize the short and long-term goals of the group sessions and what served as supports and barriers for the individuals. Give positive reinforcement by providing a handful of things that group members did well (such as did a great job being involved, asking questions to other people, or being respectful when others share). Discuss the skills required to participate and 
SENSORY MODULATION TO MANAGE CHRONIC PAIN AND SUBSTANCE USE

how these skills can and will play a part in the future. Address the importance of continuing to take the resources from group into the community and through their daily life. Thank the participants for their time, effort, and participation. Announce next group session and topic.

\section{Materials needed:}

- Whiteboard

- Whiteboard markers

- Printed handouts

- Pens and pencils for filling out the worksheets

\section{Possible adaptations:}

- To grade up: have individuals take turns reading portions of the handout aloud and apply the knowledge learned to various environment's like school, work, home, and group settings Have them identify the sensory input within those environments that may be facilitating or be a barrier to their individuals success. Have group members facilitate the conversation by asking questions and giving their input on the meaning of the content.

- To grade down: have group members write out on a piece of paper questions for people who are timid or afraid of saying their opinion out loud. Have a completed handout for those who are not able to take notes or have difficulty with not taking. Complete the "Sensory Modulation Screening Tool” as a group, reading each question aloud and instructing group members to fill it out as the group reviews it (Champagne, 2017) Providing prompts and examples for the open-ended questions within the screening tool. 


\section{Introduction in Sensory Modulation}

Sensory Processing? What do you think that is?

What senses do we as humans have? And some examples

- Olfactory (smell)

- Visual (sight)

- Gustatory (taste)

- Tactical (touch)

- Auditory (hearing)

- Vestibular (movement)

- Proprioception (body awareness)

\section{THE SEVEN SENSORY SYSTEMS}

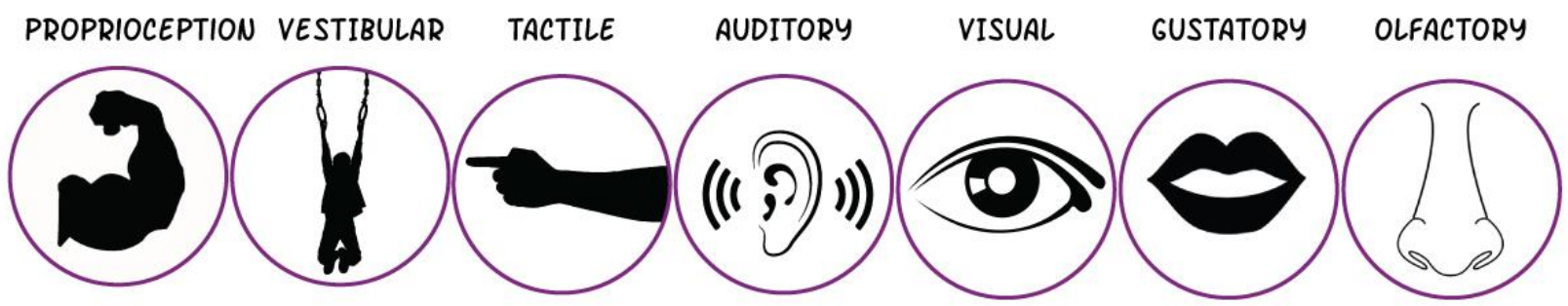

Two more additional senses:

- Oral Motor

- Deep Pressure 
We get information from these sensory receptors and they send a chemical message to our brain. Our brain then organizes, prioritizes, understands and responds to this information.

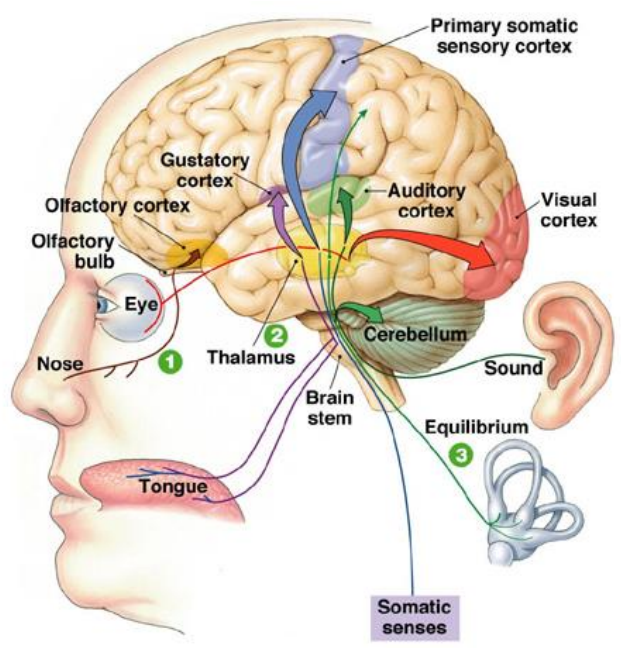

(Armesheen, n.d.)

"Sensations are nourishment for the nervous system"- A. Jeans Ayres

Just like everything else in our lives our individual body systems have sensory preferences (likes/dislikes) and individualized needs.

- Some of us have a high threshold (big bucket) meaning you need/can handle more sensory input

- Some of us have a low threshold (little bucket) meaning you notice different sensory inputs more and it is easy to get into that "sensory overload" state

- The buckets can be different sizes for different senses

Here is a visual example:

(Sanson-Fisher, 2020).

doing.therapy

SENSORY THRESHOLDS ARE SORT OF LIKE BUCKETS.

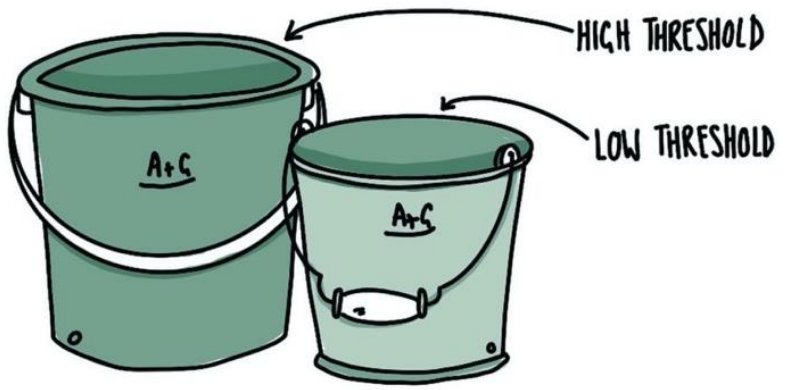

IF YOUR BUCKET IS BIG, yOULL BE ABLE TO HANDLE LOTS OF SENSORY INPUT, BUT' YOU MIGHT NEED EXTRA TO NOTICE INPUT, AND TO FEEL ALERT + GROUNDED.

If YOUR BUCKET IS SMALL, yOÚLL NOTICE SENSORY INPUT EASILY, BUT IT WILL BE EASY TO CET OVER THAT ALERT+ GROUNDED IINE OR OVERFLOW. 
Sensory modulation is defined as "the capacity to regulate and organize the degree, intensity and nature of responses to sensory input in a graded and adaptive manner. This allows the individual to achieve and maintain an optimal range of performance and to adapt to challenges in daily life" (Miller et al., 2001, p. 57)

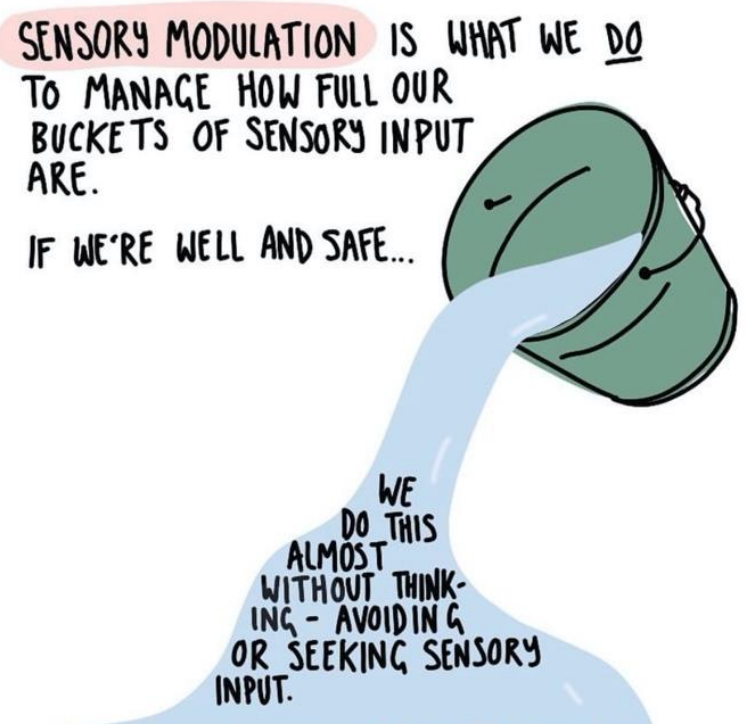

YOU MICHT CLICK A PEN TO KEEP YOU FOCUSSED, OR MOVE AROUND. I MICHT NEED QVIET WHEN I'VE HAD A ROUCH DAY. HAVE EXPERIENCED
IF WE TRAUMA, ARE UNWELL

DOING

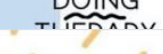

OR CURRENTLY IMPACTED

\section{0 benefits of Individualized} Sensory Modulation are:

1. Better self-awareness

2. Increased ability to self-nurture

3. Increased participation in meaningful life roles

4. Increased resilience

5. Increased self-esteem and body image

6. Better ability to engage in therapeutic activities

7. Better ability to engage in selfcare activities

8. Increased ability to engage in social activities

9. Increased ability to cope with triggers

10. Increased ability to rest and sleep

\section{BY SUBSTANCES,}

ARE IN UNFAMILIAR

ENVIRONMENTS (EG CIINICAL

SPACES) ARE TIRED OR

DISTRESSED, OR JUST

PROCESS SENSORY

INPUT DIFFERENTLY

THAN OTHERS, WE

MICHT NEED SOME

SUPPORT OR A PLAN TO

BE ABLE TO MANAGE OUR

SENSORY INPUT \& MODULATE AROUSAL DOING 
Therefore, Sensory Modulation is an important tool in recovery because it:

Helps us to create environments and situations that support us Helps us gain control over environment and situations Helps us to understand ourselves and others better

Promotes engagement in life

Is empowering

What areas of life/occupations are you struggling with? 
The Sensory Modulation Screening Tool can be found in the book below, a link to purchase has been provided.

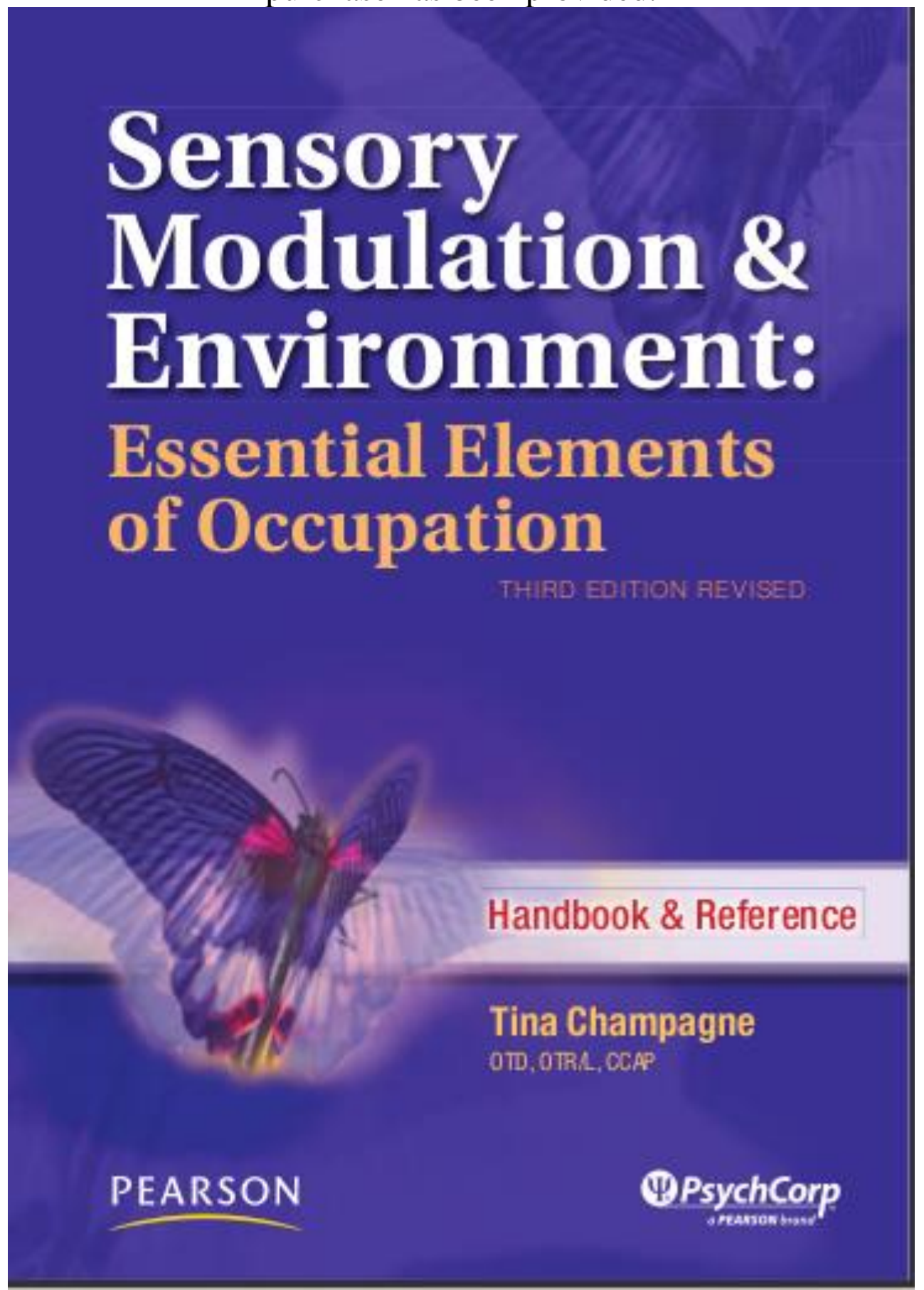

“The Sensory Modulation Screening Tool by Tina Champagne, OTR/L serves to assist in mapping the sensory modulation patterns of adolescent and adult populations. This is currently available in her book: Sensory Modulation \& Environment: Essential Elements of Occupation $\left(3^{\text {rd }}\right.$ Ed.), which is available through this web site. If interested in trialing or assisting in researching this tool please contact Tina Champagne via email: tina@ot-innovations.com" 
SENSORY MODULATION TO MANAGE CHRONIC PAIN AND SUBSTANCE USE

\section{Week Two: Sensory Lab}

\section{Length of session: 2 hours}

Group Goal: To facilitate "the identification of one's unique tendencies and preferences, and how these patterns influence self-organization" (Champagne, 2017, p.126).

\section{Two short-term goals:}

1. Group members will understand and verbalize their own sensory patterns and how that may be impacting their participation in daily life and meaningful activities with no more than three verbal cues

2. Group members will explore sensory input at different lab stations trying at least ten total sensory strategies to support occupational performance in the future.

Introduction: Introduce self as therapist. Have group members introduce themselves. Before beginning the Sensory Lab ensure that there are no allergies/drug interactions the therapists need to be aware of. Hand back individuals scored "Sensory Modulation Screening Tool" (Champagne, 2017). Review what sensation seeking, sensation avoiding, and what threshold levels mean. Answer any questions any of the group members may have about their individual results.

Activity: After all group members understand their own sensory patterns, they will be broken into small groups that will rotate through the sensory station labs. Using a majority of the group time have group members go to each sensory station. These stations should be placed around the $\mathrm{room} /$ in the hallway. Each station should have a label for sensory input being explored at the station with all the sensory items below it. Groups will rotate counterclockwise. Each group member will be given a clipboard, writing utensil, and "Sensory Modulation: Self Exploration Tool" handout to fill out at each station. They will be instructed to write down what sensory tool 
SENSORY MODULATION TO MANAGE CHRONIC PAIN AND SUBSTANCE USE

they are using and rate it $0-10$ from very calming to very alerting. It is likely that another assistant or therapist will need to be present during this group depending on how many members are participating. Group leaders should be ensuring the maintenance of safety and facility infection control standards throughout as well as assisting group members as needed.

Sharing: Ask for a volunteer to share one sensory tool that was alerting and one that was calming. Each person will share at least one alerting sensation and one calming one in a clockwise direction around the table. The therapists should identify how these vary from person to person and what is calming to one person may be alerting to another.

Processing: Have group members discuss how this activity made them feel. Have them think about how having this knowledge can be important for functioning in their daily lives. Individuals will share and others will listen and respond to other group members in a trusting, honest, and safe way. Group leader will mediate this to ensure that everyone is heard, and the group is respectful.

Generalization: Discuss generalization of how understanding your sensory processing patterns can help to develop routines or how they feel when a space does not match their preferred patterns. Ask when some of these strategies may be useful in helping group members selfregulate. The group facilitator should ask open ended questions and follow up on areas that generate spontaneous conversation. Asking open questions that reveal the meaning of the activity for the group members. Address any conflict that arose in the groups and ask what a positive response might be instead.

Application: Ask group members questions about ways they can incorporate these skills and strategies in their daily routines. Are there strategies that they could use in the morning? What about night? What about in a group, school, or public setting? What is one thing you could do to 
SENSORY MODULATION TO MANAGE CHRONIC PAIN AND SUBSTANCE USE

make an environment more calming or alerting to improve participation? What about things like sensory-based occupations? What are those/what are some examples? How might focusing on the sensory aspects of daily life serve as a support for function?

Homework: For homework have clients begin to fill out the Sensory Diet plan. Explain that this is a way to incorporate the use sensory-based coping strategies or sensory-based activities into their daily routine to facilitate success in their daily lives. Encourage them to practice these strategies and come back next week for reflection and further practice.

Summary: Summarize the short and long-term goals of the group sessions and what served as supports and barriers for the individuals. Give positive reinforcement by providing a handful of things that group members did well (such as did a great job being involved, asking questions to other people, or being respectful when others share). Address the importance of continuing to take the resources from group into the community and through their daily life. Thank the participants for their time, effort, and participation. Announce next group sessions topic.

Materials needed:

Rain stick

Different Nature Sounds on a CD or playlist Speaker or CD player with headphones Various Types of music (rock, oldies, techno, classical, musicals)

Guided Meditation

Fan

Noise maker

Pretzels

Corn Nuts

Chewy Starbursts

Chewy Chocolate/ Caramels

Sour Candies

Soft marshmallows

Mints

Lollipops

Gum

Fizzy drinks
Cold ice/drinks

Hot tea/coffee/drinks

Balloons

Party Blowers

Various fidgets

Soft and squishy

Hard and Spikey

Smooth

Clothes/ fabrics

Putty/Play Dough

Weighted blanket

Bean bags

Bean bag chair

Weighted neck wrap

Resistance bands

Massage balls/ roller

Stretching handouts

Hand weights

Squeeze ball

Play dough/putty 
Coloring books

Scenery pictures

Colorful lamp/lights

Colored glasses

Word finds

I-spy

Puzzles
Coffee

Tea

Essential oils

Particular foods (spicy, sweet, familiar, alerting) 


\section{Possible adaptations:}

- To grade up: ask individuals to write comments on the self-rating tool about times this may be useful to implement. Have individuals complete the sensory diet worksheet independently as homework, explain that this is a tool used to integrate sensory-based coping strategies or sensory-based activities into their daily routine. Encourage them to practice these strategies and come back next week for reflection and further practice.

- To grade down: ask individuals if they like or dislike the sense, a visual Likert scale with faces (happy to sad) could also be provided and this could be written on the selfrating sheet. Explain the idea of a sensory diet, have a discussion about when a little sensory input may be helpful vs. when a lot of sensory input is needed for success. 
Rain stick

\section{Sensory Stations: Auditory}

Different Nature Sounds

Various Types of Music (rock, oldies, techno, classical, musicals)

Guided Meditation

Sound of engine running, water running, fan blowing

Taste/Oral Motor

Pretzels

Corn Nuts

Chewy Starbursts

Chewy Chocolate/

Caramels

Sour Candies

Soft marshmallows

Mints
Lollipops

Gum

Fizzy drinks

Cold ice/drinks

Hot tea/coffee/drinks

Blowing up a balloon

Party Blowers

Vaping/Smoking

\section{Touch/Deep Pressure}

Various fidgets

Soft and squishy

Hard and Spikey

Smooth

Clothes you are wearing
Putty/Play Dough Weighted blanket

Bean bag tapping Weighted neck wrap 


\section{Proprioceptive}

Resistance bands

Massage balls/ roller

Stopping feet for 30

seconds

Stretching

Wall push ups
Lifting heavy things

(heavy work)

Joint Compression

Squeeze ball

Play dough/putty

\section{Visual}

Coloring books

Scenery

Lights

Colorful lamp/lights
Colored glasses

Word finds

I spy

Puzzles

\section{Smell}

Coffee

Tea

Essential oils

Particular foods (spicy, sweet, savory, familiar)

\section{Vestibular}

Pacing

Spinning in circles

Laying completely still
Rocking chair/ rocking back and forth

Jumping up and down

Dancing 


\section{Sensory Modulation: Self Exploration Tool}

This worksheet may be used to explore how you tend to respond to different kinds of sensory stimulation. Try a number of items, write down the name of each, and rate your response using the self-rating key provided. You can use the numeric and/or word scales to record your responses

Items Used

\section{Auditory}

\section{Visual}

\section{Smell}

Taste/ Oral Motor

\author{
0---1---2---3---4----5---6---7---8----9---10 \\ Very Calm Calm Calm/Alert Alert Very Alert
}




\section{Touch/ Deep Pressure}

\section{Proprioceptive}

\section{Vestibular}




\section{Sensory Diet}

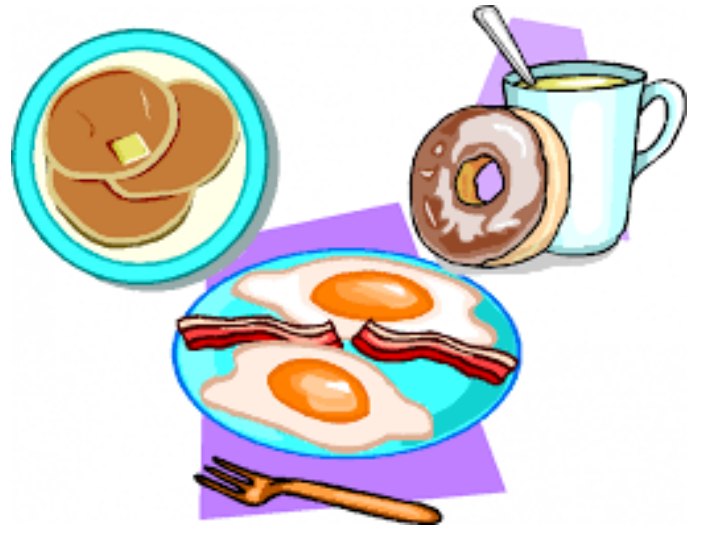

"Sensations are nourishment for the nervous system” - A. Jeans Ayres

Just as our body needs food to function optimally our nervous system needs sensory input to keep us feeling well. Sometimes we need a big breakfast, packed with nutrients in order to function optimally that day, while others we may just need a small snack to fuel us. This is the same for our nervous system. Sometimes we need to use multiple sensory strategies or ones with incredibility strong input in order to feel alert or grounded. While at other times we only need the help of a little sensory input. Think of times where you need a full sensory meal and what that looks like in order to feel well vs. a time that just a sensory snack is enough to feed your nervous system.

\section{Mealtimes}

When you need it: (highly stressful situation, coming home from a long day of work) 
What this means for me: (example: lights low, lavender essential oils, weighted blanket, hot tea, nature sounds playing)

\section{Snack times}

When you need it (example: to stay present in group/class):

What that means for me: (example: chewing gum, fidget toy) 


\section{Week 3: Sensory Strategies Game}

\section{Length of session: 2 hours}

Goal of Group: "Collaborative and active engagement in the planning and practicing of meaningful sensory modulation activities for specific therapeutic purposes; requires continued self-exploration, self-reflection, planning and lots of practicing" (Champagne, 2017, p.126).

\section{Two short-term goals:}

1. Group members will work cohesively as a team to improve interpersonal effectiveness skills, with four or less redirection or cues from the facilitator.

2. Group members will identify appropriate, sensory-based coping strategies for selfregulation to improve attention, concentration, emotional regulation, and occupational participation.

Introduction: Introduce self as therapist. Have group members introduce themselves. Warm up activity: Review last week's sensory diet homework. What were sensory snacks vs. meals? When did they need a snack vs. a meal? Allow for group members to share what worked for them and what did not. Encourage the group to continue practicing strategies. Then a brief outline of the activity for the day will be presented including the purpose and timeline for the session. Group expectations will also be established.

Activity: Pass out a note card to each group member. Have then write down a particularly difficult situation, including as much detail as possible, they either have encountered in the past or are currently facing. Do not have them put their name on the note care to maintain anonymity. Each member will then pass the cards back to the group facilitator. They group will then be split into two even teams. The purpose of the activity is to come up with as many appropriate sensorybased coping/modulating strategies as possible. Strategies given should be specific (example: 


\section{SUBSTANCE USE AND CHRONIC PAIN}

perform wall push up or take a 5 minute walking break to stay alert at work after sitting for a long period of time, not: work out) and appropriate given the situation (going on a run during an AA meeting is not an appropriate strategy for maintaining engagement in the task but isometric exercises or mindfully drinking the coffee available is). For each scenario the group is given three minutes to come up with and write down sensory strategies. Once the clock is up each team will delegate a person to write their strategies on the whiteboard. No points will be given for repeated strategies (if both teams said use a weighted blanket, then no points are given for that item) so groups are encouraged to come up with an many specific and unique strategies as possible. Examples of past/ current scenarios group members may write on their note cards are:

- Fight with family member or partner

- Worried about money because having a hard time completing a resume to start searching for new ones.

- Stressed

- A party coming up where there will be a lot of drinking

- Yelling in group or at home

- Cravings

- Relapse

Sharing: Each group member will identify and share a sensory coping strategy that they had not thought of before and when they think that strategy may be useful for them and how that would facilitate occupational participation. Have everyone share by going around the table in a clockwise fashion.

Processing: The group members will then share how they felt about this activity. How did seeing all the strategies you could use in your scenario make you feel? Group members will be 


\section{SUBSTANCE USE AND CHRONIC PAIN}

encouraged to think about a time where they used unhealthy coping strategies or did not use any coping strategies in a real-life scenario and the result of this. This may bring up some triggering thoughts or flashbacks and should be done with careful consideration and care. The group leader will mediate this to ensure that everyone is heard, and the group is respectful.

Generalization: Verbalize a few general principles learned from activity such as identifying self-based, self-regulation strategies during specific situations or occupations to facilitate performance. The group facilitator should ask open ended questions and follow up on areas that generate spontaneous conversation. Asking open questions that reveal the meaning of the activity for the group members. Address any conflict that arose in the groups and ask what a positive response might be instead.

Application: Discuss how by utilizing these strategies could improve participation in meaningful activities. Ask the group how sensory strategies could be applied in other areas of life that were maybe not discussed? Ask what areas of life could you implement a strategy in so you can be more successful? Are there certain strategies that group members could implement before, after, and during certain occupations to facilitate self-regulation, attention, and participation? What might those be? Have everyone share by going around the table in a clockwise fashion or do a round table discussion.

Summary: Ask group members to summarize the most important aspects of the group. Summarize what served as supports and barriers for the individuals. Summarize learning and emotional response to group topic. Give positive reinforcement by providing a handful of things that group members did well (such as did a great job being involved, asking questions to other people, or being respectful when others share). Discuss the skills required to participate and how these skills can and will play a part in the future. Address the importance of continuing to take 


\section{SUBSTANCE USE AND CHRONIC PAIN}

the resources from group and implementing them through their daily life. Thank the participants for their time, effort, and participation.

\section{Materials needed:}

- Whiteboard

- Whiteboard markers

- Printed handouts

- Pens and pencils for filling out the worksheets

- Note cards

- Possible scenario sheets and sensory strategy cards (grading)

\section{Possible adaptations:}

- To grade up: individuals could come up with and share with the group sensations they are currently struggling with and have the group help identify appropriate sensory strategies they could use. To grade up even further the group could be given the individuals situation and sensory processing preferences. To grade up the game extra points will be allotted to the team that comes up with the most strategies for a particular sensory system. For example: 2x points given for proprioceptive coping strategies.

- To grade down: multiple handouts are given to grade down, utilizing pictures of sensory coping strategies and provided scenarios (Moore, 2014; Moore, 2011). 


\section{Grade down option 1:}

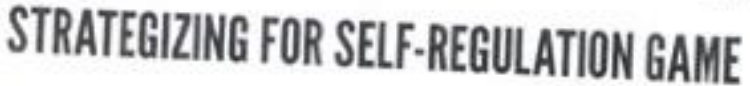

Game preparation: Print out the game pages onto cand stock, laminate and cut up the cards. Directions: Disribureck bag.

Directions: Distribute the cards to participants and ask them to answer the questions using
tools and strategies they have learned in the program. Mention the input options, deep breathing, mindfulness technigues, Mention that strategies can include sensory time in your comfort space. If the question is not appr, non-tool strategies, focused activities or them to say what they might advise somen is not appropriate to their particular life situation, ask the same tools or strategies, make a rule that the in that situation. If everyone is answering with there is time for more discussion ask other group members to be different from everyone else. If for the person.

You have been sober for a while, but you are having

trouble with a craving.

WHAT STRATEGY COULD YOU USE?

You are upset and feeling

like your emotions

are getting out of control.

WHAT STRATEGY COULD YOU USE?

are feeling very nervous

and you can't think straight.

WHAT STRATEGY COULD YOU USE?

You are noticing signs

that you might be headed

toward a crisis.

WHAT STRATEGY COULD YOU USE?
You are going to be talking with your therapist about something difficult.

WHAT STRATEGY COULD YOU USE?

You are feeling very sad and depressed and need something comforting.

WHAT STRATEGY COULD YOU USE?

You know you need to be managing your stress better.

WHAT STRATEGY COULD YOU USE?

You have a phone call coming in from someone who always seems to upset you.

WHAT STRATEGY COULD YOU USE?

The Sersory Connection Program: Curriculum for Selt-flegulation - Cooyright O 2015 Kares M. Moxse 
The Sensory Connection Program: Curriculum for Self-Regulation

\begin{tabular}{|c|c|}
\hline $\begin{array}{l}\text { You need to clean the house } \\
\text { and you don't feel } \\
\text { you have enough energy. }\end{array}$ & $\begin{array}{l}\text { You are feeling angry } \\
\text { and at the point } \\
\text { of losing control. }\end{array}$ \\
\hline WHAT STRATEGY COULD YOU USE? & WHAT STRATEGY COULD YOU USE? \\
\hline $\begin{array}{l}\text { You are feeling tense and } \\
\text { stressed out, and you know } \\
\text { you need to relax. }\end{array}$ & $\begin{array}{c}\text { Every afternoon at work, } \\
\text { you feel sluggish, and it is } \\
\text { hard to concentrate. }\end{array}$ \\
\hline WHAT STRATEGY COULD YOU USE? & WHAT STRATEGY COULD YOU USE? \\
\hline $\begin{array}{l}\text { You are having trouble } \\
\text { staying awake and focused } \\
\text { during your long commute. }\end{array}$ & $\begin{array}{l}\text { You get some very bad news } \\
\text { and you are feeling } \\
\text { extremely upset. }\end{array}$ \\
\hline WHAT STRATEGY COULD YOU USE? & WHAT STRATEGY COULD YOU USE? \\
\hline $\begin{array}{l}\text { You wake up in the morning } \\
\text { and you feel very groggy. }\end{array}$ & $\begin{array}{l}\text { You are going to a boring meeting } \\
\text { and you need something } \\
\text { to help you pay attention. }\end{array}$ \\
\hline WHAT STRATEGY COULD YOU USE? & WHAT STRATEGY COULD YOU USE? \\
\hline $\begin{array}{l}\text { Late afternoons seem to be } \\
\text { a difficult time and you become } \\
\text { very agitated. }\end{array}$ & $\begin{array}{l}\text { When the house gets noisy and } \\
\text { hectic, you start to feel anxious. }\end{array}$ \\
\hline WHAT STRATEGY COULD YOU USE? & WHAT STRATEGY COULD YOU USE? \\
\hline $\begin{array}{l}\text { You are going to bed and you } \\
\text { are worried that you might } \\
\text { not be able to go to sleep. }\end{array}$ & $\begin{array}{l}\text { You have a stressful appointment } \\
\text { and you need to keep calm } \\
\text { in the waiting room. }\end{array}$ \\
\hline WHAT STRATEGY COULD YOU USE? & WHAT STRATEGY COULD YOU USE? \\
\hline
\end{tabular}




\section{Grade down option 2:}

\section{What Helps? Activity}

This activity is designed to help people identify helpful strategies for different emotional situations. Two situations are chosen. Pictures from the attached sheets are cut out to represent various helpful strategies. They are glued under the chosen situations. When completed this poster should be made available to staff, family members or care providers so that they can help the person choose helpful coping strategies when they are in an emotional crisis.
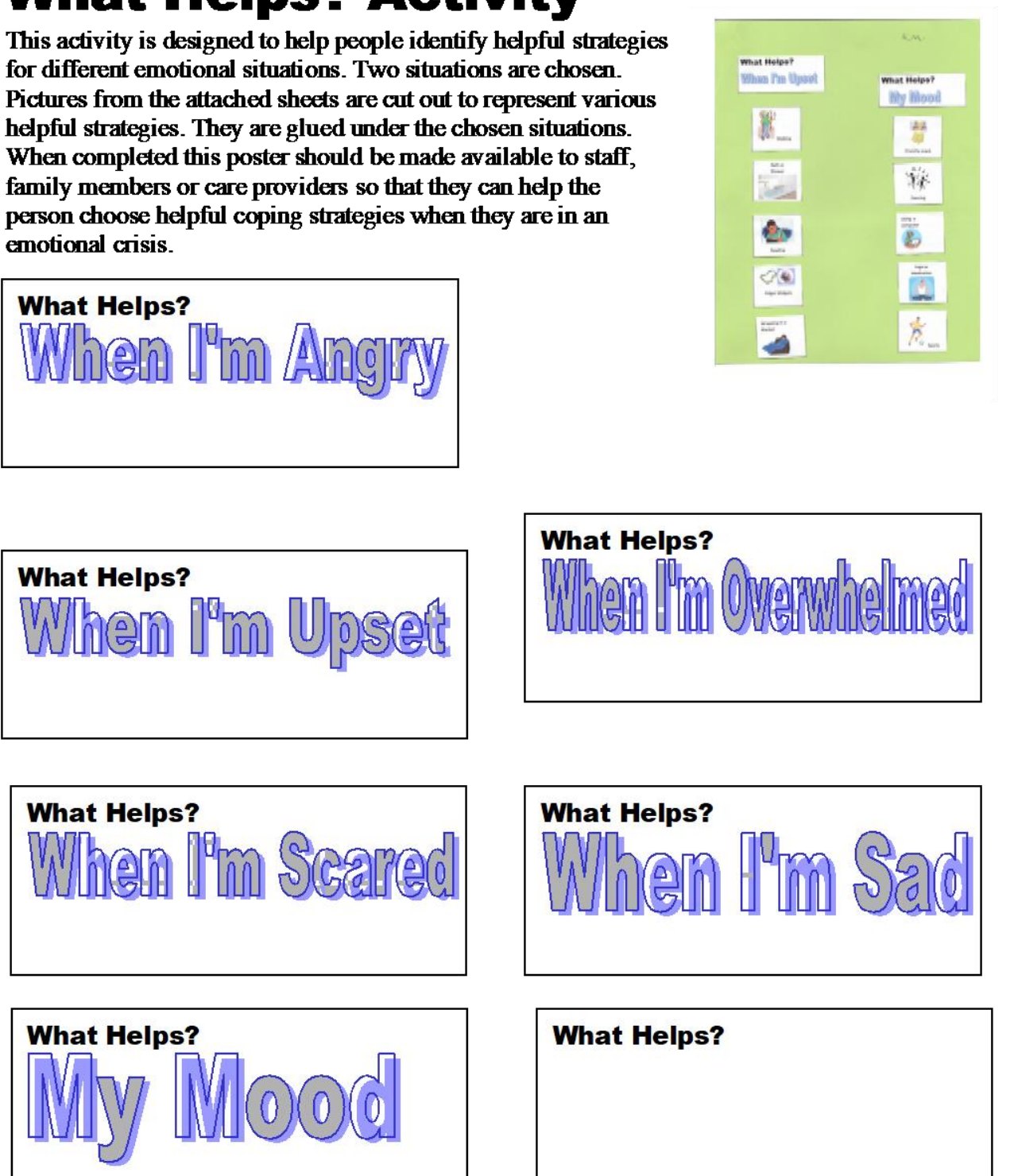

What Helps?

Copyright (C) 2011 Karen M. Moore 


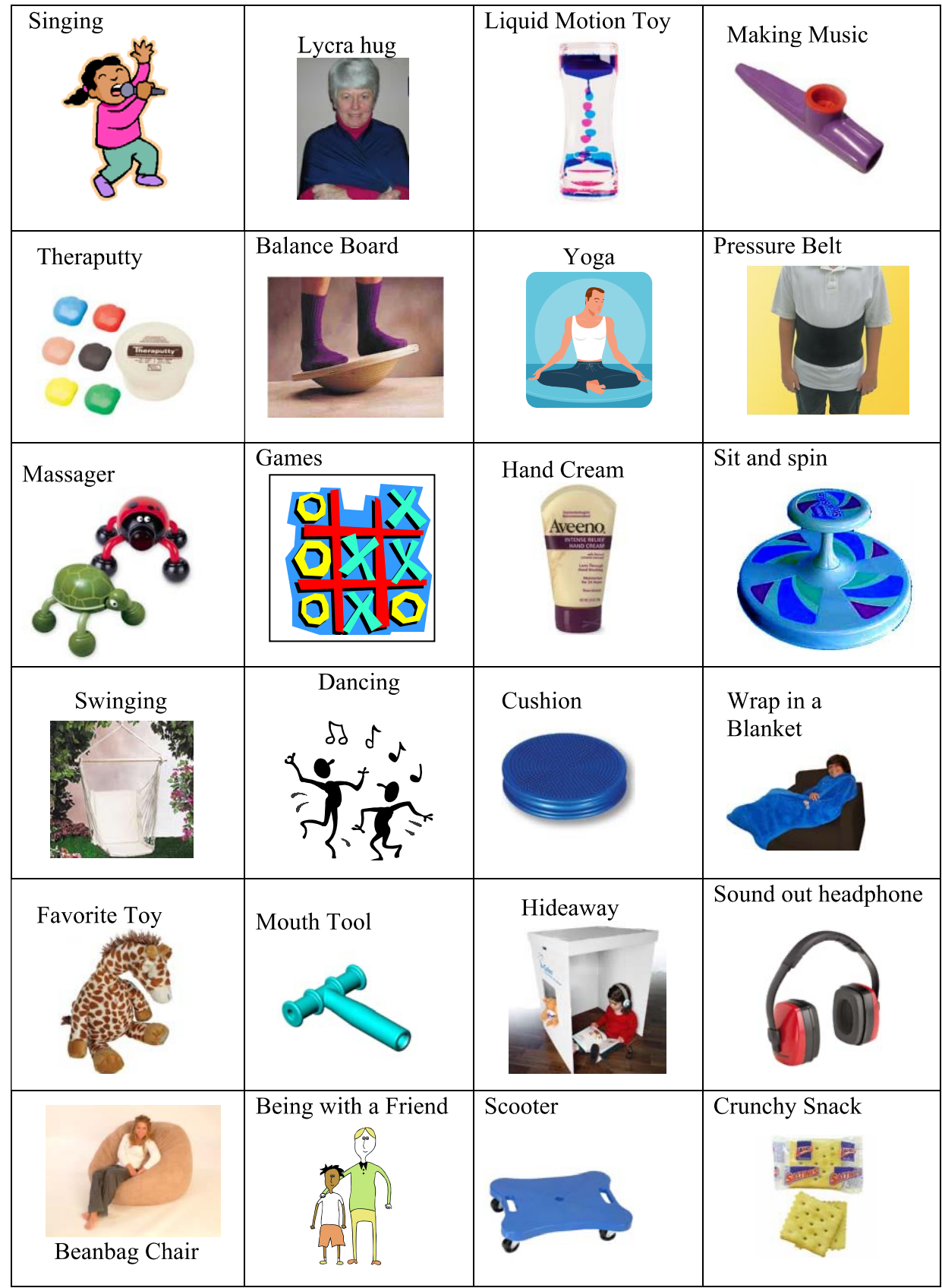




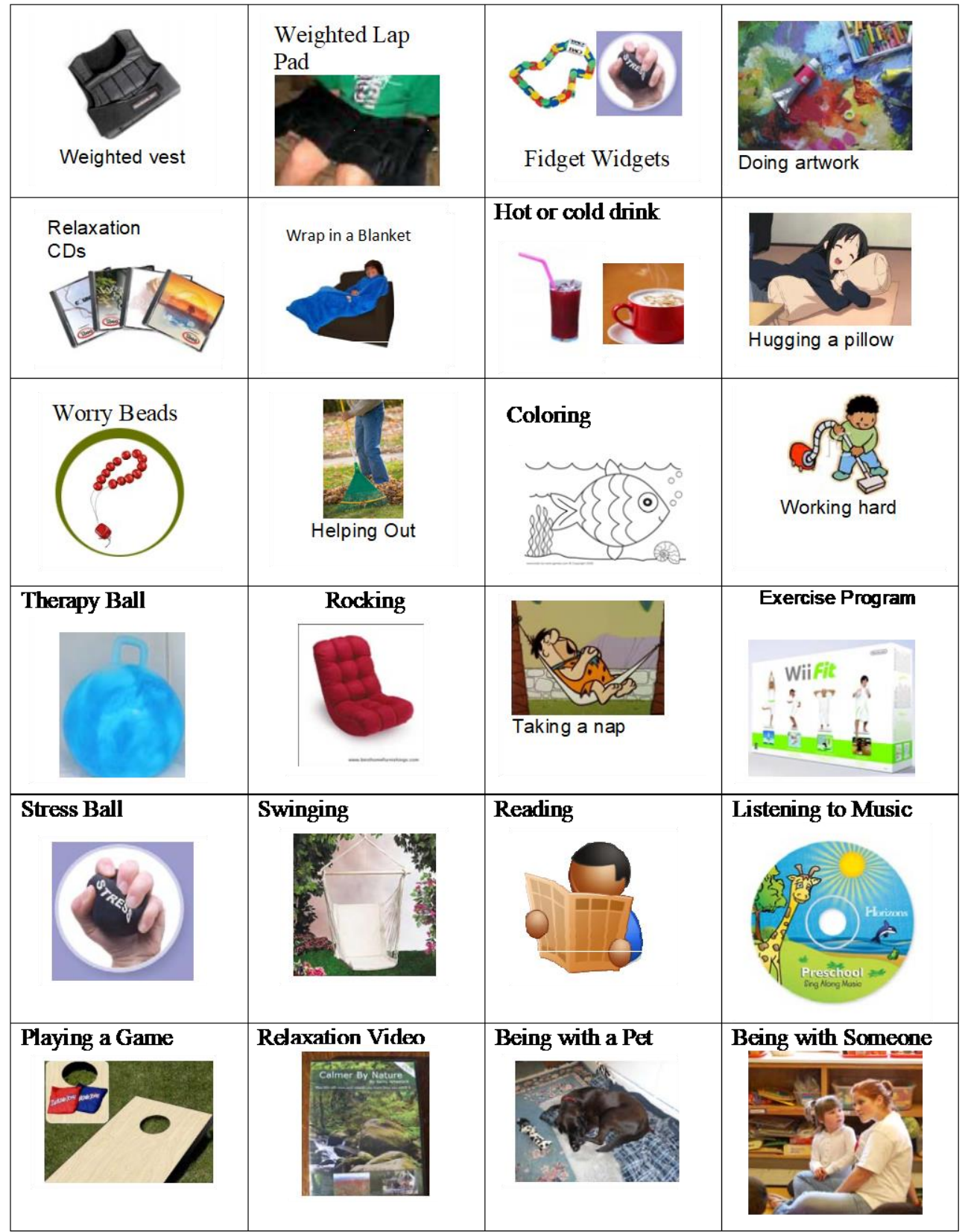




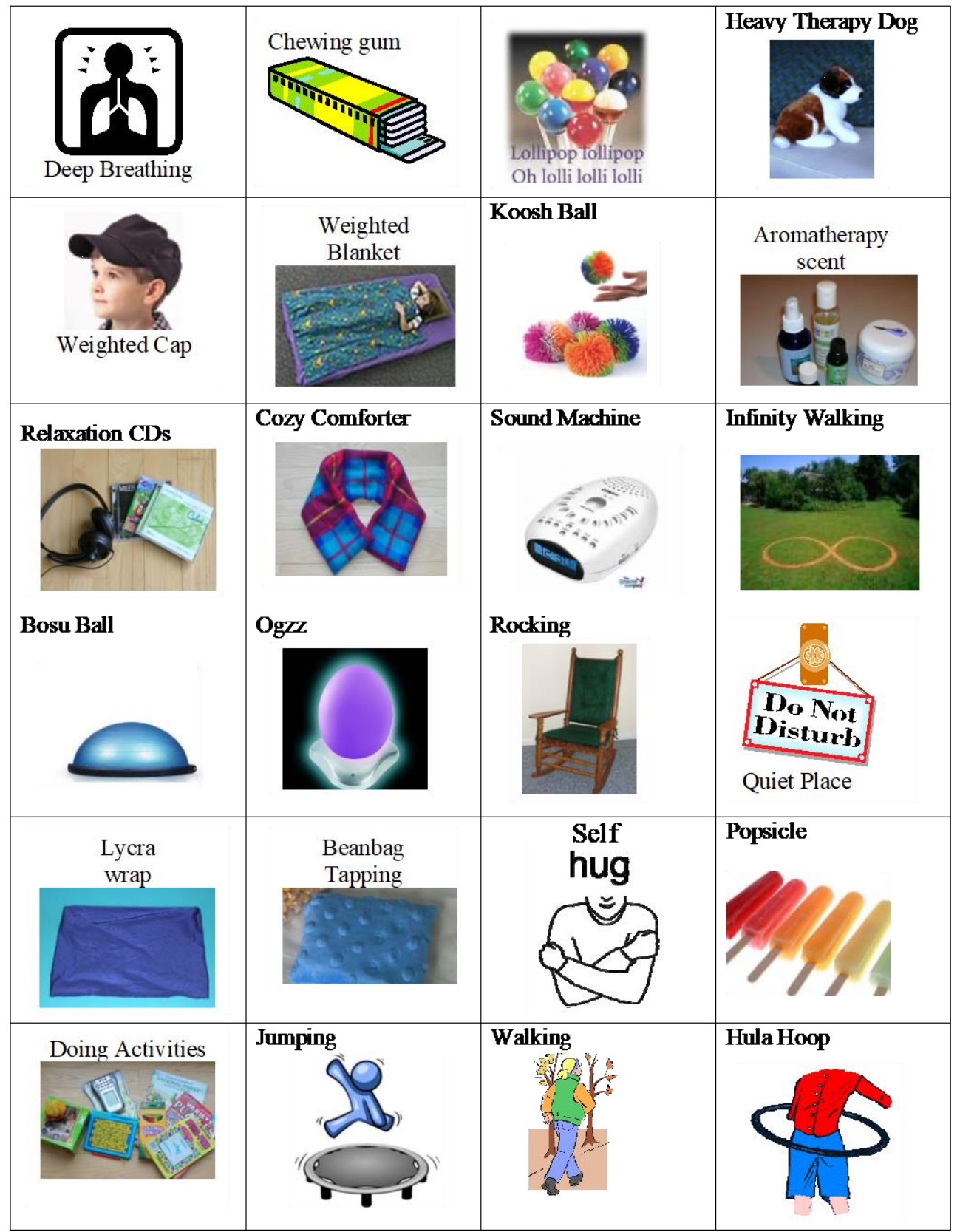




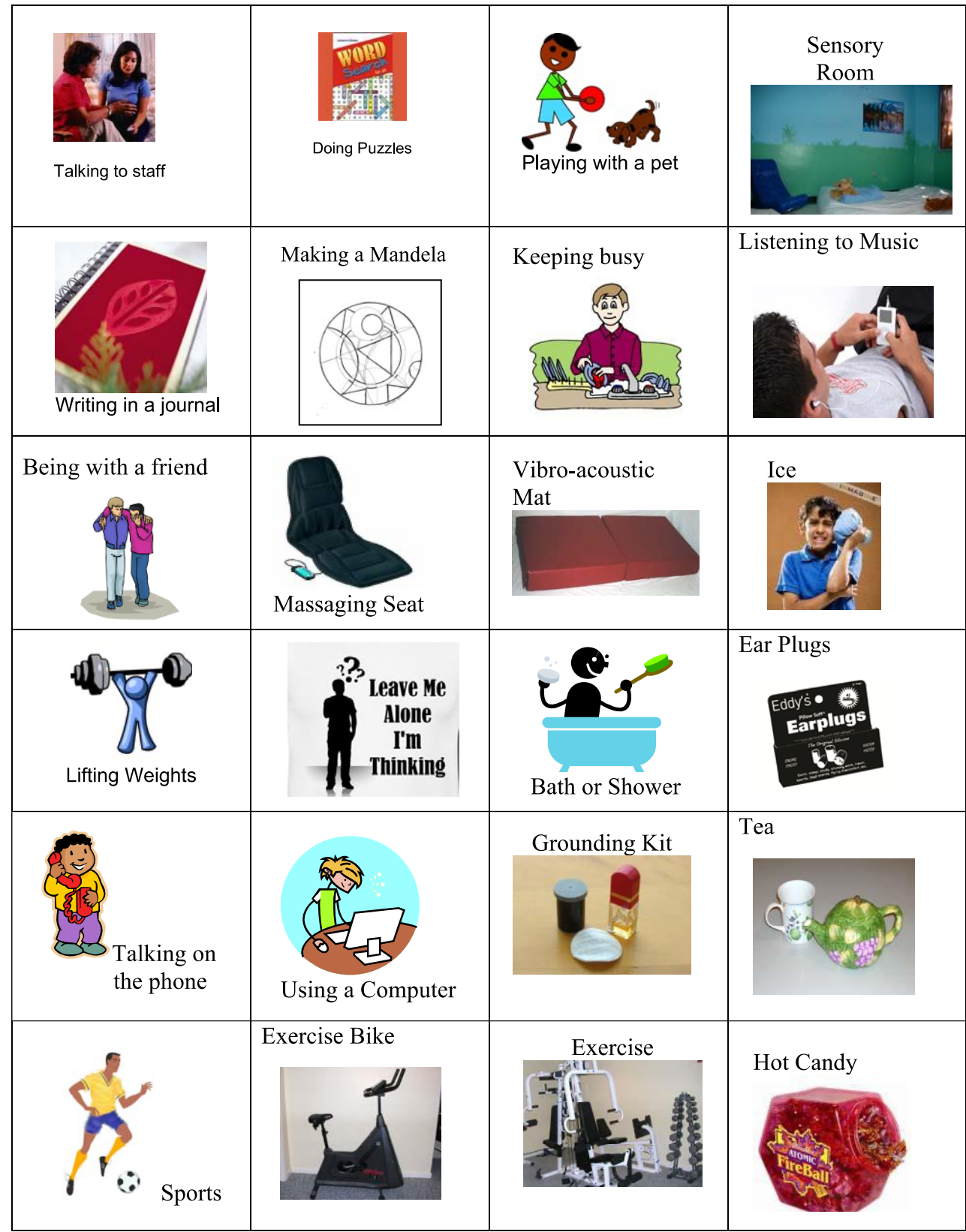




\section{Week 4: Crisis Prevention Planning and Intervention}

\section{Length of session: 2 hours}

Group Goal: Self-regulation and positive change which occurs through the "continued strengthening of helpful sensory modulation habits and lifestyle change. Through increased selfawareness and consistent use, feelings of coherence and competence in the use of meaningful sensory modulation strategies emerge, which is evidence that healthy habits are strengthening" (Champagne, 2017 pp. 126- 128). And individual repertoire expansion through the addition of new skills and skill enhancement that continues to facilitate occupational performance and health, wellness and recovery" (Champagne, 2017 pp. 126- 128).

\section{Two short-term goals:}

1. Group members will create and complete/edit already developed individual crisis intervention plans that identifies triggers, warning signs, sensory strategies, and supports with $\min / \bmod \mathrm{A}$.

2. Group members will identify where they need to place their crisis intervention plan worksheet for easy access when a crisis may arise with less than two verbal promptings.

Introduction: Introduce self as therapist. Have group members introduce themselves and begin warm-up activity. Warm-up Activity: review what the sensory systems are and sensorymodulation strategies that belong in each category. Briefly have group members share ways in which strategies did not work for them during the past week. Offer suggestions as they come up in discussion.

Activity Using the whiteboard go around and ask individuals what a crisis may look like to them, write responses on the board. Examples may include: 
SUBSTANCE USE AND CHRONIC PAIN

- Urges to relapse/cravings

- Urges to self-harm

- High pain

- High anxiety

- High depression

Then use The Sensory Connection Program: Curriculum for Self-Regulation (Moore, 2014) worksheet to guide identifying individual triggers, warning signs (physical, behavioral, emotional), and what does and does not help in that crisis state on the board together. Each group member should identify multiple examples for each category, the white board should have as many examples as possible each time. Then have group members create their own Crisis/Relapse Intervention/Prevention plan. Encourage group members to include things such as sponsors name and number, healthcare providers contact information, friends and family contact. Encourage these plans to be as specific as possible so that in the scenario group members will have a detailed action plan. This tool is intended to prevent the "occurrence or evolution of barriers to performance in context" (AOTA, 2020, p. 64).

Sharing: Have individuals show the group how they designed their Crisis Intervention Plan/Relapse Prevention Plan and what they added as supports and strong sensory input to help prevent these situations. stress. Have everyone share by going around the table in a clockwise fashion.

Processing: Group members then will be encouraged to contemplate times where they may have needed a plan like this. What happened instead? How could have things been different? Was this something in hindsight that would have been useful to communicate with family and healthcare 


\section{SUBSTANCE USE AND CHRONIC PAIN}

providers? Individuals will share and others will listen with respect. Group leader will mediate this to ensure that everyone is heard, and the group is respectful.

Generalizing: Verbalize a few general principles learned from activity such as identifying triggers, warning signs, and strategies to prevent relapse and supports. Consider how some of the strong input is a sensory-based activity/occupation, what sensory systems is that activity providing input to? The facilitator should ask open ended questions and follow up on areas that generate spontaneous conversation. Asking open questions that reveal the meaning of the activity for the group members. Address any conflict that arose in the groups and ask what a positive response might be instead.

Application: Consider how identifying these triggers, warning signs and coping strategies serve as a tool for self-regulation. This occupational therapy intervention serves to target specific client factors such as energy, temperament, orientation, emotion, and thought, or performance skills such regulation, initiation, and disclosing (AOTA, 2020). Discuss how developing a crisis plan can be used to communicate with healthcare providers, family, and supports and serve as a tool for safety and emergency maintenance. Ask each group member who they think sharing this plan with would be helpful and where they plan on placing the plan in their environment? Consider how to apply self-regulation strategies when the triggers occur could prevent further escalation of warning signs and crisis situations.

Summary: Ask group members to summarize the most important aspects of the group. Summarize what served as supports and barriers for the individuals in applying the group concepts to life. Summarize learning and emotional response to group topic. Give positive reinforcement by providing a handful of things that group members did well (such as did a great job being involved, asking questions to other people, or being respectful when others share). 


\section{SUBSTANCE USE AND CHRONIC PAIN}

Discuss the skills required to participate and how these skills can and will play a part in the future. Address the importance of continuing to take the resources from group and implementing them through their daily life. Thank the participants for their time, effort, and participation.

\section{Materials needed:}

- Whiteboard

- Whiteboard markers

- Printed handouts

- Pens and pencils for filling out the worksheets

\section{Possible adaptations:}

- To grade up: have individuals create their own personalized Crisis Intervention/Prevention Plan with art supplies. Encourage them to personalize it with quotes/saying, pictures, and colors utilizing their own sensory preferences.

- To grade down: Have individuals copy the checked items on the worksheet to one of the provided plans. Help members of the group determine the best location for this plan, make copies of it for them so it can be put in multiple locations, encourage them to provide it to caregivers. 
Make a mark beside things that make you upset, scared, or on the verge of crisis.

$\square$ Being touched

ㄴ. Loud environment

$\square$ Yelling

$\square$ Evening time

D Darkness

口 Flashbacks

$\square$ Certain time of day

$\square$ Being humiliated

Teasing

Demands from others

Being ignored

Being isolated

Being told what to do

Feeling out of control

Bad memories

Frustrations with inability to dothings

Not being able to go outside $\square$ Having nothing to do

․ Feeling overwhelmed

$\square$ Nightmares

Not being able to sleep

$\square$ Being restrained

$\square$ Seclusion

$\square$ Being anxious

$\square$ Certain place

$\square$ Feeling threatened

D Visits from friends/family

D Talking about certain problems

D Feeling misunderstood

- Hearing about other people's bad experiences

$\square$ Cravings

$\square$ Being around too many people

$\square$ Scary thoughts

Changes in routine, care providers, room (explain)

Not having control, choices, or input (explain)

Being around men or women (which?)

Time of year (when? Anniversary of event?)

Reminders of bad experiences (explain)

Contact with person who is upsetting (explain)

Going outside - large open spaces (explain)

Closed doors-feeling claustrophobic (explain)

Auditory or visual hallucinations (describe)

Psychotic thinking or mania (explain)

Paranoia-thinking someone is following or talking about you (explain)

Symptoms of fillness (explain)

Other (explain)

Ask a friend, family member, or care provider if he or she has noticed anything that seems to cause you to lose control or typically precedes a crisis.

The Sensocy Connection Program: Curriculum for Sel-Begulation - Copyright O 2015 Karen M. Mocre 


\section{WHAT ARE YOUR WARNING SIGNS?}

Check behaviors and attributes that are signs you may lose control.

D Sweating

ㅁ Crying

ㄴ Loud voice

B Bad thoughts (self or others)

D Clenching fists

$\square$ Wringing hands

D Biting arm or body part

$\square$ Banging wall or furniture

D Throwing things

- Withdrawal/isolation

$\square$ Giddiness/laughter

$\square$ Rocking

Suicidality

口 Agitation

口 Pacing $\square$ Restlessness

$\square$ Rudeness

- Signs of anger

$\square$ Yelling

ㄴ Uncooperativeness

ㅁ Extreme anxiety

ㅁ Argumentativeness

ㅁ Flashbacks

ㅁ Self-injury

ㅁ Temper tantrums

口 Withdrawal

E Emotional swings

口 Dissociation

D Disruptiveness

T Threats

Do you have warning signs that are not listed? Describe.

What are the most worrisome signs?

Ask a friend, family member, or care provider what signs he or she notices before a crisis:

The Senspry Cennection Program: Curriculum for Selt-Reguason - Cosgright O 2015 Keven M. Noore

183 


\title{
SUBSTANCE USE AND CHRONIC PAIN
}

\author{
The Sensory Connection Program: Curriculum for Self-Regulation
}

\section{WHAT HELPS?}

Identify things that help you calm down and regain self-control. You may want to fill this worksheet in as you experiment with various sensory input and other strategies.

Medication

$\square$ Being with a caring person

$\square$ Grounding strategies

S Smell box

$\square$ Holding Ice

Sucking on hot balls or strong mints

D Sucking on a popsicle or ice chips

口 Helpful fragrances

$\square$ Chewing gum/sucking on candy

D Warm or cold drink

Listening to music

$\square$ Relaxation tapes

Sound machine

$\square$ Deep breathing/mindfulness exercises

Looking at art or beautiful books

$\square$ Watching a funny or calming video

$\square$ Watching a lava lamp/bubble tube

Drapping up in a blanket

$\square$ Wrapping up in a spandex hug

$\square$ Weighted blanket

$\square$ Weighted animal, lap pad, vest, or hat

V Vibrating dog or pillow

$\square$ Beanbag chair and warm cover

Warmed lap or shoulder pad

Beanbag tapping/brushing
Dqueczing a stress ball

$\square$ Hugging a pillow

$\square$ Fidget widgets, Koosh balls

$\square$ Tossing or bouncing a ball

$\square$ Rocking in a chair or glider

ㄴ Swinging

$\square$ Exercise band rowing

$\square$ Pacing

$\square$ Walking or jogging

Hot or cold shower

$\square$ Warm bath

- Yoga or a movement routine

$\square$ Time in the sensory room

口 Something from the sensory cart/box

$\square$ Voluntary time in the quiet room

$\square$ Talking with a friend or staff person

$\square$ Calling a family member

$\square$ Keeping busy

- Helper tasks (cleaning, etc.)

口 Hard work

W Writing in a journal

Coloring, painting, or other artwork

$\square$ Doing puzzles/word searches/crosswords

$\square$ Reading

$\square$ Stroking or playing with a pet

\section{WHAT DOES NOT HELP?}

Noise

Confusion

Being Alone

Yelling $\square$ Threats

$\square$ Being restrained

$\square$ Male or female staff (which?)

D Nothing to do

The Sensory Connection Fisgant Qurriculum for Selt-Aegulason - Cooright O $2015 \mathrm{Karen} \mathrm{M.} \mathrm{Moore}$

184 


\section{Crisis Prevention Plan}

RECOGNIZE TRIGGERS, WARNING SIGNS, AND STRATEGIES TO PREVENT CRISIS

MY TRIGGERS:

PHYSICAL, EMOTIONAL, BEHAVIORAL WARNING SIGN :

SENSORY STRATEGIES TO TRY:

S U P P O RT S: 


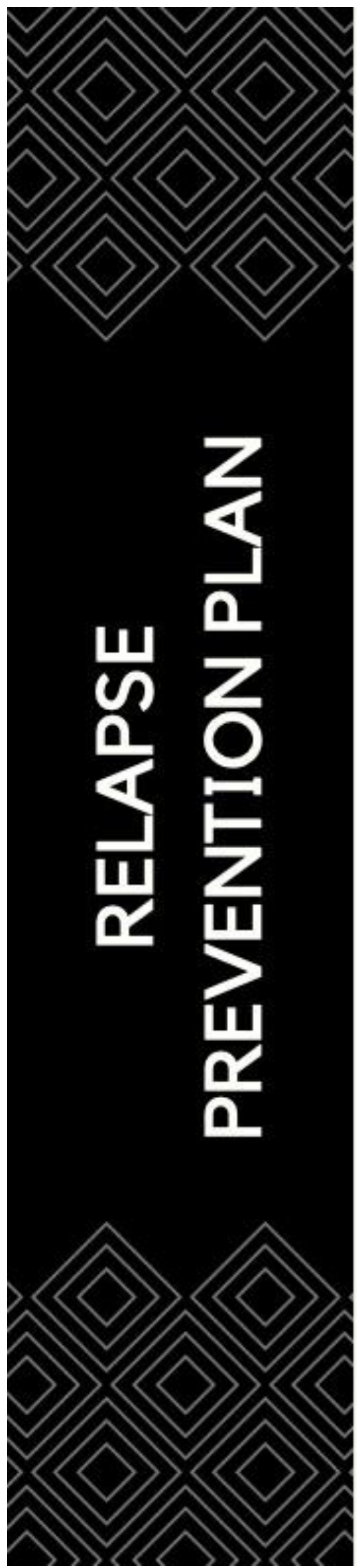

MY TRIGGERS:

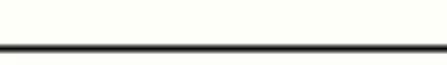

\section{RELAPSE PREVENTION STRATEGIES:}

THINK STRONG INPUT

\section{SIGNS :}

\section{SUPPORTS I CAN CALL OR GO TO:}




\section{Week 5: Stress Management}

\section{Length of session: 2 hours}

Goal of Group: Improve skills that contribute to the occupation of "Health ManagementActivities related to developing, managing, and maintaining health and wellness routines, including self-management, with the goal of improving or maintaining health to support participation in other occupations (AOTA, 2020, p.32).

Two short-term goals:

1. Client will identify individualized factors that contribute to stress and alleviate stress through a group led worksheet activity with less than 3 verbal cues or redirection.

2. Client will organize, prioritize, and sequence a to-do lists for improved daily task and routine completion including but not limited to meal preparation/planning, ADL and IADL tasks, self-care and leisure participation, and recovery-based occupations.

Introduction: Introduce self as therapist. Have group members introduce themselves and provide a brief outline of the activity for the day including the purpose and timeline for the session. Group expectations will also be established.

Activity: Pass out the following Stress Management worksheet to each member of the group (Therapist Aid LLC, 2020). As a group work through the sections encouraging everyone to share, items for each category will be written on the board to help spark ideas and find items that resonate with multiple group members. After things that contribute to stress and things that help alleviate stress have been identified and explored the group leader will pass out the two styles of planning and prioritization sheets. Have group members fill out the to-do list for today. Differentiating between top priorities and secondary tasks (Vertex42, 2015). The Eisenhower 


\section{SUBSTANCE USE AND CHRONIC PAIN}

Matrix is another technique for reducing stress and improving productivity. It prioritizes tasks by urgency and importance. This also highlights the skill of delegating and eliminating unnecessary tasks or habits that may be impacting health management.

The following video that explains the Matrix in further detail may be helpful: https://www.youtube.com/watch?v=tT890Z7TNwc. (Eisenhower, 2012).

This should take up a majority of the group time. 15-20 minutes should be left to complete the final steps of the group.

Sharing: Ask everyone in the group to share what their top 3 priorities for the day are and some strategies they plan on using to relieve stress. Have everyone share by going around the table in a clockwise fashion.

Processing: Group members then will be encouraged to contemplate times where they had unmanageable levels of stress. What did their routines, roles, habits, look like during this time? How was the stress impacting self-care, home management, meal preparation and participation? What about social and spiritual participation? How did stress impact their former substance use? Individuals will share and others will listen with respect. Group leader will mediate this to ensure that everyone is heard, and the group is respectful.

Generalization: Verbalize a few general principles learned from activity such as identifying stressors, identifying protective factors for stress, the use of organizing and planning. The facilitator should ask open ended questions and follow up on areas that generate spontaneous conversation. Asking open questions that reveal the meaning of the activity for the group members. Address any conflict that arose in the groups and ask what a positive response might be instead. 


\section{SUBSTANCE USE AND CHRONIC PAIN}

Application: Ask group members how creating a daily to-do list and creating priorities may impact their participation in things such as evening routine, meal planning and preparation, caring for others and social participation, and recovery-based occupations. Encourage group members to consider where they prioritized self-care, leisure, and recovery-based occupations. Applying concepts learned in previous group what are the sensory components of the activities that reduce stress. Ask how group members intend on continuing to build on the skills learned in group and how they intend on applying them to everyday life. Encourage group members to make to-do lists and prioritize tasks on a daily or weekly basis.

Summary: Ask group members to summarize the most important aspects of the group. Summarize what served as supports and barriers for the individuals. Summarize learning and emotional response to group topic. Give positive reinforcement by providing a handful of things that group members did well (such as did a great job being involved, asking questions to other people, or being respectful when others share). Discuss the skills required to participate and how these skills can and will play a part in the future. Address the importance of continuing to take the resources from group and implementing them through their daily life. Thank the participants for their time, effort, and participation.

\section{Materials needed:}

- Whiteboard

- Whiteboard markers

- Printed handouts

- Pens and pencils for filling out the worksheet

\section{Possible adaptations:}




\section{SUBSTANCE USE AND CHRONIC PAIN}

- To grade up: encourage client to bring in their planners or go buy one the week before so they can begin creating weekly and monthly goals and priorities. They could also include significant other and child priorities and schedules to create a master plan for household stress reduction.

- To grade down: just focus on what the client has to do today. This will help to simplify the task and work on developing skills of organizing, prioritizing, and planning. Encourage the group members to use the to-do list created in group for one day and determine how they felt and their participation in their evening routine. 


\section{Stress Exploration}

\section{Factors that Contribute to Stress}

Describe your biggest stressors in each of the following categories and rate them on a scale of 1-10, where

1 is "a little stressful" and 10 is "extremely stressful."

\section{Daily Hassles}

Common annoyances or strains of daily life.

Examples: traffic, chores, work problems, lack of sleep, homework, limited free time, argument with partner

1

rating

2

3

4

\section{Major Life Changes}

Important events, both positive and negative, that require significant adjustment.

Examples: birth of a child, separation or divorce, new job, death of a loved one, moving, major illness / injury

1

2

3

4

\section{Life Circumstances}

Permanent or long-term circumstances that make life more difficult.

Examples: poverty or financial problems, disability, chronic illness, conflictual relationships, values that conflict with culture, discrimination, job dissatification, living somewhere unsafe

1

2

3

4 


\section{Stress Exploration}

\section{Factors that Protect Against Stress}

Describe the things in your life that counteract stress.

\section{Daily Uplifts}

Positive experiences that make you happy.

Examples: eating a good meal, spending time with friends, leisure activities, spending time in nature

1

2

3

4

\section{Healthy Coping Strategies}

Positive actions that help to reduce or manage stress and other uncomfortable emotions.

Examples: exercise, talking about problems, self-care, journaling, relaxation techniques

1

2

3

4

\section{Protective Factors}

Individual characteristics or life circumstances that protect you from stress.

Examples: financial stability, good physical health, supportive family, motivation to succeed, education

1

2

3

4 

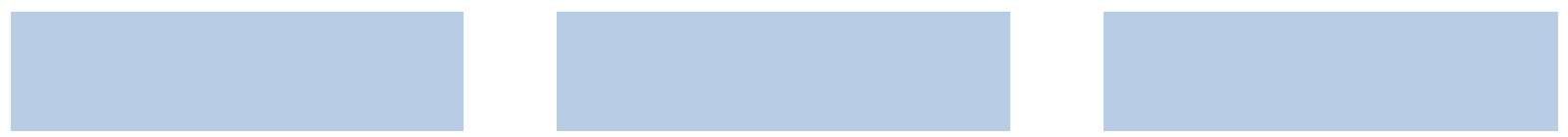

$\star$

$\star$

$\star$

$\star$

$\star$

$\star$

$\star$

$\star$

$\star$

$\square$

$\square$

$\square$

$\square$

$\square$

$\square$

$\square$

$\square$

$\square$

$\square$

$\square$

$\square$

$\square$
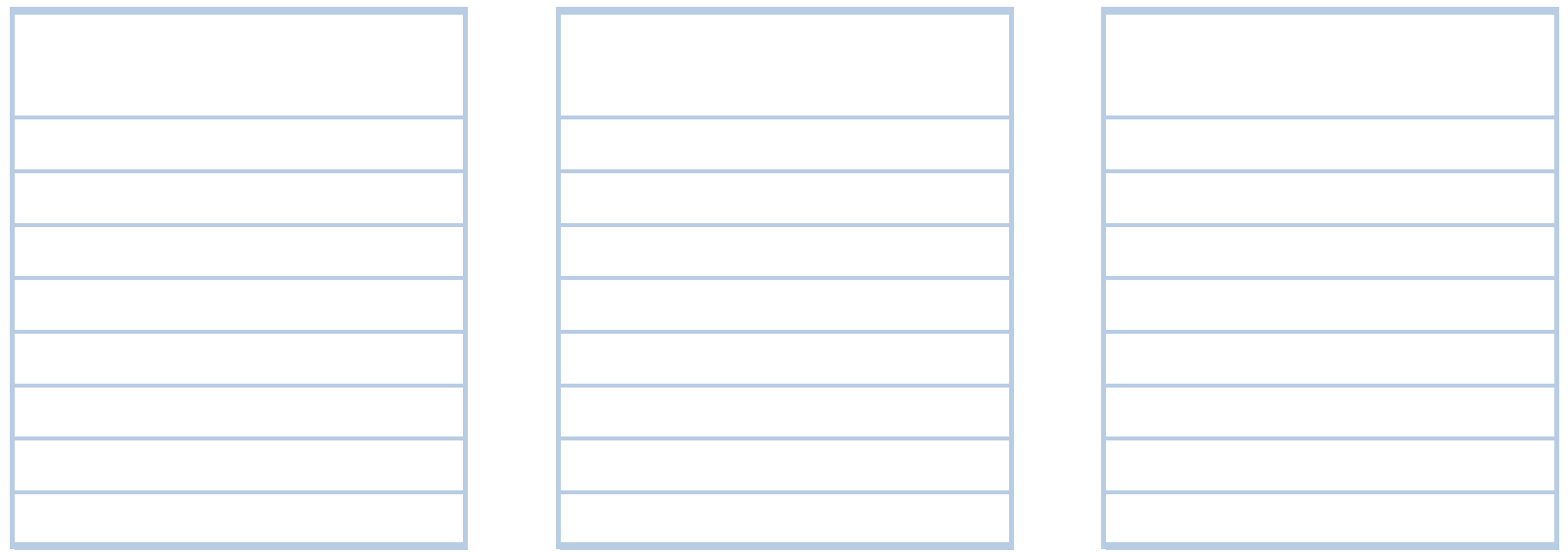

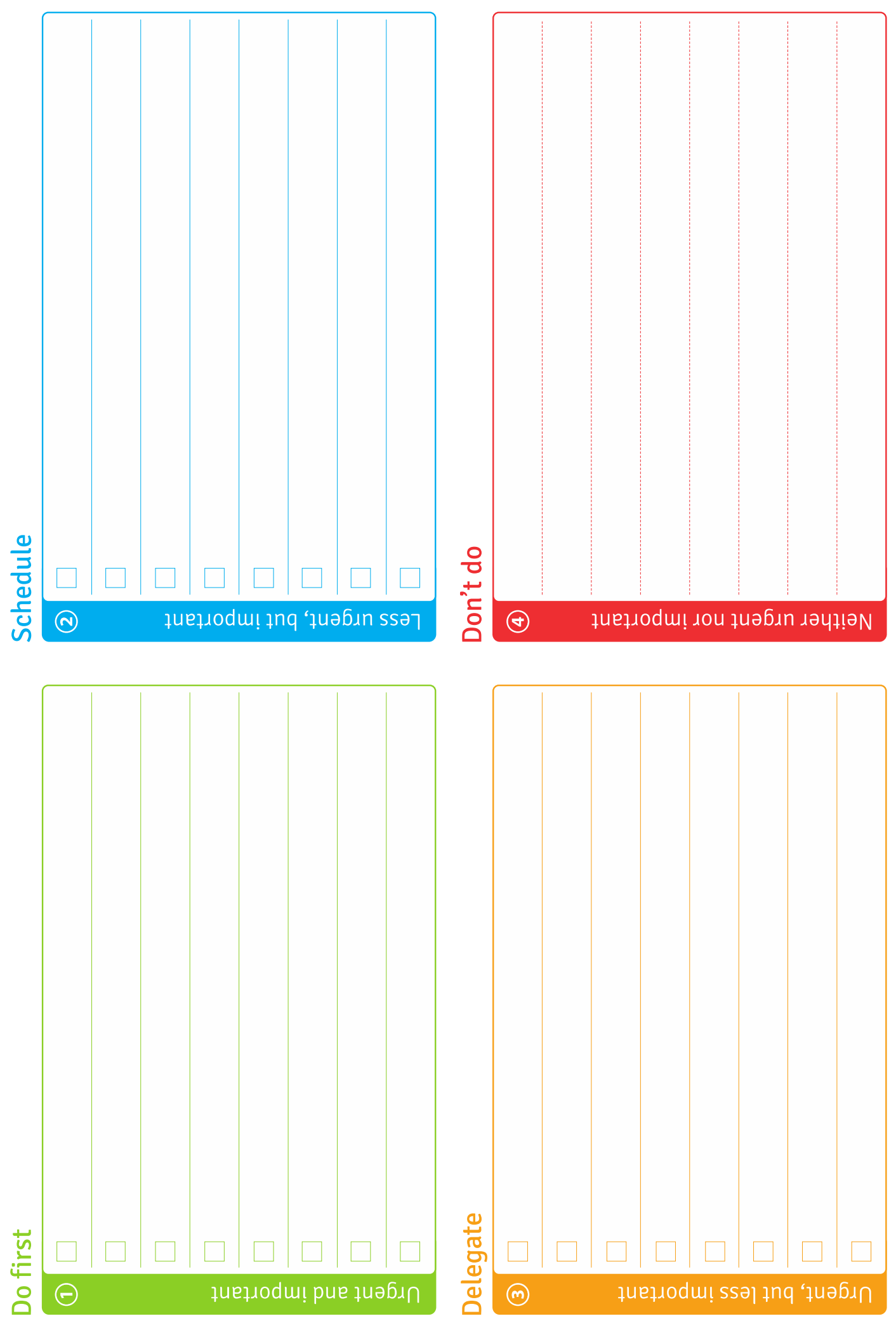


\section{Additional Specific Pain Management Group}

Note: While groups 1-5 offer strategies that support nonpharmacological, behavioral strategies for chronic pain management this group is designed specifically for individuals with chronic pain/fatigue.

\section{Length of session: 2 hours}

Group Goal: Modify techniques for pain management through improved personalized selfregulation, coping strategies, planning, and pacing techniques to support/improve participation in occupations or meaningful activities (AOTA, 2020).

\section{Two short-term goals:}

1. Group members will be able to identify 5 things that turn their "pain dial" up and 5 things that turn their "pain dial" down in order to improve health management

2. Group members will complete an activity pacing plan for returning to a desired occupation with less than 3 verbal cues.

Introduction: Introduce self as therapist. Have group members introduce themselves and begin 5-minutes warm up activity. This activity is a guided meditations "Mindfulness of Change" that will set the tone for the group, focusing on understanding individuals' pain, how their pain feels, and how it changes. Then a brief outline of the activity for the day will be presented including the purpose and timeline for the session. Group expectations will also be established. Link to guided meditation: https://www.newharbinger.com/9781684036448/the-painmanagement-workbook/ (Zoffness, 2020). 


\section{Activity: There are two main activities in this group. Depending on group members}

\section{abilities and group dynamics these can be split into multiple group sessions.}

1.) Pain Education- Education is a type of occupational therapy intervention "enable the client to acquire helpful behaviors, habits, and routines" (AOTA, 2020, p.61). The first part of the group will be dedicated to explaining pain and the biological, psychological, and social factors that contribute to a client's pain and how to use those factors to improve self-management of chronic pain. Moseley (2003) conducted a study on educating clients and patients on the neurophysiology of pain. The main take away was that:

"patients can understand the neurophysiology of pain but professionals underestimate patients' ability to understand. The implications are that (1) a poor knowledge of currently accurate information about pain and (2) the underestimation of patients' ability to understand currently accurate information about pain represent barriers to reconceptualization of the problem in chronic pain within the clinical and lay arenas." (p.1)

Using the whiteboard, the group facilitator will educate group members on what pain is and how using the Biopsychosocial approach can help to manage pain. The facilitator will draw a three circle Venn diagram to show the biological, psychological and social components that may be adding to pain. Below are some examples:

a. Biological

i. Genetics

ii. Tissue damage

iii. System disfunction

iv. Inflammation

v. Hormones 
vi. Diet*

vii. Sleep *

b. Psychological

i. Thoughts *

ii. Beliefs *

iii. Meaning assigned to pain *

iv. Emotions *

c. Social

v. Coping behaviors *

i. Family

ii. Friends

iii. Socioeconomic factors

iv. Environmental context *

v. Culture

vi. Society

The items with a $*$ should be talked about as something individuals have more control over than the other items, this should highlight how OT can help with these aspects of life. Pain is defined by The International Association for the Study of Pain as "an unpleasant sensory and emotional experience" (1994, para.1). This should highlight that pain is both physical and emotional, therefore there is a part that put brain can control. The facilitator will then introduce the "Pain Dial" analogy (Zoffness, 2021).

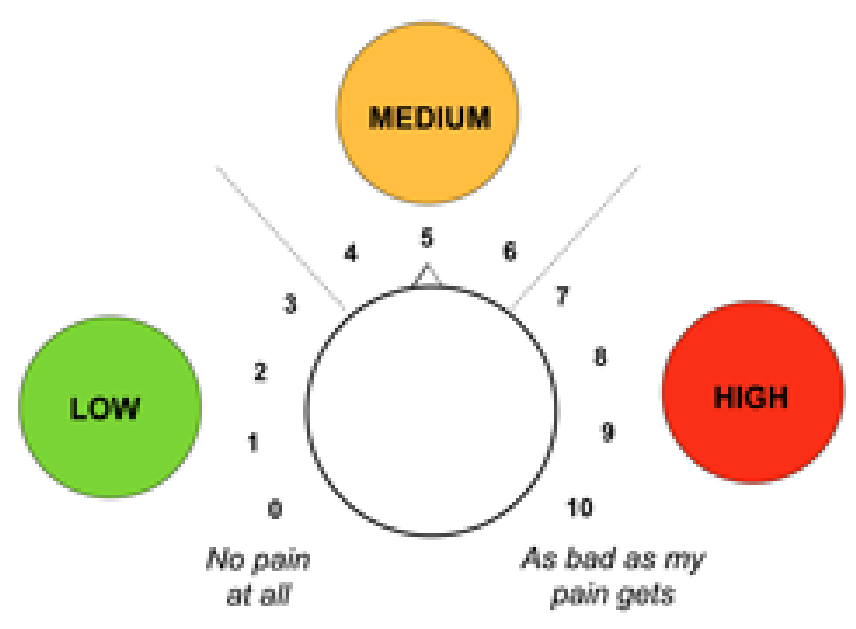

Draw something similar to this on the white board. It should represent a dial, similar to a car stereo. Then list the three things that can turn up or down the "pain dial".

1.) Thoughts- they come from the cerebral cortex of the brain

2.) Emotions- they come from the limbic system

3.) Attentional process- they come from the prefrontal cortex (Zoffness, 2020).

(Hypnosis and Suggestion, n.d.) 


\section{SUBSTANCE USE AND CHRONIC PAIN}

These parts of the brain control your stress and anxiety, mood, and attention. This means stress, anxiety, mood, and attention all contribute to your pain. When you are stressed and anxious your cerebral cortex and limbic system sends signals to your brain that turn the "pain dials" volume up. When your mood and emotions are negative (such as: sad, hopeless, anger, frustrated) the limbic system sends a signal to the brain to turn the "pain dial" up. Same goes for attention, when you are focusing on pain and not engaged in the activities of life the prefrontal cortex sends a signal to your brain turning the pain dial up. However, the opposite is true. The "Pain Dial Review" sheet (Zoffness, 2020) can be helpful when describing this. This highlights the mind-body connection and how what we think and do effects how the body feels. Pass out the following "Pain Dial" worksheet for each member of the group to complete. Encourage group members to fill in as many things that turn the "pain dial" up and as many things they can think of that turn the "pain dial" down.

2.) Pacing Strategies- Training Two different styles of Pacing strategies have been included. One is more mathematical based with time allotted for work and breaks. The other is a way of describing how much energy one has in the day and how to allocate "spoons" to completing tasks. Depending on group members type of chronic pain, goals, and abilities one may seem more appropriate that the other. Clinical judgement should be used. Both strategies should highlight that activity is good, even for those with chronic pain. This trains the mind that activity and participation in daily life is safe. Pacing is defined by Zoffness (2020) as "graded exposure activity that can help you reduce pain flares, do more of what is important to you, conserve energy for activities you value, and feel more in control of your life" (p.66). Individuals with chronic pain who received learned pacing 
interventions in therapy have been found to have clinically important changes in occupational performance and occupational satisfaction (Guy et al., 2020).

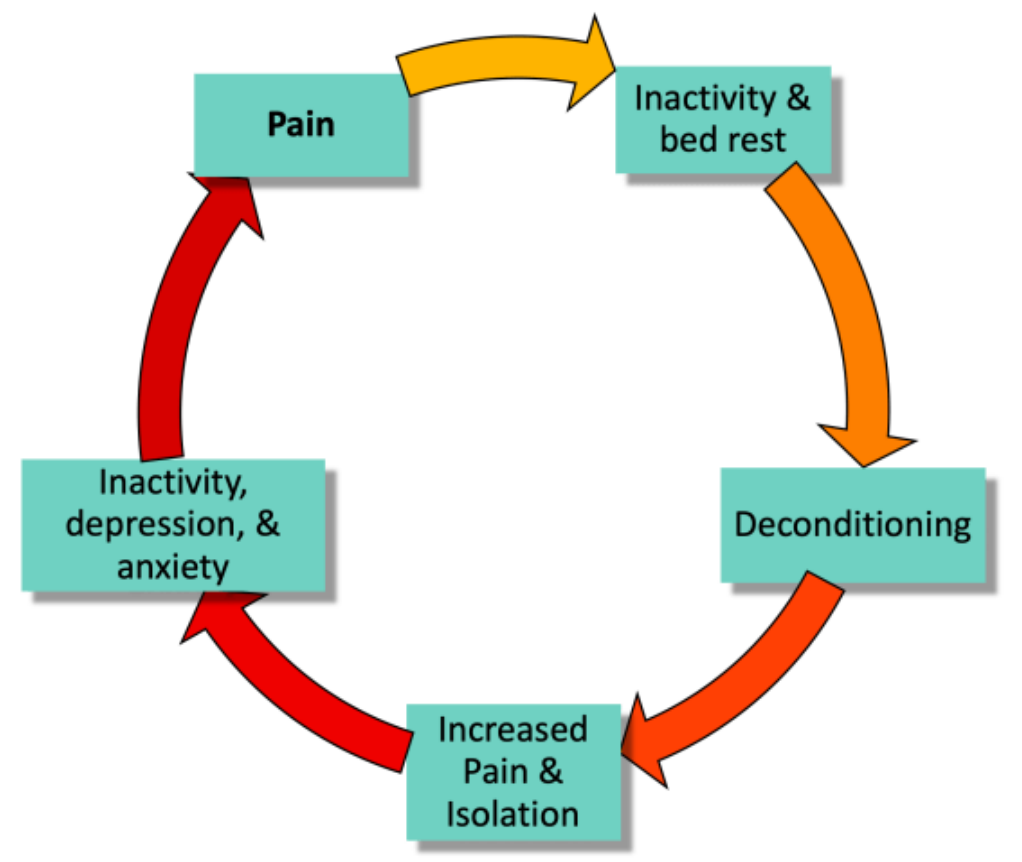

(1step2life, n.d.)

The above image can help group members understand how inactivity, also known as the overactivity-underactivity cycle, can contribute to increased pain and decreased participation in daily activities (Birkholtz et al., 2004). There is some debate about the use of timers as a pacing strategy "as short frequent rests, planning ahead and timer use can...be perceived as disruptive and unspontaneous" ((Birkholtz et al., 2004, p.485). Therefore, two pacing plans have been included in this group manual, again clinical judgement should be utilized to determine the best fit for the group. The facilitator should either assist in completing the Activity Pacing work sheet or determining how many "spoons" group members may have in the day and then identify how many spoons activities of daily living, leisure, health management tasks, work, and other meaningful 


\section{SUBSTANCE USE AND CHRONIC PAIN}

occupations use. Further information about Spoon Theory and a PDF of the story that created the theory can be found at https://butyoudontlooksick.com/articles/written-bychristine/the-spoon-theory/ and cannot be included in this manual due to copyright. Using the occupational therapy intervention of training, individuals in this group will learn the concepts and skills involved in pacing that will promote increased occupational participation.

Sharing: Ask for a volunteer to share what turns their pain dial up and what turns their pain dial down. If no one wants to volunteer the popcorn. Each person will share.

Processing: Group members will be asked about what their pain is currently. Ask if it was easy or hard to come up with things that turned their pain dial up or down? This may illicit feelings of hope or frustration, discuss this with the group. Individuals will share and others will listen with respect. Group leader will mediate this to ensure that everyone is heard, and the group is respectful.

Generalization: Ask the group members to explain what they learned in the group, ask then to verbalize general principles of pain and ways to manage pain. The facilitator should ask open ended questions and follow up on areas that generate spontaneous conversation. Ask open questions that reveal the meaning of the activity for the group members. Address any conflict that arose in the groups and ask what a positive response might be instead.

Application: Ask how the pain dial exercise and pacing plan can be applied in daily life. Ask each participant how they will be applying these concepts discussed and practiced in group to their daily life to improve occupational engagement and participation. Encourage group members to interact with one another, exchanging suggestions and ideas for application. Discuss 


\section{SUBSTANCE USE AND CHRONIC PAIN}

techniques on ensuring the pacing plan will be implemented such as communicating it to significant others, family members, friends, bosses, and co-workers.

Summary: Ask group members to summarize the most important aspects of the group. Summarize what served as supports and barriers for the individuals in applying the group concepts to life. Summarize learning and emotional response to group topic. Give positive reinforcement by providing a handful of things that group members did well (such as did a great job being involved, asking questions to other people, or being respectful when others share). Discuss the skills required to participate and how these skills can and will play a part in the future. Address the importance of continuing to take the resources from group and implementing them through their daily life. Thank the participants for their time, effort, and participation.

\section{Materials needed:}

- Whiteboard

- Whiteboard markers

- Printed "Pain Dial" and activity pacing worksheet s

- Pens and pencils for filling out the worksheet

- Speaker for playing the meditation aloud

\section{Possible adaptations:}

- To grade up: Have individuals create a weekly pacing plan for more than one meaningful activity. Have group members come up with a pain dial plan that lists strategies to implement during high pain days.

- To grade down: Have group members list things that make their pain worse or better. Help them label if this is something that belongs in the thoughts, emotions, or attention categories. Help group members come up with at least three things in each category that 


\section{SUBSTANCE USE AND CHRONIC PAIN}

helps their pain and three things that contribute to their pain. Focus on emphasizing the concept of mind-body connection and how self-regulation strategies can impact how much pain someone is feeling. The spoon theory for pacing may be easier for some individuals as it does not include mathematics or concepts of time. Actual spoons can also be brought in for a visual demonstration or activity. 
SUBSTANCE USE AND CHRONIC PAIN

The Pain Management Workbook

Pain Dial Review

\section{Pain Dial Review}

PAIN DIAL REVIEW
Volume high = Pain feels worse
Perception or belief that your body is in danger
Stressed or anxious
Body tense and tight
Worried thoughts
Negative mood
Attention focused on pain
Staying inside or in bed for long periods
Volume low $=$ Pain feels less bad
Perception or belief that your body is safe
Relaxed




\section{Pain Dial Worksheet}

Remember thoughts, mood/emotions, and attention to pain can either turn the pain volume up (making us feel worse) or they can be used to turn the pain volume down (making us feel better).

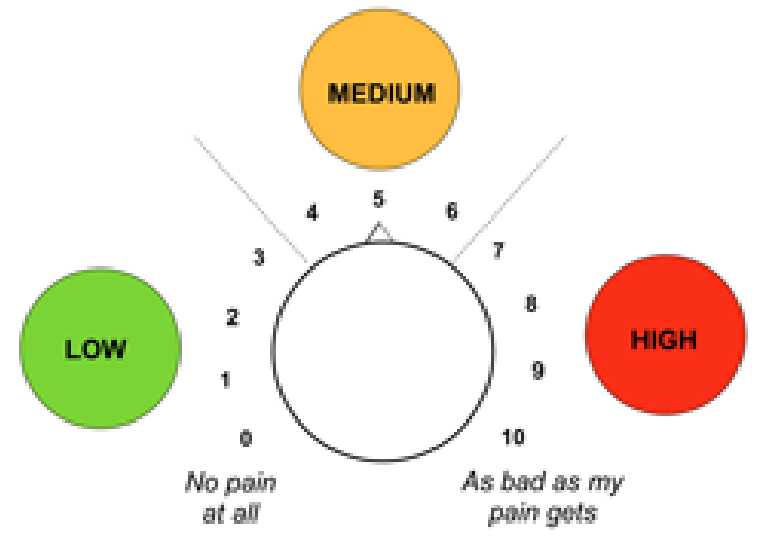

(Hypnosis and Suggestion, n.d.)

\section{List the things that turn your pain volume up (try to come up with 5 items):}

Examples: talking about my pain (attention to pain), feeling isolated and alone (mood/emotions), worrying about work and how I am going to get everything done today (thoughts of stress and anxiety).

\section{List the things that turn your pain volume down (try to come up with 5 items):}

Examples: playing with my dog (decreased attention on pain), listening to happy and uplifting music (mood/emotions), taking a walk after work (decreased thoughts of anxiety and stress). 


\section{Your Activity Pacing Plan}

Step 1. Set a goal. Pick a physical activity you'd like to resume or try. You can make it aspirational or practical, as long as it's personally meaningful.

Step 2. State your ultimate dream goal for this activity, using specific measurements like time, duration, and frequency.

Step 3. Measure the length of time (in minutes) you can do this activity comfortably on a low-pain day, then on a high-pain day.

Low-pain day:

High-pain day:

Step 4. Calculate the average by adding these times together, and then divide the total by two.

Low pain + high pain (total)

Total $\div 2=$ (average)

Step 5. Once you have an average amount of time you can do that activity, subtract a few minutes to give yourself a cushion. This will be your daily baseline.

Average minutes (cushion) $=$ (daily baseline)

Step 6. Plan to take a "rest and stretch" break after a set number of minutes, and establish the length of your break. This number will change from week to week as your strength and stamina increase.

Scheduled break every number of minutes.

Each break will be minutes.

Step 7. Determine your weekly activity increase. Aim to add a few (approximately $2-5$ ) minutes to your activity each week, depending on your tolerance, until you reach your ultimate goal.

Your weekly activity increase: minutes 


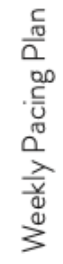

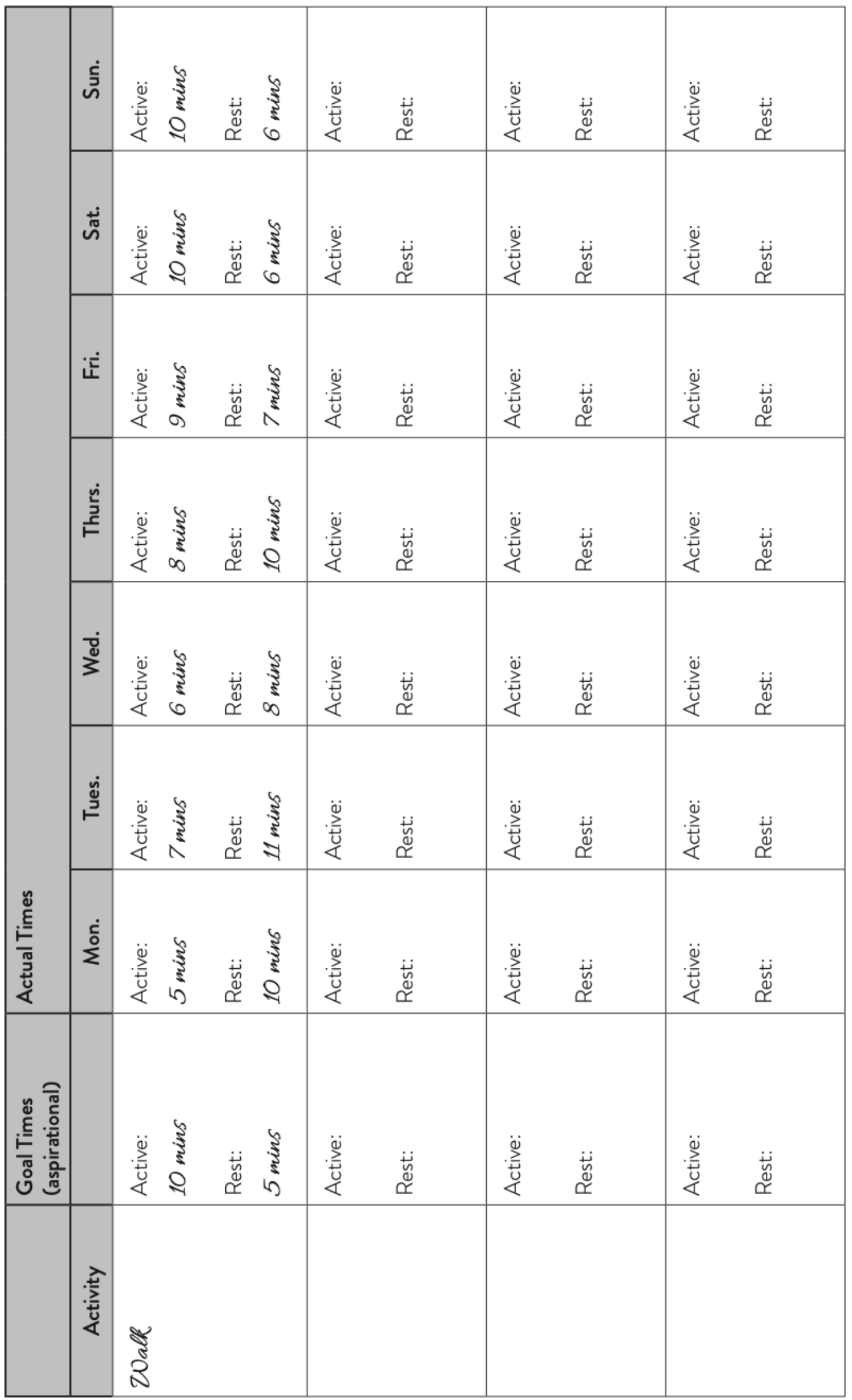




\section{the SPOON THEORY}

The "spoon theory" was originally coined by Christie Miserandino on her blog But You Don't Look Sick, where she talks about living with a chronic illness. The Spoon Theory provides a tangible example of how someone with an illness often has to expend energy on daily tasks - for example, tasks that might take someone without an iliness only one spoon can take someone battling an iliness two or three spoons. This theory is often applied to mental illnesses, as well, and it captures the physical toll that these illnesses can take on someone.

\section{Minus a Spoon, Plus a Spoon}

The central idea behind Spoon Theory is that someone with an illness has a limited number of spoons each day, and once they run out, they often can't muster the energy to do anything else that day. Whereas some people without illnesses can have an unlimited supply of spoons, those with illnesses must treat their energy - or spoons - as a type of currency: tasks can cost one or more spoons or replenish the spoon supply.

\section{To help understand The Spoon Theory and how it applies to mental illness, we've given you fifteen spoons to get you through the day.}

Pick \& choose the tasks that you'd like to complete today.

Try to stick within your allotment of 15 spoons for the day.

Woke up after the first alarm (costs 2 spoons)

Brushed your teeth

Got to work on time

Ate breakfast

Made it through a meeting

Answered all your work email (costs 2 spoons)

Ate lunch

Talked on the phone with a family member

Had a one-on-one with your manager

Went on a date (costs 2 spoons)

Had a difficult conversation (costs 3 spoons)

Contributed to a departmental meeting

Exercised (costs 2 spoons)

Took your meds and/or vitamins

Cleaned up your home (costs 3 spoons)

Spent time with your significant other/spouse

Did laundry (costs 2 spoons)

Fed the pet

Walked the pet/went for a walk

Wrote the first draft of a paper/project (costs 3 spoons)

Scheduled a doctor's appointment

Took a shower (costs 2 spoons)

Ate dinner

Eir Went to bed on time (costs 2 spoons)
Sent a difficult email (costs 2 spoons)

Pick \& choose the spoons to put in your' 'spoon bank' for when you might need them. Remember, some of these examples might not replenish you. Add your own to the bottom!

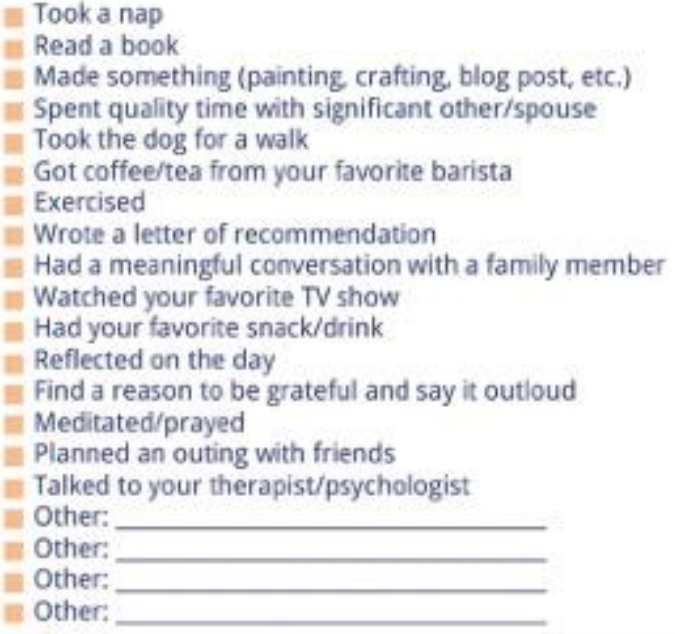

Did you have enough spoons to get through the day? What were some of the tasks that you had to choose between? How did it feel to have a limited amount of spoons?

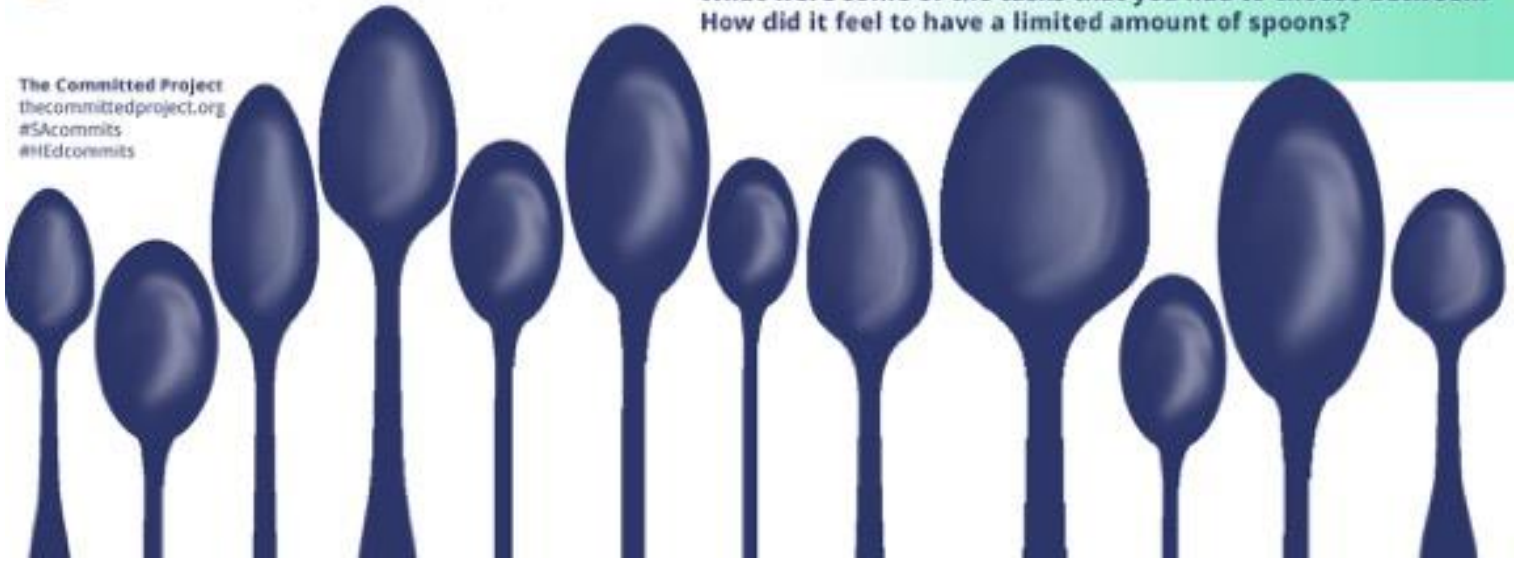

(The Committed Project, 2017). 


\section{How will I use my spoons today?}

As a chronically ill person I only have disposal each day. Therefore, I must pick and spoons at my

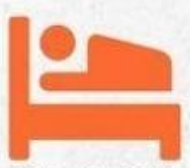

anterty

$\mid x i$

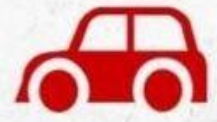

$4 \%$

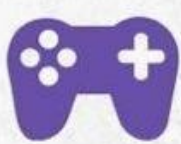

Play games
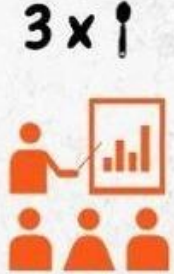

suts
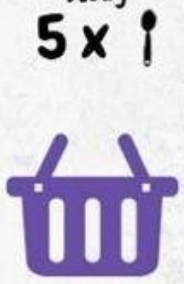

Shopping

$4 \times i$

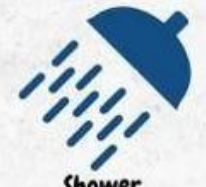

$2 \times 9$

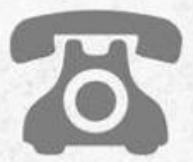

Make a phone call
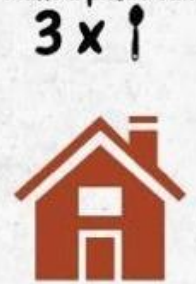

Clean the house
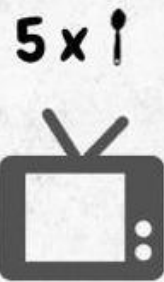

Watch TN
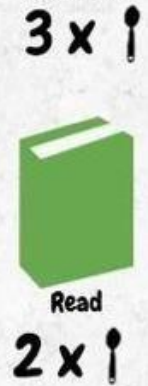

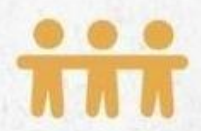

Attend social event
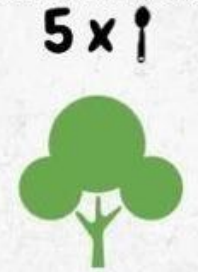

Garden

$5 \times i$

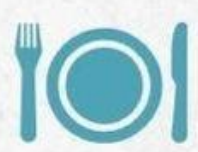

Have a meal

$2 \times i$

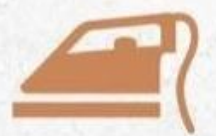

Ironing
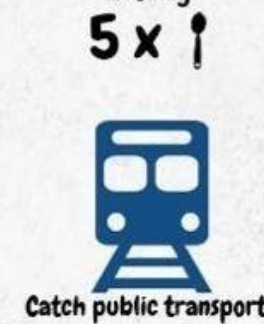

$4 \times$
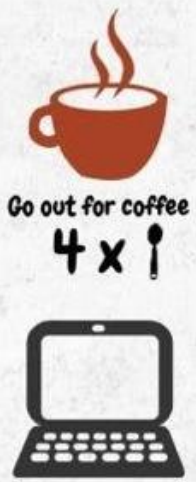

Work
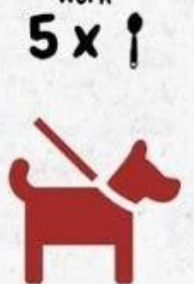

Walk the dog

$4 \times i$

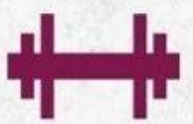

Exercise

$4 \times i$

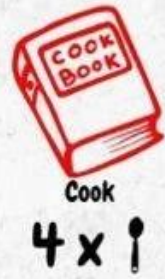

*Note - if you exceed your daily limit, be aware that you will be taking spoons from tomorrows allocation. So be sure to plan ahead accordingly. 
SUBSTANCE USE AND CHRONIC PAIN

\section{References}

1step2life. (n.d.). Pain cycle [Image]. https://1step2life.com/providers/

American Occupational Therapy Association. (2020). Occupational therapy practice framework:

Domain and process (4th ed.). American Journal of Occupational Therapy, 74(Suppl. 2), 7412410010. https://doi. org/10.5014/ajot.2020.74S2001

Birkholtz, M., Aylwin, L., \& Harman, R. M. (2004). Activity pacing in chronic pain management: One aim, but which method? Part two: National activity pacing survey. The British Journal of Occupational Therapy, 67(11), 481-487. https://doi.org/10.1177/030802260406701103

Champagne, T. (2017). Sensory modulation \& environment: Essential elements of occupation ( $3^{\text {rd }}$ ed.) Pearson Australia Group.

Cole, M. (2018). Group dynamics in occupational therapy: the theoretical basis and practice application of group intervention. Thorofare, NJ: Slack.

Dunn, W. (2001). The sensations of everyday life: Theoretical, conceptual and pragmatic considerations. American Journal of Occupational Therapy, 55, 608620. https://doi.org/10.5014/ajot.55.6.608

Eisenhower. (2012, September 2). The Eisenhower matrix: How to manage your tasks with Eisenhower [Video]. Youtube. https://www.youtube.com/watch?v=tT89OZ7TNwc Eisenhower. (n.d.) The eisenhower matrix canvas [PDF]. https://www.eisenhower.me/eisenhower-matrix-canvas/

Guy, L., Mckinstry, C., \& Bruce, C. (2019). Effectiveness of pacing as a learned strategy for people with chronic pain: A systematic review. The American Journal of Occupational Therapy, 73(3). DOI: 10.5014/ajot.2019.028555 


\section{SUBSTANCE USE AND CHRONIC PAIN}

Guy, L., McKinstry, C., \& Bruce, C. (2020). Learned pacing for adults with chronic pain: A randomised controlled trial feasibility study. Australian Occupational Therapy Journal, 67(5), 399-406. https://doi.org/10.1111/1440-1630.12653

Hypnosis and Suggestion. (n.d.). Pain dial [Image]. https://hypnosisandsuggestion.org/scripts.html

International Association for the Study of Pain. (1994). ISAP terminology: Pain. https://www.iasp-pain.org/Education/Content.aspx?ItemNumber=1698\#Pain

Miller, L., Reisman, J., McIntosh, D. \& Simon, J. (2001). An ecological model of sensory modulation. In S. Smith Roley, E. Blanche \& R. Schaaf (eds.), Understanding the nature of sensory integration with diverse populations. San Antonio, TX: Therapy Skill Builders.

Miserando, C. (2003). The Spoon Theory. But You Don’t Look Sick. https://butyoudontlooksick.com/articles/written-by-christine/the-spoon-theory/

Moore, K. (2011). What helps? Activity [PDF]. http://www.sensoryconnectionprogram.com/what_helps_poster_activity.pdf

Moore, Karen. (2014). Sensory connection program curriculum for self-regulation. Therapro.

Not alone illness. (2014, July 21). How will I use my spoons today? [Image]. WordPress. https://notaloneillness.wordpress.com/2014/07/21/choose-your-spoons-2/

Sanson-Fisher, R. [doing.therapy]. (2020, February, 25). \#sensorymodulation \#sensory \#sensoryintegration [Instagram photograph]. Retrieved from https://www.instagram.com/p/CLveoTxBI6U/?igshid=ryz16hf440hh

The Committed Project. (2017, May 5). Spoon theory [PDF]. http://thecommittedproject.org/sdm_downloads/spoon-theory/ 


\section{SUBSTANCE USE AND CHRONIC PAIN}

Therapist Aid LLC. (2020). Stress management [PDF].

https://www.therapistaid.com/worksheets/stress-management.pdf

Vertex42. (2015). Prioritized to do list [PDF].

https://www.vertex42.com/Files/download2/pdf.php?file=to-do-list-prioritized_3-up.pdf

Zoffness, R. (2020). Mindfulness of Change [Audio]. New Harbinger Publications. https://www.newharbinger.com/9781684036448/the-pain-management-workbook/

Zoffness, R. (2020). The pain management workbook: Powerful CBT and Mindfulness skills to take control of pain and reclaim your life. New Harbinger Publications. 


\section{Appendix G}

Capstone Dissemination Plan

1.) A copy of the sensory-based OT group manual will be given to the OT on staff Caitlin Belvin OTR/L at the recovery center for future use with clients in recovery for substance use and chronic pain.

2.) An email will be sent to authors who have published similar studies to inform them about the findings of this study and to discuss future implications/next steps for research in this field.

a. Catana Brown PhD, OTR/L, FAOT at cbrown2@ midwestern.edu

b. Rebecca Knowles, OTD, OTR/L, RYT at RLSKnowles@ gmail.com

c. Kelly, BA (Psych) PostGradDipPsych at john.kelly4@health.qld.gov.au

3.) Submit Poster to Present at the following conferences

\begin{tabular}{|l|l|l|}
\hline $\begin{array}{l}\text { Conference Title } \\
\text { and Date }\end{array}$ & Due Date & Web Link \\
\hline 2021 ArizOTA & June 30, 2021 & https://form.jotform.com/90897372967983 \\
October 15- & & \\
16,2021 & & \\
\hline AOTA Annual & Not calling for & https://www.aota.org/Conference- \\
Conference \& & papers yet & Events/call-for-papers.aspx \\
Expo 2022 & & \\
San Antonio, & & \\
Texas & & \\
March 31- April & & \\
3, 2022 & & \\
\hline
\end{tabular}

4.) Reach out to Brittany Soltani at brittany.soltaniot@ gmail.com about being on her OT in Mental Health Podcast she is releasing to talk about Capstone Experiences in OT Mental Health Settings and the findings of the descriptive study and implications for OT practice.

a. Connected with this person through CommunOT

5.) Potential Journals for Future Publication

a. The Open Journal of Occupational Therapy https://scholarworks.wmich.edu/ojot/author_guidelines.html

i. Cost: No cost to submit the article for review. Once a manuscript has been accepted for publication, the primary author must pay a processing fee of $\$ 300.00$ U.S. dollars and each additional author must pay $\$ 100.00$ U.S. dollars. Because OJOT is an open journal, the authors maintain the copyright and therefore are entitled to any future profits from the publication. Additionally, this publication fee includes professional copy-editing services for all manuscripts. The publication fee is requested upon acceptance of the article for publication and is nonrefundable. 
ii. Link to submit manuscript:

http://scholarworks.wmich.edu/cgi/submit.cgi?context=ojot

iii. Format: Publication Manual of the American Psychological Association (APA) $7^{\text {th }}$ edition for both text and references, Do not include a header or page numbers, as these will be provided by the system

iv. Copyright: No copyright agreement form needs to be completed.

1. However, this is an open access journal which means that all content is immediately freely available without charge to the user or his/her institution. Users are allowed to read, download, or print full texts of the articles in this journal without asking prior permission from the publisher or the author. To copy or distribute individual articles, obtain permission from the corresponding author(s).

v. Process- the manuscript must be in a Word Document, this will only include the body of the paper, all tables and graphs, references, and appendices. Upon submission at the OJOT.org site, the system will allow the author to attach or paste a cover letter to the web page. Additionally, the submission page contains fields for the article title and authors and the system will generate a title page. The author will also be prompted to enter an abstract, key words, footnote/acknowledgments, and an indication of the academic discipline(s) that best describes the submission.

1. This will be confidentially peer-reviewed by $2-3$ members of the Editorial Review Board.

2. Initial and subsequent review takes approximately 3 months.

3. It will be placed in one of four categories: accept without changes, accept with minor changes, major revisions required for acceptance, or reject.

4. If the manuscript requires revision, the author(s) have 90 days to complete those changes.

vi. Cover Letter- The cover letter should provide the editors with an overview of the contents of the manuscript, as well as the contribution the manuscript makes to the profession of occupational therapy. A statement of exclusive submission should be included in the cover letter. Also include the credentials, addresses including country, and affiliations of each author.

vii. Specific Formatting for Applied Research

1. Applied research manuscripts are reports of research findings that address specific clinical problems that are important for the practice of occupational therapy. The research questions addressed should be aimed at gaining quantitative or qualitative information about the safety, effectiveness, efficiency, demographics or value of specific treatments that address problems within the occupational therapy profession's domain. Some examples of desired manuscripts in this category include studies testing the effectiveness of guidelines for practice or technological guidelines that are currently used, or have the potential to be used, by occupational therapists. 
a. Papers submitted in this category should be 20-25 pages in length, have adequate references (20-30), and include (1-6) tables and figures as needed to clarify data. An abstract with a maximum of 200 words should be provided, including the subheadings of background, method, results and conclusion.

i. Background/Literature Review: A background of the problem with definitions of terms should be given, followed by a review of relevant, recent research that addresses the problem. The review of literature should build a foundation for the hypotheses or research questions that should be clearly presented at the end of this section.

ii. Method: This section should provide a detailed description of the design, participants, procedures, instruments, and data analyses used for the study. Include informed consent information here. (Any manuscripts with reports of research findings involving human subjects must include a statement in the methods section of the text, verifying that the study was approved by an independent, named human subjects/ethics committee and that all subjects/participants provided informed consent)

iii. Results: The demographic, quantitative, and/or qualitative data should be presented in this section. This may include tables and figures that provide the reader with clarification of information that was obtained. No interpretation of the meaning of the data should be included in this section.

iv. Discussion: This section should include an interpretation of the results in relation to the original hypotheses/research questions, a comparison to the research literature that was reviewed, the limitations of the study, and a discussion of the implications for the practice of occupational therapy or future research in the profession.

v. A brief acknowledgement should include financial and research support. Financial support may include grants or other funding sources.

vi. An abstract with a maximum of 200 words should be provided for Applied Research- Applied Research manuscripts should be structured to include background, method, results, and conclusion subheadings.

vii. Provide 3 to 6 key words in alphabetical order to be used for indexing purposes. The key words should 
reflect the main topics of your manuscript and should not repeat terms already used in the title.

viii. References should be limited to 30 for Applied Research. Each reference in a manuscript should include the DOI if one is assigned actionable links are preferred rather than the original alphanumeric string when possible.

b. American Journal of Occupational Therapy account made at following links explains further details for submission: https://ajot.submit2aota.org/?_ga=2.22039480.2082463867.1618454438-

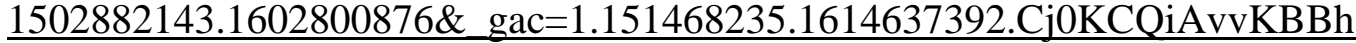
CXARIsACTePW82HeZQWXVZ49BfpVJ0vKJagW26ZvfPBrw4RdhfLaLC8PF5vUNu7kaApqoEALw_wcB

i. Cost: Authors of articles accepted for publication in AJOT have the option to make their article free to nonsubscribers for a fee of $\$ 1,500$ for research articles and $\$ 1,200$ for all other types of articles.

ii. Copyright: On acceptance of the manuscript, authors are required to convey copyright ownership to AOTA; a completed copyright transfer form must be uploaded with the submission of the manuscript, as noted earlier. Manuscripts published in the journal are copyrighted by AOTA and may not be published elsewhere without permission.

iii. Link for submission: http://ajot.submit2aota.org/?_ga=2.22376376.2082463867.1618454438$1502882143.1602800876 \&$ \&ac $=1.226531951 .1614637392 . C j 0 K C Q i A v v K B B h$ CXARIsACTePW82HeZQWXVZ49BfpVJ0vKJagW26ZvfPBrw4RdhfLaLC8PF5vUNu7kaApqoEALw_wcB

iv. Category to submit under: A Brief Report is a short report of original research that is of a pilot or exploratory nature or that addresses a discrete research question and lacks broad implications. The research can be of any design. Authors should follow the reporting guidelines stated earlier to the extent possible, given the size constraints.

v. Pre-submission checklist that must be completed can be found here: https://ajot.submit2aota.org/journals/ajot/forms/ajot_presubmission_checklist.pdf ? ga=2.223251608.2082463867.1618454438-

$1502882143.1602800876 \&$ gac $=1.254852602 .1614637392 . C j 0 K C Q i A v v K B B h$ CXARIsACTePW82HeZQWXVZ49BfpVJ0vKJagW26ZvfPBrw4RdhfLaLC8PF5vUNu7kaApqoEALw_wcB

vi. Format: Publication Manual of the American Psychological Association (APA) $7^{\text {th }}$ edition for both text and references

1. Include no more than four graphic elements (tables, figures, images, etc.).

2. The title should be no more than 15 words and reflect the primary focus of the article

3. The title page for the original (masked) submission should include only the manuscript title. 
vii. Manuscript format:

4. Key words: Authors will have the opportunity to select 2 to 10 keywords from a populated list in our online system at the time of submission.

1. Abstract: specific abstract instructions can be found here https://ajot.submit2aota.org/journals/ajot/forms/AJOT_Structured_ Abstracts.pdf?_ga=2.21971256.2082463867.1618454438$1502882143.1602800876 \&$ \&ac $=1.249978356 .1614637392 . \mathrm{Cj0K}$ CQiAvvKBBhCXARIsACTePW82HeZQWXVZ49BfpVJ0vKJagW26ZvfPBrw4RdhfLaLC8PF5vUNu7kaApqoEAL w_wcB

2. Introduction: Focused review of the relevant background literature, rationale for or purpose of the study clearly stated, and clear statement of study aims, objectives, hypotheses, and research questions.

3. Method: Identification of study design, setting, participants (including recruitment, eligibility, and consent process), measurement and outcomes, intervention protocol (if applicable), data collection, and data analysis plan.

4. Results: Presents outcomes of data analysis and clearly links to explicitly stated research questions and hypotheses. Findings should be stated without bias or subjective interpretation.

5. Discussion: Discuss the results within the context of current literature (what was already known) and explain any new insights gained from the research results. If hypotheses were set a priori, this section should indicate whether those hypotheses were supported. Include a section on limitations. For all studies, authors should consider the size of the effect and its clinical relevance in forming their discussion to keep the discussion within the bounds of their data and to not overstate the impact on occupational therapy. Future research directions can be a separate section or included in the discussion section; either way, the section should be indicated with its own heading.

6. Implications for Occupational Therapy Practice

a. This section should consist of a short introductory paragraph followed by a bulleted list of the practice implications, and it should be included in the manuscript's word count. Although Brief Reports do not require a separate section, they should clearly indicate the implications for clinical practice in their discussion.

b. If the study provides confirmatory evidence, then use wording such as "This study confirms previous work that. . .." or "The results offer further evidence that. . ."

7. Conclusions: Consider the study results within the context of how they contribute to increasing real-life function, engagement, or 
satisfaction with occupations. Authors should indicate whether the study objectives were met.

viii. Process for review:

1. All submitted manuscripts are initially reviewed by the Editor-inChief for suitability for the journal. Suitable manuscripts are then sent to editorial board members or guest editors (for special issues) as the first phase of peer review. Manuscripts may be rejected or returned to the authors for revisions at this stage. At the second stage of peer review, manuscripts are sent to at least two reviewers. The identities of the reviewers and of the authors are kept confidential.

2. The authors assume final responsibility for the content of articles, including changes made in copyediting. 